NIST GCR 21-028

\title{
Prospective Economic Impacts of Allowing Government-Operated Federal Laboratories to Assert Copyright Protection for Their Custom Software Products
}

\author{
David P. Leech \\ Economic Analysis \& \\ Evaluation, LLC \\ John T. Scott, Ph.D. \\ Dartmouth College
}

This publication is available free of charge from: https://doi.org/10.6028/NIST.GCR.21-028

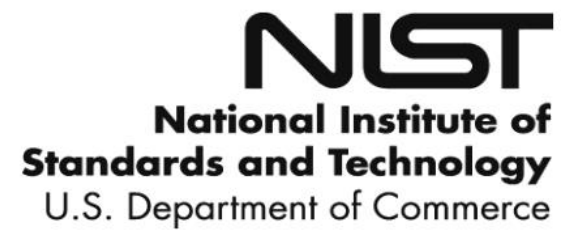


NIST GCR 21-028

\title{
Prospective Economic Impacts of Allowing Government-Operated Federal Laboratories to Assert Copyright Protection for Their Custom Software Products
}

\author{
Prepared for \\ U.S. Department of Commerce \\ Technology Partnerships Office
}

National Institute of Standards and Technology

Gaithersburg, MD 20899

David P. Leech

Economic Analysis \&

Evaluation, LLC

John T. Scott, Ph.D.

Dartmouth College

This publication is available free of charge from:

https://doi.org/10.6028/NIST.GCR.21-028

May 2021

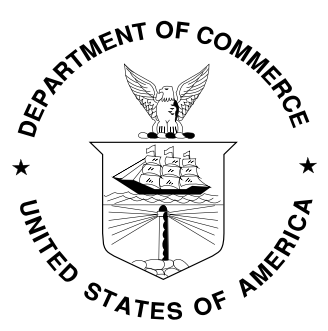

U.S. Department of Commerce Gina M. Raimondo, Secretary

National Institute of Standards and Technology James K. Olthoff, Performing the Non-Exclusive Functions and Duties of the Under Secretary of Commerce for Standards and Technology \& Director, National Institute of Standards and Technology 


\section{Disclaimer}

This publication was produced as part of contract 1333ND19FNB405279 with the National Institute of Standards and Technology. The contents of this publication do not necessarily reflect the views or policies of the National Institute of Standards and Technology or the US Government. 


\section{Preface}

This report provides an exploratory assessment of the prospective economic impacts of allowing U.S. government-operated Federal laboratories to copyright the software products they develop. Such copyrights are prohibited by current law. To assess the prospective economic impacts, we surveyed the people engaged with the software developed and used in the Federal laboratories. We surveyed the laboratories that are government-operated and not permitted to copyright their software. We also surveyed the contractor-operated Federal laboratories. The contractor-operated laboratories are permitted to copyright their software. The survey obtained information about the laboratories' software development and licensing activities and about the changes expected for those activities if the government-operated laboratories are allowed to copyright their software. The survey information is used to model the revenues and costs associated with the laboratories' software development and licensing activity and to predict the economic impacts if the government-operated laboratories are allowed to copyright the software products that they develop. Because we rely on the survey, the report would not have been possible without the thoughtful assistance of many knowledgeable individuals in the Federal agencies and their laboratories.

In addition to thanking the survey respondents, we wish to acknowledge the contributions of Karen Rogers (NIH), Michael Shmilovich (NIH), Daniel Lockney (NASA), and Amin Mehr (GSA), for their indispensable advice during the survey design phase of the project. They helped us understand the language that "makes sense" to developers and managers of custom software developed within Federal agencies. Sarah Hart (Universal Technical Resource Services, Inc., formerly with the Federal Laboratory Consortium) and Carolina Olivieri (Federal Laboratory Consortium) provided critical support in providing points-of-contact for potential survey respondents and in communicating the launch of the survey phase of the project to the Federal technology community via the FLC Digest. Finally, we acknowledge the guidance and project support provided by our NIST project manager, Nicole Gingrich, and the comments of readers at NIST. 


\begin{abstract}
U.S. copyright laws do not allow government-owned government-operated (GOGO) laboratories of Federal agencies to obtain copyright protection for the software products they develop. This report provides an assessment of the likely economic effects of allowing copyright protection for software products created in the GOGO laboratories. The report uses a formal survey of Federal agencies' GOGO laboratories and government-owned contractor-operated (GOCO) laboratories to describe their software development and licensing activities over the past five years and to make forecasts about the effects of eliminating the copyright prohibition. The survey responses indicate that if copyrights for government-created software are allowed, the availability of the software for use by others will increase dramatically. Forecasts of the economic impacts of the expected increase in the available software are made using estimated models of licensing revenues and licensing costs for the survey respondents. The forecasts for the respondents are extrapolated to their parent Federal agencies and then to all Federal agencies. Information about the economy-wide impact for the software industry is combined with the information about the software activities of the Federal agencies to project economy-wide benefits of lifting the restrictions on copyrighting software developed by GOGO laboratories. Changing the copyright law to allow copyright protection for GOGO software is expected to have a positive economic impact on the U.S. economy because the software made available will increase the productivity of its users. This report provides a first look at software activity that has not previously been systematically tracked and reported.
\end{abstract}

\title{
Key words
}

Copyright; Copyright Act of 1976; Federal agencies; Federal laboratories; Federal laboratories' induced productivity effect, software; Federal laboratories' software commercialization; Federal laboratories' software development activities; Federal laboratories' software development cost model; Federal laboratories' software licensing revenue model; Federal laboratories' software release categories; Federal Source Code Policy, 2016; Federal Technology Transfer Act of 1986; Government-owned contractoroperated (GOCO) laboratories; Government-owned government-operated (GOGO) laboratories; Government Works software; Invention licenses; Patents; Software; Software copyrights; Software licenses; Software patents; Technology transfer. 


\section{Table of Contents}

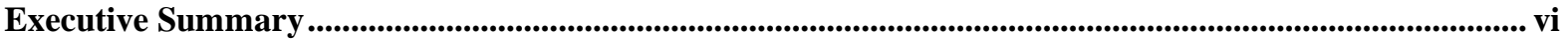

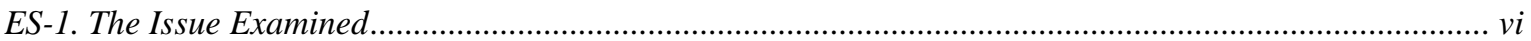

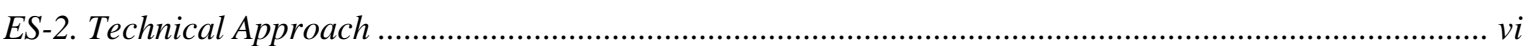

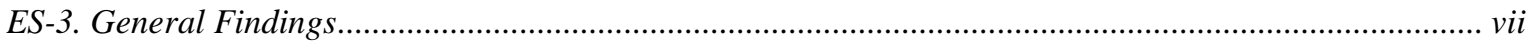

1. Introduction ............................................................................................................................................................... 1

1.1. Research Question and Focus ...............................................................................................

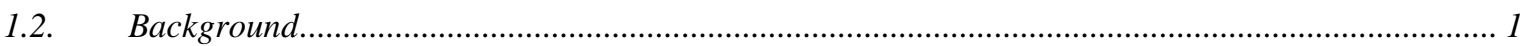

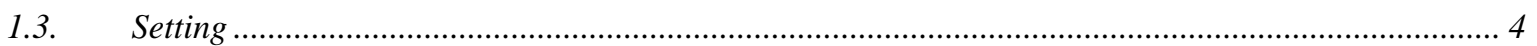

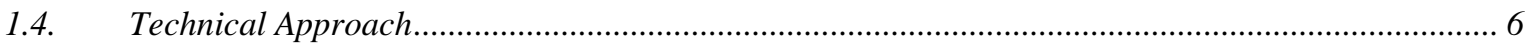

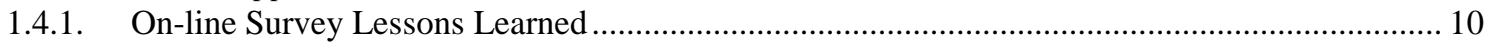

2. Survey Results and Related Economic Analysis........................................................................................... 11

2.1. Overview of the Sections in the Report........................................................................................ 11

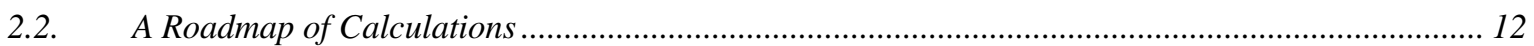

2.3. Response to the Software Copyright Impact Survey ................................................................ 13

2.4. Software Licensing \& Public Domain Software Release Activity 2015-2019................................ 15

2.4.1. The Simple Model of Software Revenues ............................................................................... 15

2.4.2. Overview of the Agencies' Software Activity for 2015-2019 ................................................... 20

2.5. Software Development and Management Costs, 2015-2019.......................................................... 26

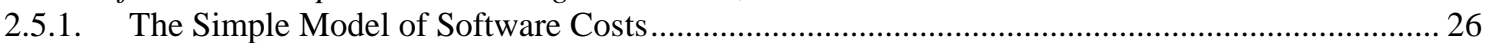

2.5.2. Overview of the Agencies' Software Development and Management Costs for 2015-2019 ....... 30

2.6. Counterfactual Software Copyright License \& Public Release Activity 2020-2024 ........................ 32

2.6.1. Overview of the Respondents' Forecasts for 2020-2024 Given Elimination of the Copyright

Prohibition for GOGO Laboratories or Laboratory Facilities ................................................................. 33

2.7. Predictions of the Effects of Allowing Copyright Protection for Software Created by GOGO

Laboratories and Laboratory Facilities................................................................................................ 42

2.7.1. Prediction of Licensing Revenues for the GOCO and GOGO Laboratories and Facilities

Providing 2020-2024 Forecasts Assuming Copyrights Are Allowed .......................................................... 43

2.7.2. Projected Costs Associated with the Projected Revenues ............................................................ 48

2.7.3. Comparison of Projected Costs and Projected Revenues........................................................... 50

2.7.4. Projection of Effects on the Software Activity of All Federal Agencies....................................... 55

2.8. Assessment of Potential Economy-Wide Effects of Federal Agencies' Software .............................. 60

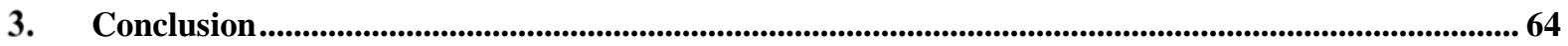

Appendix A. Software Copyright Impact Survey (OMB Control No. 0693-0033, Expiration Date:

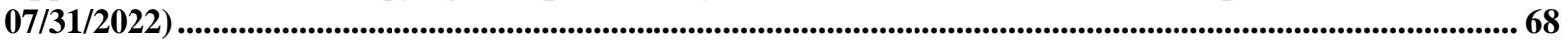

Appendix B. Economy-Wide Impact of the Software Industry......................................................................... 69

Appendix C. Estimated Licensing Revenue Functions......................................................................................................... 73

Appendix D. Examples of the Custom Software Outreach ("Marketing") Practices of Federal

Laboratories 


\section{List of Tables}

Table 1. Survey Response.

Table 2. Descriptive Statistics for the Respondents with Complete Data for the Model of Software

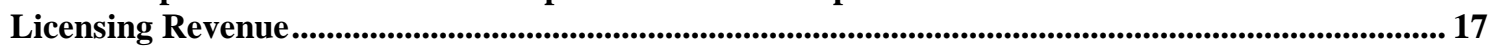

Table 3. Annual Number of Software Products Made Available for Licensing ........................................... 20

Table 4. Approximate Percentage Distribution of Intellectual Property Protection for Software Products Available for Licensing ......................................................................................................................................... 21

Table 5. Annual Number of Software Products Licensed................................................................................22

Table 6. Annual Revenues (in constant 2019 dollars) from Software Products Licensed ........................... 22

Table 7. Annual Number of Software Products Available for Download to the Public without a License23

Table 8. Approximate Percentage Distribution of Release Attributes for Software Products Available: All Responses

Table 9. Approximate Percentage Distribution of Release Attributes for Software Products Available: Smaller Selective Samples (without the respondents that reported zeros for all four release categories).

Table 10. Descriptive Statistics for the Respondents with Complete Data for the Model of Software Development and Maintenance Costs.......................................................................................................... 28

Table 11. The Software Cost Model: Least-Squares Estimates, Dependent Variable cost_19..................... 29

Table 12. The Lines of Code (LOC) for the Typical Software Product .............................................................. 30

Table 13. FTE and GS-rating for the Average Size Software Product ............................................................... 30

Table 14. FTE and GS-rating for the Software Maintenance Costs ....................................................................31

Table 15. FTE and GS-rating for Costs of Managing IP and Licensing .......................................................... 31

Table 16. Annuity fees for Software Patents ..................................................................................................................... 32

Table 17. External Legal Support Costs for IP and Licensing for Software Portfolio. ................................. 32

Table 18. Forecast of Average Annual Number of Software Products Available for Licensing if Copyright Prohibition Is Eliminated, 2020-2024 ........................................................................................ 33

Table 19. Forecast of Average Annual Number of Licensed Software Products if Copyright Prohibition Is Eliminated, 2020-2024.

Table 20. Forecast of Average Number of Times Each Licensed Software Product Would Be Licensed if Copyright Prohibition Is Eliminated, 2020-2024...

Table 21. Forecast of Average Annual Number of Seats per Licensed Software Product if Copyright Prohibition Is Eliminated, 2020-2024

Table 22. Approximate Percentage Distribution of Release Attributes for Software Products Available: All Responses . 38

Table 23. Approximate Percentage Distribution of Release Attributes for Software Products Available: Smaller Selective Samples (without the respondents that reported zeros for all seven release categories).

Table 24. Average Annual Growth Rate in Lines of Code for Software Products ...........................................40

Table 25. Average Annual Growth Rate in Revenues for Software Products ............................................... 42

Table 26. Average Annual Revenue for Software Products for a GOCO or GOGO Respondent: Actual versus Forecast in 2019 dollars

Table 27. Average Annual Costs for Software Products Available for Licensing or Download: Actual versus Forecast in 2019 dollars

Table 28. Forecast Annual Licensing Revenues in 2019 dollars for Software Products Available for Licensing or Download in 2020-2024 if the Copyright Prohibition is Eliminated ................................ 58 


\section{List of Appendix C Figures}

Figure C.1. Histogram of Licensing Revenue in Constant Dollars of 2019 Overlaid with the Normal Density Having the Same Mean and Standard Deviation ...........................................................................75

Figure C.2. Histogram of Residuals for Specification (2) in Table C.1 Overlaid with the Normal Density

Having the Same Mean and Standard Deviation

\section{List of Appendix C Tables}

Table C.1. The Software Licensing Revenue Model for the GOCO Observations: Least-Squares Estimates, Dependent Variable revenue $19_{i t}$

Table C.2. The Software Licensing Revenue Model for the GOGO Observations: Least-Squares Estimates, Dependent Variable revenue19 ${ }_{\text {it }}$

Table C.3. The Software Licensing Revenue Model for the GOGO Observations Plus the Mixed Case: Least-Squares Estimates, Dependent Variable revenue $19_{i t}$.

Table C.4. Comparison of OLS and Tobit Estimates of the Software Licensing Revenue Model for the GOCO Observations: Dependent Variable revenue $19_{i t}$ 


\section{Executive Summary}

The importance of software code to all sectors of the economy has intensified since the 1980s when laws were enacted to encourage the transfer of technology from Federal agencies and laboratories to the commercial and non-profit sector. According to a 2016 estimate, the Federal government spent more than $\$ 6$ billion annually on purchased software through more than 42,000 transactions. ${ }^{1}$ But Federal government employees also develop custom software in pursuit of the various agencies' missions. This report provides an exploratory first look at the Federal agencies' software development activities. Using the responses to a survey of the agencies' laboratories and facilities, the activities are described. Based on the survey responses, the report concludes, conservatively, that if the agencies were allowed to copyright and license the software that their laboratories and facilities develop, it could potentially add as much as $\$ 4.3$ billion (FY2019 dollars and based on the U.S. GDP in 2019) in value-added to the annual output of the economy because the use of the Federal agencies' software would increase the productivity of the industries where the software is used.

\section{ES-1. The Issue Examined}

In this report, we provide an assessment of the likely economic effects of allowing copyright protection for government-created software products. U.S. copyright laws do not allow the government-owned government-operated (GOGO) laboratories of Federal agencies to obtain copyright protection for the software products they develop. They are deemed "Government Works" and, as such, they cannot be protected by copyright. ${ }^{2}$ In contrast, the Federal agencies' government-owned contractor-operated (GOCO) laboratories can obtain copyrights for the software they create because their employees are not Federal employees and their software products are not considered Government Works.

In the context of the strong and growing demand for software to support economic activity, and the belief that commercial software developers prefer that transferred software has strong intellectual property (IP) protection as a condition for further commercial development and sale, allowing copyright protection for the software products created by GOGO laboratories would arguably have a large economic impact, increasing the productivity of the U.S. economy by enabling the Government Works software to realize commercial potential.

\section{ES-2. Technical Approach}

In this report we use a formal survey of Federal agencies' GOGO and GOCO laboratories and laboratory facilities to describe their software activities over the past five years and to make forecasts about the effects of eliminating the copyright prohibition for software produced by the Federal agencies' GOGO and GOCO operations. ${ }^{3}$

\footnotetext{
${ }^{1}$ M-16-12: Improving the Acquisition and Management of Common Information Technology: Software Licensing. Office of Mgmt. \& Budget, Exec. Office of the President, June 2, 2016.

${ }^{2}$ For information about U.S. "Government Works" qualifications and exemptions, see https://www.usa.gov/government-works.

${ }^{3}$ The survey, "Software Copyright Impact Survey," OMB Control No. 0693-0033, Expiration Date: 07/31/2022 is provided in Appendix A. A discussion of potential biases in the survey response is provided in Section 1.4.
} 


\section{ES-3. General Findings}

The responses to the survey indicate that if copyrights for Government Works software are allowed, the availability of the software for use by others will increase dramatically.

Respondents to the survey report that as compared with the annual numbers of licensed software products for the last five years, over the next five years, if copyright protection is allowed, the annual number of licensed software products by the agencies' laboratories and laboratory facilities will increase by almost 60 times for GOGO operations and by about 3 times for GOCO operations. Respondents explained that copyright protection would make the use of the released software more effective because users would be willing to contribute to its development for commercial use and share their work with others. Both commercial users and the government would be protected from users who otherwise might claim proprietary interests in the developed software and even sell it back to its originators.

The software licensing revenue model developed on the basis of our Software Copyright Impact Survey posits licensing revenues to be a function of: (1) the number of software products licensed (swprodlicd); and (2) intellectual property protection afforded by patents or copyrights (IPprotected). With the revenues measured in constant dollars of 2019, the estimated revenue model predicts that the expected value of the annual revenue from a copyrighted software product, using the mean number of products for the sample of the respondents who are able to copyright their software, ranges from $\$ 2,573$, when the respondent does not have copyright or patent protection for its software, to $\$ 5,908$, when the software does have copyright protection. ${ }^{4}$ The average annual license revenues reported by survey respondents (2015-2019) are about $\$ 83,000$ for the GOCO respondents, over thirty times more than the $\$ 2,645$ average annual revenues reported by the GOGO respondents. ${ }^{5}$

According to the simple cost model developed from our Software Copyright Impact Survey responses, the expected annual software costs for a lab or lab facility (cost_19) are a function of: (1) the average annual number of software products available for licensing + the average annual number of software products available for download by the public without a license (total_products); and (2) the average lines of code for the responding lab's or facility's typical software product $(\operatorname{avgLOC})$. Accordingly, with costs measured in 2019 dollars, the

\footnotetext{
${ }^{4}$ From Table 2, during 2015-2019, average annual number of licensed products is 21 for the respondents who are able to copyright their software. Then, using the estimated revenue model from Appendix $\mathrm{C}$, Table $\mathrm{C} 1$, the expected value of the annual revenue from a copyrighted software product, using the mean number of products for the sample, is estimated to be $\$ 5,908=(164+70042+2565 \times 21) / 21$. If the respondent did not have IP protection for its software products, the expected value for the product's annual revenue is $\$ 2,573=(164+$ $2565 \times 21) / 21$.

${ }^{5}$ The survey asked respondents to "Estimate the annual total dollar amount of revenues generated by software licenses" for each of five fiscal years, 2015-2019. The question stipulated that total revenues should include at least license issue royalties, minimum annual royalties, earned royalties, sub-licensing royalties, and benchmark royalties. The GOGO revenues can be for licenses for software that is quite explicitly not copyrighted - stating so in the licensing agreement. The GOCO revenues, on the other hand, are almost entirely for copyrighted software. See the discussion in Section 2.4.2.
} 
estimated cost model coefficient for total_products shows the marginal effect on costs from adding an additional software product available for licensing or available for download by the public without a license. At the margin, holding constant the software product size, for another product the annual costs increase by $\$ 256,976$. (The model controls for the product's size with avgLOC and the estimated coefficient for avgLOC is $\$ 18.98$, showing that given the number of products, costs are higher when the products are larger as measured by their average number of lines of code. $)^{6}$ The average annual cost (2015-2019) of custom software, available for licensing or download without a license, reported by survey respondents is $\$ 1,273,945$.

For the 2020-2024 timeframe, survey respondents forecast the number of "software products licensed," "licenses per licensed software product," and "seats per licensed software product." GOGO respondents anticipate an almost 60-fold increase in the number of software products licensed if copyright is allowed; GOCO respondents expect about a 3-fold increase. The average annual software licensing revenues for the GOGO respondents are expected to increase by 51 times or $5100 \%$, while the average for the GOCO respondents is expected to increase by 2.43 times or $243 \% .^{7}$

To forecast the economic effects of eliminating the copyright prohibition on Government Works, we use the simple models outlined above to predict annual revenues and costs for 2020-2024 across the Federal government. Respondents to the Software Copyright Impact Survey forecast annual licensing revenues of \$3,444,379 (2020-2024) should the copyright prohibition be eliminated. ${ }^{8}$ To extrapolate the forecasts to the parent agencies of the respondents, we use the detailed employment information that is provided by the U.S. Office of Personnel Management (OPM) in its FedScope database. Based on that data, the licensing revenue for the parent agencies represented by the survey respondents is estimated at $\$ 44,238,828$ in software license revenues annually (2020-2024). Software Copyright Impact Survey respondents account for $51.4 \%$ of the total IT employment for all Federal agencies. ${ }^{9}$ Thus, for all Federal agencies if the software copyright prohibition is eliminated, the forecast of the annual 2020-2024 licensing revenues is estimated to be $\$ 86,067,759 .{ }^{10}$

Costs are also projected to grow considerably. For survey respondents, the average annual cost of software made available (2020-2024) if the GOGO copyright prohibition is eliminated is estimated to be $\$ 18,800,000$. Most of these costs would be incurred whether or not the software is made available for licensing since the software is developed for internal

\footnotetext{
${ }^{6}$ In other words, in terms of lines of code, for an average software product, an additional 100 lines of code costs $\$ 1,898.00$.

${ }^{7}$ The projected revenues for the 2020-2024 period are quite accurate in the sense that the $95 \%$ confidence intervals for the estimates cover a small range even using the conservative standard errors of the forecast (see Table 26).

${ }^{8}$ Table 1, Section 2.3, describes the responses from the 14 Federal agencies surveyed.

${ }^{9}$ From FedScope, the sum of the IT employment for the agencies represented by the 23 respondents is 43,776 . The sum of IT employment for all Federal agencies (summing over the FedScope reports for the cabinet level agencies, the large independent agencies, the medium independent agencies, and the small independent agencies) is 85,167 . So, the Federal agencies in our sample of respondents take the proportion $0.514=$ $43776 / 85167$ of the IT employment at all Federal agencies.

$10 \$ 86,067,759=\$ 44,238,828 / 0.514$.
} 
use by the agencies. But if copyrighting the software is allowed, respondents estimate that more of it will be made available and the additional costs of making the software available would be the costs associated with obtaining the copyrights and managing the licensing process. ${ }^{11}$ For the survey respondents for which the projection was made, the costs (an overestimate as explained in the report) of making the software available to others would be approximately the $\$ 1,310,360$ annually over the years $2020-2024$ (6.97\% of the projected costs, based on cost estimates by survey respondents for 2015-2019). Using the same procedure that we used to extrapolate the expected licensing revenues for those survey respondents, we estimate the sum of the annual costs for their 10 parent agencies would be $\$ 151.8$ million. For all Federal agencies the forecast of the annual additional costs (again, an overestimate as explained in the report) incurred for making the products available for all Federal agencies (2020-2024) is $\$ 295.3$ million. $^{12}$

While the estimated annual costs of eliminating the copyright restriction on custom software exceeds the $\$ 86$ million in additional revenues expected to be generated, those expected revenues are dwarfed by the estimated potential of $\$ 4.3$ billion in annual economy-wide benefits (based on the performance of the U.S. economy in the latest year, 2019, reported by the Bureau of Economic Analysis) from the increased productivity for the users of copyrighted GOGO- and GOCO-developed software.

The projected annual licensing revenue of $\$ 86$ million greatly understates the value of the software to those using it, in part because much of the agencies' software is made available without any charge. To generate estimates of the annual economy-wide benefits of lifting the restrictions on Government Works copyrighting, we combine information about the economy-wide impact for the software industry with information about the software activities of the Federal agencies.

Generally speaking, the economy-wide productivity gains from software result because of the software's contribution to capital deepening from the accumulation of informationtechnology capital and because of software's contribution to multifactor productivity growth. A reliable benchmark - the derivation of which is detailed in Appendix B of this report - is that the private sector's software contributes $15 \%$ of the annual growth in the nation's output. We use the benchmark estimate for the software produced by the software industry to provide an estimate of the potential economy-wide impact of the Federal agencies' software above and beyond its contribution to the economy's output that is made by the software operations of the agencies as they accomplish their missions. In light of the anticipated 60fold increase in the amount of custom-developed software that is licensed to others if GOGOs are permitted copyright protection, the indirect or induced economic impact of the agency's software will become quantitatively important. The approach taken to estimating the downstream benefits of allowing for copyright protection of Government Works allows an estimate of those benefits that could not be obtained by using the agencies' expected

\footnotetext{
${ }^{11}$ The focus of this report is the software that the agencies make available to others for licensing or download without a license. A complete inventory of the agencies' software for their internal use is beyond the scope of the report.

${ }^{12} \$ 295.3$ million $=\$ 151.8$ million $/ 0.514$.
} 
licensing revenues. Those revenues vastly understate the amount of the agencies' software that is used downstream because some survey respondents report that they envision continuing to provide their software free of charge. They assess the overall benefits from maximizing the transfer of their custom-developed software to be more important than the benefits of generating, let alone maximizing, revenue for their agencies.

In terms of numbers of employees, the proportion taken by the Federal agencies' software operations in the total software operations for the economy is conservatively estimated as 0.034. To estimate the downstream productivity effect of the Federal agencies' software for the economy as a whole, we use the productivity benchmark of 0.15 multiplied by the growth in economy-wide value added ( $\$ 847.5$ billion over the year 2018 to 2019 ) to have the induced productivity effect for the software industry as a whole during the most recent year for which the Bureau of Economic Analysis reports the information about value added for the U.S. economy. We then multiply that by the Federal agency's software operations' size, as measured by employment, relative to the size of the software industry (0.034). Thus, the estimate of the potential induced productivity effect of the Federal agencies' softwareinduced because (as reported by Software Copyright Impact Survey respondents) allowing copyright protection for Government Works software will result in a large increase in custom-developed software made available for licensing - is $\$ 4.3$ billion annually ( $0.034 \mathrm{x}$ $0.15 \times \$ 847.5$ billion) based on the most recent year for which the U.S. economy's growth in value added is reported. That $\$ 4.3$ billion estimate represents the potential value of the increased output in the economy as a whole from using software made available by the agencies should the Government Work prohibition on copyright protection for custom software be eliminated. Of course, until the U.S. economy has recovered from the pandemic of 2020, we cannot expect the growth in the U.S. economy to be as much as it was from 2018 to 2019, and consequently, the software industry's contribution to positive economic growth cannot be expected to be what we observed for the most recent year of data. However, the potential of software for driving economic growth is well estimated by the 2018-2019 experience.

In conclusion, changing the copyright law to allow copyright protection for GOGO Government Works software is expected to have a positive economic impact on the U.S. economy because the software made available will increase the productivity of the users. We emphasize that findings of this report are a first look at software activity that has not previously been systematically tracked and reported. ${ }^{13}$

\footnotetext{
${ }^{13}$ The proportion of public domain software-released to the general public without copyright or copyleft restrictions-is expected to decline by 30\%. The details of that decline are discussed in Section 2.6.1, and definitions of the terms such as copyleft and the distinctions between open source and public domain software are provided in Section 1.4. As documented in Section 2.6.1, the reduction in the proportion of Government Works public domain software is mirrored by an increase in the proportion of copyrighted software. So, despite the increase in software made available and licensed, the loss of public domain software may lessen productivity for some users of the agencies' publicly released software.
} 


\section{Introduction}

\subsection{Research Question and Focus}

The primary question this report seeks to answer concerns the potential economic impact to the U.S. economy if government-operated laboratories were able to assert copyright protections for software works produced by government employees. ${ }^{14}$

The focus of the research is custom-developed computer software developed and maintained by employees of government-owned government-operated laboratories and facilities (GOGOs), that, with exceptions, currently may not copyright custom-developed software, and custom-developed software written by employees of government-owned contractor-operated laboratories and facilities (GOCOs) that may copyright software.

By definition, custom-developed computer software includes code written for software projects, modules, plugins, scripts, middleware, and application programing interfaces (APIs). ${ }^{15}$

\subsection{Background}

In the 1980s, Congress began passing a series of laws that have enabled Federal technology transfer activities. The Stevenson-Wydler Act established technology transfer as a Federal policy and required Federal labs to set up Offices of Research and Technology Application (ORTAs). The Stevenson-Wydler Act was amended by the Federal Technology Transfer Act of 1986 which sets out guidelines to encourage commercialization through licensing of the inventions developed within Federal agencies. ${ }^{16}$ According to a House of Representatives Report accompanying the act:

"The Federal Government funds approximately half of this country's total research and development, and much of this work is performed in government-owned laboratories. The national interest demands that these Federal laboratories be more responsive to our economic need for their new technologies. Where appropriate these technologies should be transferred from the Federal sector and translated into new commercial products and processes." 17

\footnotetext{
${ }^{14}$ A secondary research question was to determine if the experiences of contractor-operated laboratories in copyrighting and licensing software were applicable to the prospects of government-operated laboratories doing the same in the event that restrictions on them-discussed below-were eliminated. We return to this secondary research question in the "Background" and "Setting" subsections below.

${ }^{15}$ Executive Office of the President, Office of Management and Budget, Memorandum for the Heads of Departments and Agencies, "Federal Source Code Policy: Achieving Efficiency, Transparency, and Innovation through Reusable and Open Source," August 8, 2016, Appendix A: Definitions, p. 14. Softwarehttps://www.whitehouse.gov/sites/whitehouse.gov/files/omb/memoranda/2016/m_16_21.pdf ${ }^{16}$ Pub. L. No. 99-502, 100 Stat. 1785.

${ }^{17}$ U.S. Congress, House of Representatives, Committee on Science and Technology, Federal Technology Transfer Act of 1985, Report (to accompany H.R. 3773), 99th Cong., 1st Sess., 1985, H. Rep. 99-415, p. 3.
} 
The House Report goes on to recognize that legislative changes were needed to improve the ability of the Federal laboratories to identify innovations with commercial potential. ${ }^{18}$

With regard to one form of intellectual property — copyright — the statutes maintain a distinction between government-owned government-operated labs (GOGOs) and government-owned contractor-operated labs (GOCOs) ${ }^{19}$ The technology transfer statutes maintain the prohibition of copyright for "Government Works" codified in Copyright Act of 1976.

With some important exceptions, current U.S. copyright laws do not allow GOGO laboratories to assert copyright protections over creative works that fall under the definition of Government Works, defined as works created as part of the official duty of Federal employees; writings, images, computer code, software, and databases are not subject to copyright protections in the U.S. ${ }^{20}$ GOCO labs, however, are able to assert copyright protections over computer software because (by definition) the employees at GOCO laboratories are not Federal employees and not subject to the restrictions placed on GOGO labs.

In retrospect, even though the Federal Technology Transfer Act of 1986 was intended to "improve the ability of the Federal laboratories to identify innovations with commercial potential," it may not have anticipated dramatic changes in the technology landscape, specifically the rapid expansion of the role of software. That said, the authors of the Act were cognizant of the issue. The act required the Department of Commerce to identify barriers which tend to restrict or limit the transfer of Federally funded software to the private sector and State and local governments. ${ }^{21}$

\footnotetext{
${ }^{18}$ Ibid.

${ }^{19}$ The statutory provision that prohibits the government from securing copyright protection in its own creative works is rooted in historical legal precedent going back before its codification in the Printing Act of 1895 and the Copyright Act of 1909. Some of the uncertainties in these laws were rectified by the Copyright Act of 1976 but that act retained the restriction on copyright protection for Government Works. See, Ruth L. Okediji, "Government as Owner of Intellectual Property? Considerations for Public Welfare in the Era of Big Data, Vanderbilt Journal of Entertainment \& Technology law, Vol. 18, No. 2, pp. 33-362.

${ }^{20}$ Regarding the important exceptions to the current copyright law regarding Government Works, the United States Government is not precluded from receiving and holding copyrights transferred to it by assignment, bequest, or otherwise. In addition, works prepared for the government by independent contractors may be protected by copyright. The U.S. government may also assert copyright outside of the United States for U.S. Government Works. And works of state and local governments may be protected by copyright. Exceptions are also available for certain works of the National Institute for Standards and Technology (NIST) - in accordance with the Standard Reference Data Act, 15 U.S.C. § 290e, which empowers the Secretary of Commerce to secure copyright on behalf of the United States in Standard Reference Data (SRD) prepared by NIST - and the U.S. Postal Service. See, https://www.usa.gov/government-works. The U.S. Postal Service is exempted from Section 105 of Title 17 in accordance with The Postal Reorganization Act of 1970, Pub. L. 91-375, which enacted Title 39, Postal Service. See, Title 17, Section 105, Historical and Revision Notes, House Report 94-1476, https://www.govinfo.gov/content/pkg/USCODE-2011-title17/html/USCODE-2011-title17.htm

${ }^{21}$ Return on Investment Initiative for Unleashing American Innovation (NIST Special Publication 1234), April 2019. 〈https://doi.org/10.6028/NIST.SP.1234〉
} 
NIST's Return on Investment (ROI) Initiative Green Paper (2019) was the culmination of a broad-ranging and inclusive review of policies and practices that constrain technology commercialization. Among these constraints is the absence of copyright protections for computer software, databases and other relevant Government Works. The report collects anecdotal evidence that the Government Works exception has created a disincentive for GOGO researchers to envision and develop software with potential for commercial use and that this has led to slower and less efficient development of GOGO-developed software by the private sector.

Summarizing previous research on the matter, as well as recent inputs from study participants, the report states:

“Agencies' ability to identify and transfer software is generally more limited than the system that is in place for patented inventions resulting from the lack of copyright protection and registration for Federally developed software. It is, however, possible for private sector actors to add value to Government Works, creating derivative works which enjoy copyright protection for the additional material and modifications made by the private sector author.

According to stakeholders, the ineligibility of the Federal Government to secure copyright protection for software that results from R\&D at Government-operated laboratories has frustrated endeavors to release and participate in open source development. ... There is an argument that software that qualifies as Government Works must be protected by copyright in the United States in order to grant public users a copyright license that complies with the terms of open source use."22

The NIST report on the copyright constraint concludes with the finding that, "the 'Government Works' exception to copyright protection for software products of R\&D at Government-Owned, Government-Operated Laboratories constrains commercialization." 23

As reported below, the survey and research conducted for this report found additional evidence supporting many of the claims made in NIST's "Green Paper" report. Survey evidence was collected and analyzed to estimate the extent to which commercialization of Federal laboratory-developed software would add to Federal laboratory licensing revenue going forward, as well as generate additional economy-wide benefits, if the Government Works copyright exception was eliminated. ${ }^{24}$

\footnotetext{
22 Ibid., pp. 40-41.

${ }^{23}$ Ibid. p. 42.

24 "Elimination" of the Government Works exception is a more stark option than that contemplated by NIST's ROI Initiative Green Paper (i.e., “a narrowly tailored change to the Government Works exception would be consistent with the original intent of the Bayh-Dole Act, while recognizing the transformational shift of including digital products like software in a 21 st Century definition of IP." (p. 43)) but for survey and economic analysis purposes "elimination" was a more tractable approach.
} 


\subsection{Setting}

The first research task (though of secondary overall importance) was to assess the applicability of data provided to NIST by the Department of Energy (DOE) concerning GOCO license revenues from software copyrights. NIST requested the following aggregated data from DOE:

- Total number of software products reported by DOE labs

- Total number of licensed software products; and

- Total dollar amount of royalties received from software licensing.

DOE responded with software product quantities (FY14-18) from 20 GOCO, and 1 GOGO lab, organized, per year, in terms of:

- Open-source products available for licensing

- Open-source products licensed

- Other no-cost software available for licensing

- Other no-cost software licensed.

No revenue estimates were provided. DOE reported that such data was considered confidential by the labs providing the information and that licensing revenue data collected by DOE from the labs mingled the licensing revenues for copyrighted software with the licensing revenues from other sources. ${ }^{25}$ Without revenue data, the utility of the DOE GOCO data for modeling GOGO revenues in the absence of the prohibition on copyright protection for Government Works could not be determined. Furthermore, the reported categories of software for the DOE GOCO data do not cover all types of software products, and in the absence the definitions of DOE reporting categories "open-source" and "other no-cost software" - even the scope of the information supplied was somewhat ambiguous. ${ }^{26}$

In retrospect, DOE's inability to provide the detailed data needed to model the relationship between the numbers of various kinds of software products developed by GOCOs, the nature of the IP protection afforded them, and the annual revenues they generate was a glimpse of a more general problem of accounting for the custom software developed across Federal agencies. During the survey phase of this project the authors communicated with many potential survey respondents. Many of those invited to participate in the survey conducted by the authors observed that the lack of access to well-organized information about custom-developed software hampered their ability to respond - GOGOs and GOCOs alike. Typical reactions to the "Software Copyright Impact Survey" (discussed in the following section) included the following comments:

${ }^{25}$ This rendered impossible a simple, rough derivation of copyright revenue from data annually reported in NIST's Federal Laboratory Technology Transfer Summary Report to the President and the Congress. <https://www.nist.gov/system/files/documents/2019/10/30/fy2016_fed_lab_tech_transfer_rept_fina_9-1019.pdf $>$

${ }^{26}$ The authors requested from DOE the data dictionary that accompanied DOE's "data call" to GOCO laboratories, but DOE did not provide the information. 
- "Great questions, all things we should start to monitor, but we are nowhere close." (U.S. Army Corps of Engineers)

- " "I just don’t keep track of software." (Department of Agriculture)

- "As a patent attorney I am intimately familiar with the intellectual property issues involving software release but have no idea about the number of software projects, revenue, percentages of software distributed under any particular IP, development costs, etc." (Army Research Laboratory)

- "Things like how much software was released to the public? I have no idea, nor do I know anyone at the center that does." (Naval Information Warfare Center)

- "It is very detailed in the requested information. Much of it we do not currently capture.” (Lawrence Livermore National Laboratory)

- "In view of the ... detailed nature of the information sought, we will be unable to provide responses to a majority of the questions with sufficient accuracy and quality."(Federal Aviation Administration)

- "I am having trouble collecting the relevant information." (Department of Transportation)

- "I do not know of any source at [this organization] that would have such information." (Department of Commerce)

- " $[\mathrm{We}]$ don't really have the tracking and management systems in order to do much official tech transfer with this type of technology." (National Institutes of Health)

We were not completely unprepared for these comments. We had been told by a technology transfer official during the survey design phase (discussed below) that NASA is the only agency with a comprehensive inventory of custom software. A technology transfer professional from a different agency verified that assertion.

Some noted that the cause of poor access to information about custom software was a "catch-22": without the incentive to copyright, organizing information about the nature and extent of efforts to develop custom software has been a low priority for many. Since some Federal agencies do keep sufficient track of their custom-developed software to respond to the detailed questions posed in the survey, the "catch-22" rationale may not be the sufficient cause of the general lack of readily accessible information about customdeveloped software. Clearly though, agencies' priorities seem to be affected by the regulatory prohibition on seeking copyright protection for custom software.

With the foregoing background and setting, in the following subsection the technical approach taken to ascertain the data that forms the basis of the economic analysis presented in Section 2 is discussed. 


\subsection{Technical Approach}

A formal survey of Federal agencies was a project requirement. It may be that very few, if any, surveys of Federal agency custom software practices and operations have ever been conducted. It is highly likely that the survey discussed here is the first such survey conducted to assign economic value to Federal agencies' custom software practices and operations.

Normally, a survey of Federal agency employees would not require Office of Management and Budget (OMB) approval under the Paperwork Reduction Act. ${ }^{27}$ However, since data on GOCO licenses and license revenues provided by DOE was insufficient for modeling purposes (discussed in the subsection above), a survey encompassing both GOGOs and GOCOs was required. Since GOCO employees are not Federal employees - and, therefore, the survey encompassed non-Federal employeesthe process for developing an OMB-approved "Software Copyright Impact Survey" was required and followed. ${ }^{28}$

After a review of relevant literature concerning software copyright law and practice, the origin and nature of the copyright prohibition, and readily available data on Federal agencies' licensing revenue, a "red flag" from our communications with DOE analysts was noted. It appeared that the definition and scope of "custom-developed software" were not generally understood in the technology transfer community; the community thought to be the best source of the relevant information by Federal technology transfer experts. ${ }^{29}$ It also became clear that "software release" categories - such as "open source" and "public domain" - were not routinely distinguished in many agencies. To obtain survey results that reported information that was roughly comparable between survey respondents required that the various categories be distinguished. The focus ("customdeveloped software") and scope needed to be articulated within the survey instrument.

Following OMB's 2016 Federal Source Code Policy, we defined the technical focus of the survey to be "custom-developed computer software" including code written for software projects, modules, plugins, scripts, middleware, and application programing interfaces (APIs). ${ }^{30}$

\footnotetext{
${ }^{27}$ The Paperwork Reduction Act (PRA) of 1995 (44 U.S.C. 3501 et seq.) requires that agencies obtain Office of Management and Budget (OMB) approval before requesting most types of information from the public.

${ }^{28}$ In terms of "lessons learned" (discussed further below) it is noteworthy that GOCO employees routinely (and perhaps are required to) maintain ".gov" email addresses. So, even though our "information collection" required OMB approval because it encompassed non-governmental survey respondents, the process of obtaining GOCO points-of-contact was no more difficult than obtaining them for potential GOGO survey respondents. The FLC maintains points-of-contact for both GOGOs and GOCOs, even though they cannot distinguish the two groups with certainty.

${ }^{29}$ Another "lesson learned" for subsequent Federal agency survey projects is that in addition to the community of Federal technology transfer agents, the Federal software development community-for example, "digital.gov" - could well be an excellent source of data and insight regarding the kinds of issues explored in the Software Copyright Impact Survey discussed here. That "community of practice" was not identified as a survey target population until late in the survey execution phase.

${ }^{30}$ Executive Office of the President, op. cit.
} 
Working from documents provided by NASA, ${ }^{31}$ and after communications with technology transfer officials in NIH as well as a software specialist at GSA (ever mindful of general considerations of survey length and detail constraints), we settled on the following software release categories that, combined with the OMB's definition, indicated the intended breadth of the survey's focus on "custom software":

- Percent released as open source

- Percent released to the general public or other agencies for noncommercial use (exclusive of open source)

- Percent released to the general public without copyright or copyleft restrictions

- Percent released under other conditions.

In addition to asking about release categories, we asked about the percentage distribution of the kinds of intellectual property for their software products available for licensing:

- Percentage copyright only

- Percentage copyleft only

- Percentage patented only

- Percentage copyrighted and patented.

By asking respondents for the release categories of their available software, and also asking them for the specific kinds of IP protection for their licensed software, we were able to gather a lot of information in a way that let the respondents, despite their different perspectives on "open source" and other key terms, tell us about their software and its release characteristics.

Concerning some of the important terms in the four release categories, there was some potential for respondents to have different interpretations of "open source." In the words of one expert, there are "many different words for the same thing." 32 Software that is "free" is sometimes considered open source, and there are other terms including FOSS (Free Open Source Software) and FLOSS (Free/Libre Open Source Software). They are, for practical purposes, technically the same, but differ in terms of the software philosophy they promote (with one emphasizing the freedom to distribute the software, the other emphasizing that the license incurs no license fee, that it is free of cost). ${ }^{33}$ Moreover, there can be substantial licensing revenues associated with open source software, typically fees for services supporting the use of the software. ${ }^{34}$

${ }^{31}$ Release of NASA Software (NASA Procedural Requirements, NPR 2210.1C. Expiration Date: December 11, 2020). https://nodis3.gsfc.nasa.gov/displayDir.cfm?Internal_ID=N_PR 2210_001C_\&page_name=Chapter1\&sear ch term=software\%20release

${ }^{32}$ Karl Fogel, Producing Open Source Software, Copyright (C) 2005-2019 under the CreativeCommons Attribution-ShareAlike (4.0) license. Version: 2.316 p. 193. < https://producingoss.com/ >

${ }^{33}$ Ibid.

34 "[That "open source" means the software is free of charge] is a common misconception about what "open source" implies .... Open source software programmers can charge money for the open source 
Thus, people using software may characterize software products as "open source" for a variety of reasons. However, the key distinction is that the users of the software can actually see and modify the source code. The reason for the variety in the characteristics associated with open source software is that the term "open source" has evolved and now "designates a broader set of values [that] embrace and celebrate principles of open exchange, collaborative participation, rapid prototyping, transparency, meritocracy, and community-oriented development." 35

There are restrictions associated with open source software. ${ }^{36}$ Within the category of (licensed) open source software, "copyleft" licenses refers to those that not only grant the "free" use of the software (at no cost) but also require that the freedom applies to any derivative work. A GNU General Public License (GPL) is considered the canonical example of a copyleft license. ${ }^{37}$ It stipulates that any derivative works must also be licensed under the GPL. By contrast, a so-called "permissive" open source license (noncopyleft) does not contain a clause requiring that the license apply to all derivative works. $^{38}$

To be in the "public domain" means that no one has the right to restrict copying the software. Public domain refers to works that may be used by anyone, anywhere, anytime without permission, license, or royalty payment. Material in the public domain can be incorporated into a copyrighted work, and the derivative is thus under the same overall copyright as the original copyrighted work. ${ }^{39}$ A work may enter the public domain because the term of copyright protection has expired, because copyright has been

software they create or to which they contribute. But in some cases, because an open source license might require them to release their source code when they sell software to others, some programmers find that charging users money for software services and support (rather than for the software itself) is more lucrative. This way their software remains free of charge, and they make money helping others install, use, and troubleshoot it." https://opensource.com/resources/what-open-source, accessed September 15, 2020, italics in original.

${ }^{35}$ The quote is from https://opensource.com/resources/what-open-source, and the discussion there is insightful, including the following. "Open source software is software with source code that anyone can inspect, modify, and enhance. "Source code" is the part of software that most computer users don't ever see; it's the code computer programmers can manipulate to change how a piece of software-a "program" or "application"-works. Programmers who have access to a computer program's source code can improve that program by adding features to it or fixing parts that don't always work correctly. What is the difference between open source software and other types of software? Some software has source code that only the person, team, or organization who created it - and maintains exclusive control over it — can modify. People call this kind of software "proprietary" or "closed source" software." Only the original authors of proprietary software can legally copy, inspect, and alter that software." Accessed Oct. 14, 2020. ${ }^{36} \mathrm{From}$ https://opensource.com/resources/what-open-source, accessed Oct. 14, 2020: "Open source licenses affect the way people can use, study, modify, and distribute software. In general, open source licenses grant computer users permission to use open source software for any purpose they wish. Some open source licenses — what some people call "copyleft" licenses - stipulate that anyone who releases a modified open source program must also release the source code for that program alongside it. Moreover, some open source licenses stipulate that anyone who alters and shares a program with others must also share that program's source code without charging a licensing fee for it."

${ }^{37}$ See https://en.wikipedia.org/wiki/GNU, accessed September 13, 2020.

${ }^{38}$ Fogel, op. cit., p. 195.

${ }^{39}$ Ibid., pp. 194-95. 
abandoned, or in the U.S., because it is a U.S. Government Works and there is currently no other statutory basis for the government to restrict its access. A work is not in the public domain simply because it does not have a copyright notice. ${ }^{40}$

Finally, "other conditions" is a catch-all phrase intended to capture custom software that is classified or export controlled.

To reemphasize, we were concerned that asking survey respondents about their software development and licensing activities too narrowly_ as in the DOE's "data call" that focused only "open source" and "other no-cost software"- would have missed other kinds of custom software that would turn out to be significant. In addition, we had a theoretical interest in the question of how much public domain software (considered by some scholars and developers as an important source of economic benefits) might be reduced in the wake of the hypothesized change in the IP protection afforded Government Works. Finally, recognizing that there was likely to be a considerable amount of custom software deemed sensitive for confidentiality and national securityrelated reasons, we wanted to at least indicate that some measure of its quantitative scope should be included in survey responses.

Unlike the starting point that would have been provided by DOE — wherein "open source software" and "other no-cost software" could be construed as different names for the same thing — our focus was intended to be more comprehensive. ${ }^{41}$

In addition to getting a handle on the kinds of custom software being developed in GOCOs and GOGOs, the survey also sought estimated quantities, costs, and revenues associated with custom software historically (2015-2019) and anticipated in a counterfactual future (2020-2024) free of copyright restrictions on Government Works.

With a survey, there is always concern about whether something about the respondents would lead them to give a distorted understanding of the true values of the variables about which we are gathering data. There can be concerns about the credentials and experience of the respondents. In the case of the Software Copyright Impact Survey, there is reason to think there may be an upward bias in the reported anticipated increase in the software made available for licensing if the copyright prohibition for Government Works software is lifted. As discussed in detail just below, a problem with the execution of the survey caused many potential respondents not to provide a response because they were not certain that the survey was a government-sanctioned survey. Although that problem reduced the number of respondents, there is no reason to expect that it would lead to biased information from those who did open their invitations, discover that the survey was sanctioned, and respond. As discussed in subsection 1.3, some respondents observed that the lack of access to well-organized information about custom-developed

\footnotetext{
${ }^{40} \mathrm{https}$ ://cendi.gov/publications/04-8copyright.html\#216

${ }^{41}$ In fact, as will be illustrated in Section 2.4.2 of this report, Table 9, had we focused only on "open source" software, the focus of the data provided by DOE, we would have excluded as much as 65 percent of the custom software developed in GOGOs and as much as 36 percent of the custom software developed in GOCOs.
} 
software hampered their ability to respond. That problem would be expected to increase the variance in the responses, but would not be expected to introduce bias in the average response. Relatedly, NIST did not want to trouble software developers themselves by attempting to survey members of the digital.gov community of practice. However, all of the respondents are identified in their role as advocates for technology transfer. Because the study investigates the argument that allowing copyright protection for Government Works software would be good for technology transfer, one might reasonably say that the GOGO survey population would be predisposed to provide answers that reflect positively on the effects of eliminating the restrictions on copyrighting GOGO software. The potential "optimistic" bias would come with the information about the counterfactual scenario that is discussed in Section 2.6. The bias could cause an overestimate of the anticipated increase in software made available for license. Although the authors of the report do not believe that the potential "optimistic" bias is severe, it should be kept in mind when considering the results of this report.

The survey was conducted using a Survey Monkey platform. ${ }^{42}$ The Federal Laboratory Consortium (FLC) provided information containing email points of contact for approximately 280 technology transfer managers in the laboratories of thirteen Federal agencies. In addition, FLC-identified technology transfer managers, alternative respondents referred by initial points of contact were invited to participate in the survey. Ultimately, 361 individuals were invited to take the survey. Individualized URL links were provided to potential respondents. Appendix A contains a non-interactive PDF version of the survey. The actual on-line survey had several drop-down menus of prepopulated answers (yes/no, parent organization, and quantity ranges). The survey opened April 14, 2020 and closed July 31, 2020. Detailed survey response data is reported in Section 2.3 below.

\subsubsection{On-line Survey Lessons Learned}

In addition to "lessons learned" reported in footnotes above - concerning the finding that "gov" email addresses are required of GOCO employees and the late realization that software development communities of practice likely are a good population to tap into in successive economic impact surveys of Federal agency software activities - it is important to recognize a significant glitch in the execution of the survey, especially the use of a commercial (.com) email address by the survey manager and co-author of this report. Having conducted numerous on-line, email, and telephone surveys in the pastmostly, but not solely, focused on the commercial world, in search of commercially propriety information, the authors were, of course, used to suspicion and a relatively low number of survey responses. But we were taken aback by the level of suspicion exhibited by several correspondents. (The survey invitation, and the OMB-approved survey instrument itself, provided the email address for one of the authors, and invited potential survey respondents to communicate general concerns and questions about the interpretation of specific survey questions.) We assume that this suspicion accounts for

\footnotetext{
${ }^{42}$ The Survey Monkey platform has multiple subscription plans. See, https://www.surveymonkey.com/pricing/individual/?ut_source=sem_lp\&ut_source2=sem\&ut_source $3=$ me gamenu. The survey conducted for this study employed an annual personal plan subscription.
} 
the fact that the majority of potential survey respondents (approximately 60\%) did not open the survey invitation. ${ }^{43}$ One correspondent wrote, in part, "I first suspected that this is a phishing email, as this does not come from NIST address." Another correspondent (who, after assurances, provided a survey response to the best of his ability) asked for additional information, "if you are truly conducting a sanctioned survey." The assurances that were required by many survey respondents were available in the survey introduction, but that approach assumed, wrongly, that potential survey respondents would open their invitations.

In future surveys focused on a population of Federal employees, it is strongly advised that the survey be executed from a Federal agency (.gov) email address. ${ }^{44}$ Short of that, detailed assurances about the legitimacy of an on-line survey need to be included in the subject line of the email inviting survey participation. Where available, too, professional networks or publications should be invited to announce that a survey is forthcoming and encourage participation. ${ }^{45}$

Of course, some glitches seem inevitable. Some correspondents informed us that their agency's IT offices blocked potential respondents' access to on-line survey applications.46 Other agencies used email clients that were incompatible with the online Survey Monkey survey application used for this survey.

\section{Survey Results and Related Economic Analysis}

\subsection{Overview of the Sections in the Report}

Section 2.2 provides a roadmap to help the reader follow the sequence of calculations that are made throughout the report. Section 2.3 describes the response to the survey that we used to gather information from GOCO and GOGO laboratories and laboratory facilities.

\footnotetext{
${ }^{43}$ Over the course of the three-month survey period, weekly "reminders" were emailed to the survey population. Approximately mid-way through the survey period, the NIST project manager's email address was included in the subject line of the survey "reminder." No dramatic improvement in survey responses was observed. In previous surveys the authors have been accused of "phishing." Still, we found the level of suspicion on the part of Federal employees, to a survey which, especially after mid-survey adjustments that included the NIST project leader's email address, was to all appearances being conducted on behalf of NIST, to be remarkable.

${ }^{44} \mathrm{We}$ are not suggesting that time-consuming surveys need to be conducted by Federal agency employees alone. Rather, we are suggesting that those charged with the survey design and execution be granted temporary ".gov" email addresses to avoid the suspicions described.

45 One correspondent observed that he "had not heard of this from normal NIST channels like the Interagency Working Group for Technology Transfer (IAWGTT)." Whether or not such an announcement was made at the outset of the survey, the mid-survey message adjustments did appeal to the IAWGTT. No dramatic improvement in survey responses was observed. The NIST study and survey were announced in the Federal Laboratory Consortium's FLC Digest but the assurances that this could have provided to the FLC members targeted by the survey may not have reached the intended audience.

${ }^{46}$ This must be a relatively common problem since the support desk of the survey application used for this survey (Survey Monkey) readily provides written instructions for willing survey respondents to communicate with their organization's IT departments concerning the details of how to "white list" Survey Monkey's online application.
} 
Section 2.4 describes the survey respondents' software licensing and public domain software release activity for 2015-2019. Section 2.5 describes their software development and management costs for 2015-2019. Section 2.6 describes the respondents' projections, if the copyright prohibition is lifted, for their software copyright licensing and public release activity for 2020-2024. Section 2.7 uses the respondents' projections from Section 2.6 to make predictions of the effects of allowing copyright protection for software created by GOGO laboratories and laboratory facilities. The predictions are developed first for the respondents, then second for their parent agencies, and finally for all Federal agencies. Section 2.8 provides a prospective assessment of the economy-wide impact of the Federal agencies' software operations. Section 3 concludes the report with a summary of its key findings. Appendix A provides the Software Copyright Impact Survey; Appendix B explains the benchmarks used for the economywide impact of the software industry; Appendix $C$ provides the technical details about the simple licensing revenue function; Appendix D provides examples of the custom software outreach (marketing) practices of Federal laboratories; and Appendix E provides examples of the custom software developed in Federal laboratories.

\subsection{A Roadmap of Calculations}

In case it will be helpful to have a roadmap that describes the sequence of calculations that are made throughout the report, here is an overview of the road to be traveled.

After describing in Section 2.3 the response to the Software Copyright Impact Survey, in Section 2.4.1 we provide an overview of the simple model of licensing revenues that we estimate in Appendix C. The model is used (in Section 2.7) to compare the expected revenue for a software product with its expected cost. It is also used (in Section 2.7) to predict annual revenues over the period 2020-2024 if copyright protection is allowed.

Section 2.4.2 describes the GOCO and GOGO respondents' reports about each of the items of information about 2015-2019 software activity covered in the survey. A description of the distribution (in the samples of GOCO and GOGO respondents) is provided for each item of information about the respondents' software activity.

In Section 2.5.1, a model of software costs as a function of the number of software products and the average size (measured by lines of code) of those products is estimated using the reported experience for the survey respondents during the fiscal years 2015 through 2019. The cost model is used subsequently (in Section 2.7) to calculate the expected addition to the average cost for a software product if it is protected with IP and made available for licensing. The cost model is also used (in Section 2.7) to predict the annual software costs that would be incurred over the period from 2020 to 2024 if copyright protection is allowed for GOGO software products.

Section 2.5.2 describes the GOCO and GOGO respondents' answers to each of the individual questions about their costs. A description of the distribution (in the samples of 
GOCO and GOGO respondents) is provided for each item of information about the respondents' costs.

Section 2.6 presents the respondents' forecasts for their software activity for fiscal years 2020 through 2024 assuming that copyright can be obtained for GOGO software products. Then, in Section 2.7 the respondents' forecasts reported in Section 2.6 are juxtaposed with the revenue and cost models estimated, respectively, in Section 2.4.1 and Appendix $\mathrm{C}$ and in Section 2.5. From the juxtaposition we develop overall predictions about how the elimination of the software copyright prohibition for GOGO laboratories and facilities would be expected to affect annual licensing revenues and costs over the next five years.

From the projected revenues and costs for the respondents to our survey, we estimate the revenues and costs across all Federal agencies by using information about the proportion of all Federal agency software activity taken by the respondents. To extrapolate the forecasts to the parent agencies of the respondents to the survey, we use the detailed employment information that is provided by the U.S. Office of Personnel Management (OPM) in its FedScope database. ${ }^{47}$ The data provide the employment of various types for each Federal agency and its component organizations. Having extrapolated the respondents' forecasts to the parent agencies of the respondents, we then extrapolate the forecasts for the parent agencies to the have a forecast for all Federal agencies. Thus, we are able provide a forecast for the respondents who provide sufficient data to use with the models, a forecast for their parent agencies, and finally a forecast for all Federal agencies.

The final calculation that we make provides an estimate of the potential economy-wide economic impact of the Federal agencies' software. The calculation is made and explained in Section 2.8.

\subsection{Response to the Software Copyright Impact Survey}

Table 1 describes the response to our "Software Copyright Impact Survey." The survey is attached as Appendix A. We cast a wide net across agencies, hoping to receive reports from places where the Federal agencies would be creating software products. We invited 361 representatives of 14 Federal agencies to complete the survey questions. Those invited to respond were chosen as persons within the agencies who would be knowledgeable about the software licensing and public domain software release activity in the agencies' laboratories or facilities for which they would be responding. The agencies are listed in Table 1 along with the number of individuals associated with each agency who were invited to complete the survey. The table also shows for each agency the number of individuals who responded, and the percentage who responded from each agency. Each respondent provided answers for one or more laboratories or laboratory facilities within an agency.

\footnotetext{
${ }^{47}$ https://www.fedscope.opm.gov
} 
Table 1. Survey Response

\begin{tabular}{|l|c|c|c|c|c|}
\hline Agency* & $\begin{array}{l}\text { Number } \\
\text { Invited to } \\
\text { Take the } \\
\text { Survey }\end{array}$ & $\begin{array}{l}\text { Number of } \\
\text { GOCO } \\
\text { respondents }\end{array}$ & $\begin{array}{l}\text { Number of } \\
\text { GOGO } \\
\text { respondents }\end{array}$ & $\begin{array}{l}\text { Total } \\
\text { Number } \\
\text { Responding }\end{array}$ & $\begin{array}{l}\text { Percentage } \\
\text { Responding }\end{array}$ \\
\hline DHS & 6 & 0 & 2 & 2 & 33.33 \\
\hline DOC & 42 & 0 & 9 & 9 & 21.43 \\
\hline DOE & 44 & 13 & 0 & 13 & 29.55 \\
\hline DOI & 7 & 0 & 3 & 3 & 42.86 \\
\hline DOL & 1 & 0 & 0 & 0 & 0 \\
\hline DOT & 7 & 0 & 4 & 4 & 57.14 \\
\hline DoD & 132 & 2 & $27 * *$ & 29 & 21.97 \\
\hline EPA & 7 & 0 & 0 & 0 & 0 \\
\hline GSA & 1 & 0 & 1 & 1 & 100 \\
\hline HHS & 62 & 0 & 11 & 11 & 17.74 \\
\hline NASA & 21 & 0 & 3 & 3 & 14.29 \\
\hline NSF & 12 & 4 & 0 & 4 & 33.33 \\
\hline USDA & 18 & 0 & 4 & 4 & 22.22 \\
\hline VA & 1 & 0 & 1 & 1 & 100 \\
\hline $\begin{array}{l}\text { All } \\
\text { Agencies }\end{array}$ & 361 & 19 & 65 & 84 & 23.27 \\
\hline
\end{tabular}

*Department of Agriculture (USDA), Department of Commerce (DOC), Department of Defense (DoD), Department of Energy (DOE), General Services Administration (GSA), Department of Health and Human Services (HHS), Department of Homeland Security (DHS), Department of the Interior (DOI), Department of Labor (DOL), National Science Foundation (NSF), Department of Transportation (DOT), Department of Veterans Affairs (VA), Environmental Protection Agency (EPA), National Aeronautics and Space Administration (NASA).

**Includes one respondent reporting on multiple labs/facilities that were predominantly GOGO but included some GOCO activity.

Source: Authors' tabulations from “Software Copyright Impact Survey," OMB Control No. 0693-0033, Expiration Date: 07/31/2022

For the entire group of 361 potential respondents, 84 or $23.3 \%$ responded. Of the respondents, $77.4 \%$ were GOGO respondents (counting the one respondent that was predominately GOGO), and 22.6\% were GOCO respondents. Not all of the responses shown in Table 1 were complete; a few were so incomplete that they provided no useful information at all. The numbers of observations for each part of the questionnaire will be reported with the overview, provided subsequently, of the responses for the items.

Most responses had at least some useful information, and we will describe in overview the information provided about the various items in the survey. Moreover, there were enough respondents with sufficiently complete information to estimate some simple models of the revenues and costs for the software products of the agencies' laboratories and facilities. We will provide and discuss those estimated models and use them with the survey results to predict what might be expected if the copyright prohibition for GOGO laboratories was lifted. 
We have looked at the agencies to gather information about the agencies' custom software activities that have not previously been tracked. Because the information that we gathered with the Software Copyright Impact Survey has not previously been tracked and reported systematically, providing responses to the survey was a challenge for many respondents. The report should be considered to be only an exploratory first look that develops new information about the agencies' software activities and about the possible effects of allowing agencies to copyright government-works software.

\subsection{Software Licensing \& Public Domain Software Release Activity 2015-2019}

As explained in Section 2.3, not all of the responses shown in Table 1 were complete; consequently, the number of observations available will vary as we describe various aspects of the agencies' software activity for the five years from 2015 through 2019 . For the overview of the relationship between licensing revenues and the number of licensed software products, there were enough complete responses to estimate a very simple model of the revenue function separately for the GOCO laboratories or laboratory facilities and for the GOGO laboratories or laboratory facilities.

\subsubsection{The Simple Model of Software Revenues}

For the relationship between licensing revenues and the number of licensed software products, for each of the respondents who answered the relevant questions, there are five observations - one for each fiscal year from 2015 through 2019. Some GOGO labs, despite the prohibition on copyrighting their software, have revenues from licensed software products either because the products were patented or because they were copyrighted software that had been transferred to the agency or were protected with copyrights outside of the United States. Most GOGO labs, however, because they lack the ability to copyright their software, do not have software products available for licensing. The GOCO labs, in contrast, do typically have copyrighted software products available for licensing.

To describe the simple relationship between licensed software products and licensing revenues, we use three variables. For the $i^{\text {th }}$ responding laboratory/laboratories or laboratory facility/facilities, the annual number of licensed software products in fiscal year $t$ is denoted swprodlicdit. The $i^{\text {th }}$ respondent's software licensing revenue for fiscal year $t$ was reported in nominal dollars, but we have used the U.S. Bureau of Economic Analysis gross domestic product implicit price deflator to convert it to constant dollars of 2019. The $i^{\text {th }}$ respondent's software licensing revenue in constant 2019 dollars is for fiscal year $t$ denoted revenue $19_{i t}$. To describe whether or not there was intellectual property (IP) protection with either copyrights or patents or both, the variable IPprotected $_{i t}=1$ when there were copyrights or patents, and $=0$ when there was no copyright or patent protection.

For the respondents providing complete information for the three variables, there were 7 GOCO respondents, 26 GOGO respondents, and 1 respondent reporting a mixed case where for multiple laboratories, the majority were GOGO. Separating the GOCO and 
GOGO respondents, Table 2 shows the descriptive statistics for the revenue model's variables for those respondents. The descriptive statistics for the one respondent reporting for a collection of GOGO and GOCO laboratories are not included in Table 2. However, in Appendix $\mathrm{C}$ we present the estimated revenue model with and without that observation and with a control for its presence.

There are marked differences among GOGO respondents and also among the GOCO respondents, and the samples are small for this exploratory study. It is especially interesting then to have a complete picture of the distributions for the variables about which the respondents have reported. Thus, in the tables of descriptive statistics, in addition to the usual report of the number of observations, the mean, and the standard deviation for each variable, the tables show the value of each variable at the $25^{\text {th }}, 50^{\text {th }}$, $75^{\text {th }}$, and $100^{\text {th }}$ percentiles of the distribution. The value at the $50^{\text {th }}$ percentile is the median. Additionally, the skewness and kurtosis of the distribution for each variable is provided. ${ }^{48}$ Because the GOGO and GOCO labs and facilities differ greatly in their software operations, the distributions for the variables are asymmetric (skewed right, excepting the IP protection variable for the GOCO sample) and more peaked than the normal distribution, especially so for the GOGO respondents.

Subsequently, we develop a simple model of licensing revenues (in order to be able to predict what might happen if GOGOs are allowed to copyright their software). It is important to understand that the distribution for the reported licensing revenues can be asymmetric (as they clearly are), and yet we can estimate a useful descriptive model. The model explains the revenue with explanatory variables, and it is the distribution of the error (the part of revenue that is not explained by the model) that we need to address. We describe the distribution of the error with the presentation in Appendix $\mathrm{C}$ of the technical details of the simple model.

\footnotetext{
${ }^{48}$ Skewness measures the asymmetry of the variable's distribution. Skewness is zero for a symmetric distribution. Typically, if the median is greater than the mean, there is negative skewness - the distribution is skewed to the left. Typically when the median is less than the mean, the skewness measure is positive and the distribution is skewed to the right. Kurtosis measures the peakedness of the variable's distribution. A smaller kurtosis measure accompanies a flatter distribution. As a benchmark, the normal distribution has a skewness measure of zero and a kurtosis measure of 3. Stata Base Reference Manual, Release 12, A Stata Press Publication, StataCorp LP, College Station, Texas, 2011, Version 12, p. 2087.
} 
Table 2. Descriptive Statistics for the Respondents with Complete Data for the Model of Software Licensing Revenue

\begin{tabular}{|c|c|c|c|c|c|c|c|c|c|}
\hline \multicolumn{6}{|c|}{ GOCO } & \multicolumn{4}{|c|}{ percentiles } \\
\hline Variable & $n$ & mean & Std. Dev. & skewness & kurtosis & $25^{\text {th }}$ & $50^{\text {th }}$ & $75^{\text {th }}$ & $100^{\text {th }}$ \\
\hline revenue $19_{i t}$ & 35 & $\$ 94,779$ & 161,460 & 1.71 & 5.36 & 0 & 5,214 & 212,314 & 654,506 \\
\hline swprodlicd $_{\text {it }}$ & 35 & 21.3 & 45.0 & 2.09 & 5.66 & 0 & 2 & 10 & 148 \\
\hline IPprotected $_{i t}$ & 35 & 0.571 & 0.502 & -0.289 & 1.08 & 0 & 1 & 1 & 1 \\
\hline \multicolumn{6}{|c|}{ GOGO } & \multicolumn{4}{|c|}{ percentiles } \\
\hline Variable & $n$ & mean & Std. Dev. & skewness & kurtosis & $25^{\text {th }}$ & $50^{\text {th }}$ & $75^{\text {th }}$ & $100^{\text {th }}$ \\
\hline revenue $19_{i t}$ & 130 & $\$ 2,438$ & 13,362 & 8.47 & 81.9 & 0 & 0 & 0 & 136,750 \\
\hline swprodlicd $_{\text {it }}$ & 130 & 0.354 & 0.979 & 3.02 & 11.7 & 0 & 0 & 0 & 5 \\
\hline IPprotected $_{\text {it }}$ & 130 & 0.192 & 0.396 & 1.56 & 3.44 & 0 & 0 & 0 & 1 \\
\hline
\end{tabular}

Notes: The variable revenue $19_{i t}$ denotes the $i^{\text {th }}$ respondent's software licensing revenue in constant 2019 dollars for fiscal year $t$. The variable swprodlicd ${ }_{i t}$ denotes for the $i^{\text {th }}$ respondent the annual number of licensed software products in fiscal year $t$. The variable IPprotected $d_{i t}=1$ when there were copyrights or patents, and $=0$ when there was no copyright or patent protection.

Source: Authors' computations from “Software Copyright Impact Survey," OMB Control No. 0693-0033, Expiration Date: 07/31/2022

Observe that the revenues, numbers of licensed software products, and IP protection for the GOGO labs and lab facilities are less than those for the GOCO labs and lab facilities. Indeed, most GOGOs have no licensed software products. That is what we would expect given that the GOGO labs and lab facilities are not allowed to copyright their software. Moreover, the one respondent (not shown) that reported complete data for the three variables for a mixture of GOGO and GOCO labs and lab facilities, the majority of which were GOGO facilities, the mean revenue and number of licensed products were less than those for the GOCO reporters but more than those for the GOGO reporters, just as one would expect given the numbers for the respondent's GOCO labs and lab facilities would pull up the average for the GOGO operations included in the report. As expected, the respondent with the mixed group of GOGO and GOCO operations reported IP protection.

About $19 \%$ of the GOGO respondents report IP protection for their software, while about $57 \%$ of the GOCO respondents report IP protection. In addition to having less IP protection, the GOGO respondents have almost no copyright protection. There can be occasional exceptions, because internationally protected products and products transferred to the labs may be copyrighted, but as we shall see in detail subsequently, what IP protection the GOGO respondents have is almost all from patents on their software. In great contrast, and again as we subsequently document in detail, the GOCO respondents have very little patent protection for their software but a considerable amount of copyright protection. That difference is extraordinarily fortunate for the purpose of using the experience of the GOCO labs and facilities with copyrighted software to make predictions about what should be expected if GOGO labs are allowed to copyright their Government Works software. ${ }^{49}$

In the estimated models for GOCO and GOGO respondents, revenues are expected to depend on the number of licensed software products and whether or not there was IP

\footnotetext{
${ }^{49}$ Recall from the discussion in Section 1.1, making use of GOCO experiences to predict the behavior of GOGOs in the absence of copyright restrictions was a secondary goal of this study.
} 
protection. The simple models might be thought of as testing the theory that revenues would depend on those two explanatory variables. The causal relationship is

commonsensical and uncontroversial. Regarding the underlying theory, the licensing revenues that are collected do of course reflect some of the market value to those outside the agency who use the software. ${ }^{50}$ However, given what the GOGO respondents to the Software Copyright Impact Survey have told us (discussed in detail subsequently) about what would happen if copyright protection for Government Works software is allowed, any negotiated fees for federal licenses to use the agencies' software will be expected to be far less than the value of the software to the private sector, and moreover, much of the software would be provided without any charge. For that reason, all of our interpretations in this report are based on the expectation that software licensing revenues will not reflect all of the market value that is created by the use of the software that the agencies make available to others. Still, from the licensee side of the negotiating table, fees paid for the licenses will reflect a portion of the future market value- but not all of that value — of the features the software will enable. ${ }^{51}$

For this exploratory study, as a part of providing a first glimpse at the software activity of the federal agencies' labs and facilities, the models provide a way to describe the relationship between licensing revenues and the number of licensed products and the extent to which those products are protected with IP. The descriptive relationships are subsequently used to provide predictions about how licensing revenues would be expected to change if GOGO labs and facilities were allowed to copyright their software.

The simple variable describing whether or not there was IP protection is used in the model because there is not enough information in either the GOCO or the GOGO samples to estimate each sample's model with a more refined breakdown of the types of intellectual property. As we have explained, and as we will see in detail subsequently, for the GOCO respondents almost all of the IP for their software is from copyrights. In contrast, almost all of the IP for the GOGO respondents is from patents simply because they are not allowed to copyright their software. The result, as we have said (but it bears repeating) is fortunate. It is fortunate because we need to use the GOCO respondents' experience with copyrights to provide a glimpse of what might happen if the GOGO

\footnotetext{
${ }^{50}$ Here in this paragraph we focus on the views from legal authorities and economic reasoning about licensing revenues and market values. In the very simple revenue model that can be estimated from limited data, we see that a statistically significant descriptive relationship can be estimated between licensing revenues and the number of licensed products and the extent of their IP. Stated differently, an observed relationship is discerned apart from the random error. Future research, with much larger samples of respondents, will be able to refine the estimated revenue function.

${ }^{51}$ Instructive is Jacob Erlich's observation, "How, then, can reasonable royalty payments be established? As stated in Georgia-Pacific Corporation v. Plywood-Champion Papers, Inc. (166 USPQ 239) "Where a willing licensor and a willing licensee are negotiating for a royalty the hypothetical negations would not occur in a vacuum of pure logic. They would involve a marketplace confrontation of the parties, the outcome of which would depend upon such factors as their relative bargaining strength; the anticipated amount of profits ... and any other economic factor that normally prudent businessmen would ... take into consideration in negotiating the hypothetical license." (Jacob N. Erlich, "Licensing Government-Owned Inventions and Establishing Royalty Payments Thereon," chapter 5, pp. 89-100, in Valuation of Intangible Assets in Global Operations, edited by Farok J. Contractor, (Westport, Connecticut: Quorum Books, 2001), at p. 91.
} 
respondents were allowed to copyright their software. It is also fortunate that within the GOCO sample, not all of the respondents have copyright protection for their software, because with the variance in the copyright protection within the GOCO sample, we can estimate the effect of the IP protection on revenues.

Abolishing the copyright prohibition would put GOGOs on equal footing with GOCOs in terms of their opportunities for licensing software products. The GOGOs would be free to choose the same types of IP protection as the GOCOs. We then make a prediction of what might happen if GOGOs are allowed to copyright their software. To get the prediction, we combine the estimated model for the GOCOs (who have the freedom to copyright) with the choices that the GOGOs tell us that they would make (if they were allowed to copyright their software) about their number of licensed products and their IP. In other words, we estimate for the GOCO respondents a model of revenues that shows the opportunity for revenues given the ability to copyright, but use in the model the numbers of licensed products and IP that the GOGOs say they would choose if they were allowed to copyright their software. The GOCO estimated model (used to make predictions about what would happen if the GOGOs are permitted to copyright their software) is especially appropriate because the IP effect in the estimated model is coming from copyrights.

The prediction from the foregoing procedure shows the potential for the GOGOs should they decide to take advantage of the opportunity for revenues. Copyright protection is what is driving the results for the GOCO estimated model. So we can use the GOCO observations to see what effect having copyright protection has for licensing revenues. Of course, the GOGO respondents could choose to offer no licensed products and to simply make software available for download without any charge even if the software is copyrighted. So they may choose not to take full advantage of the opportunity to earn more revenues, and we have taken pains to include those respondents that say they would do just that and consequently have no licensing revenues. We are careful to include such respondents so that we get a better picture of what revenues might actually be for GOGO respondents if they were allowed to copyright their software. But many respondents do say that they will increase the number of products available for licensing. The use of the simple model to forecast their revenues merely shows the potential for their revenues.

Appendix $\mathrm{C}$ provides the details of the estimated models of licensing revenue. A model is estimated for the GOGO respondents for comparison, but as explained in the foregoing discussion it is the estimated model for the GOCO respondents that will be useful for providing an exploratory look at what might be expected to happen if GOGO labs and facilities were allowed to copyright their software. The estimated function for the GOCO respondents in Appendix $\mathrm{C}$ shows that for a GOCO respondent with the average number (21 from Table 2) of licensed software products, the expected average annual licensing 
revenues per licensed product would be $\$ 5,908$ if the respondent had IP protection for its software and would be $\$ 2,573$ if there were no IP protection. ${ }^{52}$

We turn next to a detailed look at all of the agencies' software activity over the five years from fiscal year 2015 through fiscal year 2019.

\subsubsection{Overview of the Agencies' Software Activity for 2015-2019}

Annual Number of Software Products Made Available for Licensing. Each respondent was asked to report, for each for the five fiscal years from 2015 through 2019, the number of custom-developed software products made by their laboratory/ies or facility/ies that were made available for licensing. It was noted that for GOGO labs it is understood that copyrighted software products transferred to Federal agencies or protected outside the U.S. are available to be licensed. Table 3 shows the results of the annual number of software products made available. The dramatic difference between GOCO and GOGO labs or facilities in the numbers of software products available for licensing is clear, with the annual average number being 25 for GOCO respondents but not quite 1 for the GOGO respondents. The results shown in Table 3 are similar to what we saw in Table 2 for the subset of the respondents with all the data used in the estimation of the simple revenue functions, and the asymmetry and peakedness of the distributions are discussed with the discussion of Table 2. Appendix D provides some examples of how Federal agencies go about making their custom software available to potential users. Appendix E provides some examples of custom software developed by GOGO and GOCO laboratories.

\section{Table 3. Annual Number of Software Products Made Available for Licensing}

\begin{tabular}{|l|l|l|l|l|l|l|l|l|l|l|}
\hline \multicolumn{4}{|c|}{ GOCO } & \multicolumn{4}{c|}{ percentiles } \\
\hline Variable & $n$ & mean & Std. Dev. & skewness & kurtosis & $25^{\text {th }}$ & $50^{\text {th }}$ & $75^{\text {th }}$ & $100^{\text {th }}$ \\
\hline $\begin{array}{l}\text { Annual number of software products } \\
\text { made available for licensing }\end{array}$ & 46 & 24.9 & 40.79 & 1.90 & 5.62 & 1 & 2 & 36 & 148 \\
\hline \multicolumn{7}{|c|}{} & GOGO* & & \multicolumn{5}{|c|}{ percentiles $^{\text {th }}$} \\
\hline Variable & $n$ & mean & Std. Dev. & skewness & kurtosis & $25^{\text {th }}$ & $50^{\text {th }}$ & $75^{\text {th }}$ & $100^{\text {th }}$ \\
\hline $\begin{array}{l}\text { Annual number of software products } \\
\text { made available for licensing }\end{array}$ & 154 & 0.87 & 2.08 & 3.15 & 14.09 & 0 & 0 & 0 & 13 \\
\hline
\end{tabular}

*Includes one respondent reporting on multiple labs/facilities that were predominantly GOGO but included some GOCO activity.

Source: Authors' computations from "Software Copyright Impact Survey," OMB Control No. 0693-0033, Expiration Date: 07/31/2022

Intellectual Property Protection for Software Products Available for Licensing. Each respondent was asked for the approximate percentage distribution of the kinds of intellectual property protection for their software products available for licensing. The average of the responses are shown in Table 4. For GOCO labs or facilities, most available software products had some sort of intellectual property protection, and the

\footnotetext{
${ }^{52}$ Using specification (2) in Table C. $1, \$ 5,908=(164+70042+2565 \times 21) / 21$ when there is IP protection. Without the IP protection, the expected value for the product's annual revenue is $\$ 2,573=(164+2565 \mathrm{x}$ 21)/21. These estimates are discussed in great detail in Section 2.7.3.
} 
majority (59\% on average across the respondents) of that was copyleft, but the average response was $27 \%$ of the software products were copyrighted (23\% with copyright only and another $4 \%$ with both copyright and patent protection. For the GOCO respondents just $5.5 \%$, on average across the respondents, of their software products were patented. In contrast, the GOGO respondents reported almost no copyright protection for their software products, but $26 \%$, on average across the respondents, were patented. It should be noted that the small amount of copyright protection in the GOGO sample is not from the one mixed-case respondent that reported for a group of labs and facilities that were predominantly GOGO but included some GOCO ones. That respondent reported that $0 \%$ of its software had copyright protection.

\section{Table 4. Approximate Percentage Distribution of Intellectual Property Protection for Software Products Available for Licensing}

\begin{tabular}{|l|l|l|l|l|l|l|l|l|l|l|}
\hline \multicolumn{9}{|c|}{ GOCO } & \multicolumn{4}{|c|}{ percentiles } \\
\hline Variable & $n$ & mean & Std. Dev. & skewness & kurtosis & $25^{\text {th }}$ & $50^{\text {th }}$ & $75^{\text {th }}$ & $100^{\text {th }}$ \\
\hline Copyright only & 8 & 22.7 & 32.7 & 1.3 & 3.3 & 0 & 3.3 & 40 & 95 \\
\hline Copyleft only & 8 & 59.4 & 41.7 & -0.47 & 1.5 & 12.5 & 77.5 & 97.5 & 100 \\
\hline Patented only & 8 & 1.5 & 2.1 & 0.97 & 2.1 & 0 & 0 & 3.3 & 5 \\
\hline Copyrighted and patented & 8 & 4.0 & 6.5 & 1.8 & 5.0 & 0 & 0.84 & 5 & 20 \\
\hline \multicolumn{9}{|c|}{ GOGO* } \\
\hline Variable & $n$ & mean & Std. Dev. & skewness & kurtosis & $25^{\text {th }}$ & $50^{\text {th }}$ & $75^{\text {th }}$ & $100^{\text {th }}$ \\
\hline Copyright only & 33 & 2.4 & 13.8 & 5.5 & 31.0 & 0 & 0 & 0 & 80 \\
\hline Copyleft only & 33 & 12.4 & 31.9 & 2.3 & 6.3 & 0 & 0 & 0 & 100 \\
\hline Patented only & 34 & 26.2 & 43.2 & 1.1 & 2.2 & 0 & 0 & 80 & 100 \\
\hline Copyrighted and patented & 33 & 0 & 0 & - & - & 0 & 0 & 0 & 0 \\
\hline
\end{tabular}

Notes: *Includes one respondent reporting on multiple labs/facilities that were predominantly GOGO but included some GOCO activity.

Source: Authors' computations from "Software Copyright Impact Survey," OMB Control No. 0693-0033, Expiration Date: 07/31/2022

Table 4's average percentage for each category should be viewed in light of the fact that not all respondents provided a complete percentage distribution of the IP protection for their products. Thus, for example, a respondent might provide a percentage for a particular category, say $60 \%$ for example, but then choose $<5 \%$ for the remaining categories, essentially not knowing a good estimate for those categories and just recording in essence $0 \%$, or perhaps the remaining $40 \%$ of the licensed software simply had no IP protection. For GOGO respondents in such cases, it may be especially likely that the answer for those categories is indeed $0 \%$, and the software is available and even licensed, yet without formal IP protection. For example, one GOGO respondent reports software available for licensing, licensed software, licensing revenues, no intellectual property for the software, $0 \%$ released as open source, and $90 \%$ released without copyright or copyleft restrictions. In such cases, formal licensing agreements between the agency and the licensees are executed, specifying restrictions on the licensees' uses of the software, and the products are licensed and generate licensing revenues without IP protection. The formal, confidential license agreements in these cases specify "No copyright to Software is claimed in the United States under Title 17, U.S. Code."

\footnotetext{
${ }^{53}$ Thus, the distinction is between a mere contractual license agreement and a transferrable copyright/patent-based license agreement.
} 
Annual Number of Software Products Licensed. Each respondent was asked to report for each of the five fiscal years from 2015 through 2019 the number of software products licensed and the number of times on average each product was licensed. Examining the responses, for the respondents as a whole, the reliable report is for the number of products licensed, and so we summarize just that report. Table 5 shows that the annual number of products licensed averaged about 21 for the GOCO respondents and only 0.62 for the GOGO respondents. From the details provided in Table 5 about the distribution, clearly for the GOGO respondents licensed products are concentrated among less than $25 \%$ of the respondents.

\section{Table 5. Annual Number of Software Products Licensed}

\begin{tabular}{|l|l|l|l|l|l|l|l|l|l|l|}
\hline \multicolumn{9}{|c|}{ GOCO } & \multicolumn{4}{c|}{ percentiles } \\
\hline Variable & $n$ & mean & Std. Dev. & skewness & kurtosis & $25^{\text {th }}$ & $50^{\text {th }}$ & $75^{\text {th }}$ & $100^{\text {th }}$ \\
\hline $\begin{array}{l}\text { Annual number of software } \\
\text { products licensed }\end{array}$ & 35 & 21.3 & 45.0 & 2.1 & 5.7 & 0 & 2 & 10 & 148 \\
\hline \multicolumn{3}{|c|}{} & & & & \multicolumn{5}{c|}{ percentiles $^{*}$} \\
\hline Variable & $n$ & mean & Std. Dev. & skewness & kurtosis & $25^{\text {th }}$ & $50^{\text {th }}$ & $75^{\text {th }}$ & $100^{\text {th }}$ \\
\hline $\begin{array}{l}\text { Annual number of software } \\
\text { products licensed }\end{array}$ & 152 & 0.62 & 1.29 & 2.0 & 5.8 & 0 & 0 & 0 & 5 \\
\hline
\end{tabular}

*Includes one respondent reporting on multiple labs/facilities that were predominantly GOGO but included some GOCO activity.

Source: Authors' computations from "Software Copyright Impact Survey," OMB Control No. 0693-0033, Expiration Date: 07/31/2022

Annual Licensing Revenues. Respondents were asked to estimate the annual total dollar amount of revenues generated by software licenses. We converted the annual amounts reported into constant 2019 dollars using the U.S. Bureau of Economic Analysis GDP implicit price deflator. Table 6 shows that the average annual revenues reported were about $\$ 83,000$ for the GOCO respondents, over thirty times more than the $\$ 2,645$ average annual revenues reported by the GOGO respondents. Most GOGO respondents do not have software licensing revenues. The distribution of the revenues for the GOGO respondents is highly skewed right and quite peaked. In other words, the licensing revenues are concentrated in just a few of the respondents.

Table 6. Annual Revenues (in constant 2019 dollars) from Software Products Licensed

\begin{tabular}{|c|c|c|c|c|c|c|c|c|c|}
\hline \multicolumn{6}{|c|}{ GOCO } & \multicolumn{4}{|c|}{ percentiles } \\
\hline Variable & $n$ & mean & Std. Dev. & skewness & kurtosis & $25^{\text {th }}$ & $50^{\text {th }}$ & $75^{\text {th }}$ & $100^{\text {th }}$ \\
\hline $\begin{array}{l}\text { Annual revenues for } \\
\text { software products licensed }\end{array}$ & 40 & $\$ 82,931$ & 154,061 & 1.9 & 6.2 & 0 & 3,707 & 88,936 & 654,506 \\
\hline \multicolumn{6}{|c|}{ GOGO* } & \multicolumn{4}{|c|}{ percentiles } \\
\hline Variable & $n$ & mean & Std. Dev. & skewness & kurtosis & $25^{\text {th }}$ & $50^{\text {th }}$ & $75^{\text {th }}$ & $100^{\text {th }}$ \\
\hline $\begin{array}{l}\text { Annual revenues for } \\
\text { software products licensed }\end{array}$ & 143 & $\$ 2,645$ & 12,970 & 8.4 & 83.2 & 0 & 0 & 0 & 136,750 \\
\hline
\end{tabular}

*Includes one respondent reporting on multiple labs/facilities that were predominantly GOGO but included some GOCO activity.

Source: Authors' computations from “Software Copyright Impact Survey,” OMB Control No. 0693-0033, Expiration Date: 07/31/2022 


\section{Annual Number of Software Products Available for Download without a License.}

Each respondent was asked to report, for each fiscal year from 2015 through 2019, the number of software products available for download to the public without a license. Table 7 shows only a small difference between the GOCO and GOGO respondents for the average number, with the GOCO respondents averaging 1.6 such products available annually, and the GOGO respondents averaging 1.3. The distributions shown in Table 7 show that, as compared with the GOCO respondents, a larger percentage of the GOGO respondents have software available for download without a license.

Table 7. Annual Number of Software Products Available for Download to the Public without a License

\begin{tabular}{|c|c|c|c|c|c|c|c|c|c|}
\hline \multicolumn{6}{|c|}{ GOCO } & \multicolumn{4}{|c|}{ percentiles } \\
\hline Variable & $n$ & mean & Std. Dev. & skewness & kurtosis & $25^{\text {th }}$ & $50^{\text {th }}$ & $75^{\text {th }}$ & $100^{\text {th }}$ \\
\hline $\begin{array}{l}\text { Annual number available for } \\
\text { download without a license }\end{array}$ & 25 & 1.6 & 3.27 & 1.5 & 3.2 & 0 & 0 & 0 & 8 \\
\hline \multicolumn{6}{|c|}{ GOGO* } & \multicolumn{4}{|c|}{ percentiles } \\
\hline Variable & $n$ & mean & Std. Dev. & skewness & kurtosis & $25^{\text {th }}$ & $50^{\text {th }}$ & $75^{\text {th }}$ & $100^{\text {th }}$ \\
\hline $\begin{array}{l}\text { Annual number available for } \\
\text { download without a license }\end{array}$ & 145 & 1.3 & 2.63 & 2.5 & 8.1 & 0 & 0 & 2 & 10 \\
\hline
\end{tabular}

*Includes one respondent reporting on multiple labs/facilities that were predominantly GOGO but included some GOCO activity.

Source: Authors' computations from "Software Copyright Impact Survey," OMB Control No. 0693-0033, Expiration Date: 07/31/2022

Release Attributes. Each respondent was asked to estimate, for the five fiscal years from 2015 through 2019 as a whole, the percentage distribution of the software products available from the respondent's laboratory/laboratories (or laboratory facility/facilities) across the categories for release attributes shown in Table 8. Using all responses from the survey recipients, GOCO respondents are 2.4 times as likely (56\% compared with $23 \%$ ) as GOGO respondents to release a software product as open source, while GOGO respondents are 2.5 times as likely (15\% compared with $6 \%$ ) to release a product to the general public for noncommercial use exclusive of the open source releases. While none of the GOCO respondents report releasing software to the general public without copyright or copyleft restrictions, the GOGO respondents report that $25 \%$ of their software is released in that way. For GOCO respondents, the percentage of software released under "other conditions" is 3.4 times as much (24\% compared with $7 \%)$ as for GOGO respondents. The "other conditions" include releases restricted for national security reasons. The reason, presumably, is that the majority of the GOCOs are DOE labs working with military-related software (see Table 1). 
Table 8. Approximate Percentage Distribution of Release Attributes for Software Products Available: All Responses

\begin{tabular}{|c|c|c|c|c|c|c|c|c|c|}
\hline \multicolumn{6}{|c|}{ GOCO } & \multicolumn{4}{|c|}{ percentiles } \\
\hline Variable & $n$ & mean & Std. Dev. & skewness & kurtosis & $25^{\text {th }}$ & $50^{\text {th }}$ & $75^{\text {th }}$ & $100^{\text {th }}$ \\
\hline $\begin{array}{l}\text { Percent released as } \\
\text { Open source }\end{array}$ & 7 & 55.7 & 37.2 & -0.70 & 1.8 & 0 & 70 & 85 & 95 \\
\hline $\begin{array}{l}\text { Percent released to the } \\
\text { general public or other } \\
\text { agencies for noncommercial } \\
\text { use (exclusive of open } \\
\text { source) }\end{array}$ & 6 & 6.25 & 8.27 & 0.77 & 1.8 & 0 & 1.2 & 15 & 20 \\
\hline $\begin{array}{l}\text { Percent released to } \\
\text { general public without } \\
\text { copyright or copyleft } \\
\text { restrictions }\end{array}$ & 6 & 0 & 0 & - & - & 0 & 0 & 0 & 0 \\
\hline $\begin{array}{l}\text { Percent released under } \\
\text { other conditions }\end{array}$ & 6 & 23.75 & 37.7 & 1.3 & 3.1 & 0 & 1.2 & 40 & 100 \\
\hline \multicolumn{6}{|c|}{$\mathrm{GOGO}^{*}$} & \multicolumn{4}{|c|}{ percentiles } \\
\hline Variable & $n$ & mean & Std. Dev. & skewness & kurtosis & $25^{\text {th }}$ & $50^{\text {th }}$ & $75^{\text {th }}$ & $100^{\text {th }}$ \\
\hline $\begin{array}{l}\text { Percent released as } \\
\text { Open source }\end{array}$ & 34 & 22.5 & 35.7 & 1.3 & 3.1 & 0 & 0 & 30 & 100 \\
\hline $\begin{array}{l}\text { Percent released to the } \\
\text { general public or other } \\
\text { agencies for noncommercial } \\
\text { use (exclusive of open } \\
\text { source) }\end{array}$ & 34 & 15.1 & 28.9 & 1.8 & 5.2 & 0 & 0 & 15 & 100 \\
\hline $\begin{array}{l}\text { Percent released to } \\
\text { general public without } \\
\text { copyright or copyleft } \\
\text { restrictions }\end{array}$ & 34 & 25.3 & 39.3 & 1.1 & 2.5 & 0 & 0 & 50 & 100 \\
\hline $\begin{array}{l}\text { Percent released under } \\
\text { other conditions }\end{array}$ & 33 & 7.3 & 24.1 & 3.5 & 13.5 & 0 & 0 & 0 & 100 \\
\hline
\end{tabular}

*Includes one respondent reporting on multiple labs/facilities that were predominantly GOGO but included some GOCO activity.

Source: Authors' computations from "Software Copyright Impact Survey," OMB Control No. 0693-0033, Expiration Date: 07/31/2022

In Table 8, for the GOCO respondents, the 7 responses for open source releases includes a respondent who reported $70 \%$ for the open source category and then left all of the others three fields blank. One of the remaining 6 respondents has licensed software and revenues, reports nothing available for download to the public, and fills out 0 s for the distribution percentages for each category. The remaining 5 respondents report percentages that sum to $100 \%$ for the four distribution categories. For those 5 respondents, the averages for the four categories for open source, noncommercial use exclusive of open source, releases without copyright or copyleft restrictions, and then the other releases are respectively $64 \%, 7.5 \%, 0 \%$, and $28.5 \%$ as compared with the $55.7 \%$, $6.25 \%, 0 \%$, and $23.7 \%$ shown in Table 8 for all of the GOCO respondents that provided an answer. The results for the smaller, selective sample of the six GOCO respondents, including the one who reported $70 \%$ for open source releases and then left the other fields blank are shown in Table 9. Thus, Table 9 eliminates the one respondent whose answer for the distribution of release types was zero in all four categories. 
Table 9 also shows the responses for the analogous selective sample of GOGO respondents. Of the 34 and 33 GOGO respondents shown in Table 8, there were 13 respondents who report four zeros for the percentages in the four release categories. Presumably those respondents were indicating that they do not have software characterized by any of the four release categories. If we eliminate those 13 respondents, we are left with the 21 and 20 respondents shown for the selective GOGO sample in Table 9. On average, and noting that a few of the respondents do not treat the categories as mutually exclusive, those respondents report $36 \%, 25 \%, 41 \%$, and $12 \%$ of their software respectively in the open source, noncommercial use exclusive of open source, public release without copyright or copyleft restrictions, and other release categories, as compared with the entire set of 34 and 33 GOGO respondents who on average reported $22.5 \%, 15.1 \%, 25.3 \%$, and $7.3 \%$ respectively for the four categories.

Table 9. Approximate Percentage Distribution of Release Attributes for Software Products Available: Smaller Selective Samples (without the respondents that reported zeros for all four release categories)

\begin{tabular}{|c|c|c|c|c|c|c|c|c|c|}
\hline \multicolumn{6}{|c|}{ GOCO } & \multicolumn{4}{|c|}{ percentiles } \\
\hline Variable & $n$ & mean & Std. Dev. & skewness & kurtosis & $25^{\text {th }}$ & $50^{\text {th }}$ & $75^{\text {th }}$ & $100^{\text {th }}$ \\
\hline $\begin{array}{l}\text { Percent released as } \\
\text { Open source }\end{array}$ & 6 & 65 & 31.6 & -1.3 & 3.4 & 60 & 75 & 85 & 95 \\
\hline $\begin{array}{l}\text { Percent released to the } \\
\text { general public or other } \\
\text { agencies for noncommercial } \\
\text { use (exclusive of open } \\
\text { source) }\end{array}$ & 5 & 7.5 & 8.5 & 0.48 & 1.4 & 0 & 2.5 & 15 & 20 \\
\hline $\begin{array}{l}\text { Percent released to } \\
\text { general public without } \\
\text { copyright or copyleft } \\
\text { restrictions }\end{array}$ & 5 & 0 & 0 & - & - & 0 & 0 & 0 & 0 \\
\hline $\begin{array}{l}\text { Percent released under } \\
\text { other conditions }\end{array}$ & 5 & 28.5 & 39.6 & 1.0 & 2.5 & 0 & 2.5 & 40 & 100 \\
\hline \multicolumn{6}{|c|}{ GOGO* } & \multicolumn{4}{|c|}{ percentiles } \\
\hline Variable & $n$ & mean & Std. Dev. & skewness & kurtosis & $25^{\text {th }}$ & $50^{\text {th }}$ & $75^{\text {th }}$ & $100^{\text {th }}$ \\
\hline $\begin{array}{l}\text { Percent released as } \\
\text { Open source }\end{array}$ & 21 & 36.4 & 39.4 & 0.61 & 1.7 & 0 & 20 & 75 & 100 \\
\hline $\begin{array}{l}\text { Percent released to the } \\
\text { general public or other } \\
\text { agencies for noncommercial } \\
\text { use (exclusive of open } \\
\text { source) }\end{array}$ & 21 & 24.5 & 33.5 & 1.1 & 2.9 & 0 & 0 & 50 & 100 \\
\hline $\begin{array}{l}\text { Percent released to } \\
\text { general public without } \\
\text { copyright or copyleft } \\
\text { restrictions }\end{array}$ & 21 & 41.0 & 43.1 & 0.37 & 1.37 & 0 & 25 & 95 & 100 \\
\hline $\begin{array}{l}\text { Percent released under } \\
\text { other conditions }\end{array}$ & 20 & 12 & 30.0 & 2.5 & 7.5 & 0 & 0 & 2.5 & 100 \\
\hline
\end{tabular}

*Includes one respondent reporting on multiple labs/facilities that were predominantly GOGO but included some GOCO activity.

Source: Authors' computations from "Software Copyright Impact Survey," OMB Control No. 0693-0033, Expiration Date: 07/31/2022

There are idiosyncratic responses - a few respondents will report a percentage considerably less than 100 for a single release category and then leave the other 
categories blank or enter essentially zero (choosing $<5 \%$ when from the context of their answers throughout it is clear that is denoting zero); there are respondents who record essentially zeros (choosing < 5\%) for all four categories; although most respondents treat the release categories as mutually exclusive, there are a couple of cases where a respondent reports software characterized by multiple release categories. For example, a respondent reports that $100 \%$ of its software is released as open source, but also $100 \%$ of it is released without copyright or copyleft restrictions. Or another reports that $100 \%$ of its software is in the category for release to the general public for noncommercial use exclusive of open source and also reports $100 \%$ of its software is released without copyright or copyleft restrictions. Being aware of the idiosyncrasies in the reporting, Table 9 is probably the best characterization of the release categories for the GOCO and GOGO respondents. However, Table 8 also provides the perspective of GOGO respondents that have software but, presumably because they do not release it, report essentially zero percent of the software in any of the release categories.

\subsection{Software Development and Management Costs, 2015-2019}

For the overview of the relationship between software development and management costs and the number of software products available for licensing or for download without a license, there were enough complete responses to estimate a very simple model of the cost function for the agencies' laboratories or laboratory facilities. We describe the simple model here in this section, and then we use the model (in conjunction with the simple revenue model) subsequently when we make predictions about how lifting the prohibition on GOGO software copyright might be expected to affect the agencies' software licensing activity. After describing the simple cost model for the laboratories with sufficient data to estimate the model, we will describe, for each item about costs on the survey, the detailed information provided by the respondents for their 2015-2019 software development and management costs.

\subsubsection{The Simple Model of Software Costs}

To describe the relationship between software development and management costs and the number of software products available for licensing or for download without a license, we use five variables.

For the period over fiscal years 2015 through 2019, the average annual cost of software development and management for the $i^{\text {th }}$ responding laboratory or laboratory facility (or laboratories or laboratory facilities if the respondent is submitting a report for multiple labs or facilities) is denoted cost_19. The respondents reported the cost for the software development and management as annual FTEs required for the various types of costs, and also reported the GS-rating for the personnel associated with the FTEs. We estimated the 2019 amount of the annual salary and wages and benefits for the GS-ratings by using (1) the U.S. OPM's 2019 General Schedule (GS) schedule of salary and wages. ${ }^{54}$ Then, (2)

\footnotetext{
${ }^{54}$ https://www.opm.gov/policy-data-oversight/pay-leave/salaries-wages/2019/general-schedule-gs-salarycalculator/.
} 
figuring the annual amount of total compensation using the GAO's assessment of the relationship of the salary and benefits. ${ }^{55}$

The dependent variable in the simple model of software costs measures, for software products available for licensing or download without a license, the laboratory or laboratory facility's annual software development and maintenance cost in 2019 dollars. The annual software cost, denoted cost_19, is computed, based on respondents' assessment of the annual averages over the fiscal years 2015-2019, as the sum of (1) [(average annual full-time equivalent (FTE) person years to develop the typical-in terms of having the average lines of code for the lab's software products - software product)x(2019 annual total compensation for the GS-rating of the FTE)]x[average annual number of software products available for licensing + average annual number of software products available for download to the public without a license], and (2) (average annual FTE for writing supporting software to maintain the developed software products)x(2019 annual total compensation for the GS-rating of the FTE), and (3) (average annual FTE for administrative support of the inventory of developed software products)X((2019 annual total compensation for the GS-rating of the FTE), and (4) (average annual FTE for IP protection and licensing administration for the software portfolio)x(2019 annual total compensation for the GS-rating of the FTE), and (5) average annual annuity fees to maintain software patents, and (6) average annual external legal expenses for software portfolio. Summarizing, the variable cost_19 equals the sum of the 2015-2019 annual averages for the cost of (1) software development, (2) supporting software to maintain developed software, (3) administrative support for managing developed software, (4) licensing administration, (5) annuity fees for software patents, and (6) external legal support expenses for IP protection and licensing for software portfolio.

The variable total_products is, for the fiscal years from 2015 through 2019, the sum of the respondent's average annual number of software products available for licensing and its average annual number of software products available for download by the public without a license. The variable avgLOC is the average lines of code for the responding lab's or facility's typical software product. The labs and lab facilities will be developing different types of software, and the variable avgLOC is used as a way to control for such differences. Another control for differences in the types of software products is with the qualitative variable $d G O C O$; it equals 1 if the lab or facility is government owned and contractor operated and is zero otherwise. Controlling for the variable $d G O C O$ allows the costs for the GOCO operations to differ from the costs of the GOGO operations. To describe whether or not there was intellectual property (IP) protection with either copyrights or patents or both, the variable IPprotected $=1$ when there were copyrights or patents, and $=0$ when there was no copyright or patent protection. ${ }^{56}$

${ }^{55}$ HUMAN CAPITAL: Trends in Executive and Judicial Pay Suggest a Reexamination of the Total Compensation Package, GAO-06-1116T, September 20, 2006, which stated: "[For] the balance of total compensation between pay and benefits within and across executive-level positions, overall Federal civilian employees receive, in broad terms, most of their compensation - about 67 percent - in salary and wages and about 33 percent in the form of benefits or deferred compensation."

${ }^{56}$ If there were a much larger sample of GOCO respondents, and if for that larger sample there was experience with both copyrights and patents, and if there was variance across the observations in that 
For the respondents with complete information for the five variables, there were 2 GOCO respondents, 13 GOGO respondents, and 1 respondent reporting a mixed case where for multiple laboratories, the majority were GOGO. Table 10 shows the descriptive statistics for the cost model's variables for those 16 respondents. Observe that the average annual cost for the 16 respondents is highly skewed, with the mean considerably greater than the median. The average lines of code for the respondents' typical software products are also highly skewed. The cost model estimated in Table 11, and discussed next, supports the view that the skewed distribution for cost is the result of the skewed distribution of product sizes.

Table 10. Descriptive Statistics for the Respondents with Complete Data for the Model of Software Development and Maintenance Costs

\begin{tabular}{|c|c|c|c|c|c|c|c|c|c|}
\hline & & & & & & \multicolumn{4}{|c|}{ percentiles } \\
\hline Variable & $n$ & mean & Std. Dev. & skewness & kurtosis & $25^{\text {th }}$ & $50^{\text {th }}$ & $75^{\text {th }}$ & $100^{\text {th }}$ \\
\hline cost_19 & 16 & $\$ 1,273,945$ & $2,599,641$ & 3.0 & 11.2 & 71,838 & 221,813 & $1,332,334$ & $10,500,000$ \\
\hline total_products & 16 & 2.15 & 2.32 & 0.89 & 2.6 & 0 & 2 & 3.4 & 7.2 \\
\hline avgLOC & 16 & 44,822 & 124,186 & 3.4 & 12.8 & 550 & 3,575 & 18,152 & 500,000 \\
\hline IPprotected & 16 & 0.375 & 0.50 & 0.52 & 1.3 & 0 & 0 & 1 & 1 \\
\hline$d G O C O$ & 16 & 0.125 & 0.34 & 2.3 & 6.1 & 0 & 0 & 0 & 1 \\
\hline
\end{tabular}

Notes: The variable cost_19 is, for the fiscal years from 2015-2019, the respondent's average annual cost of software development and management. The variable total_products is, for the fiscal years from 2015 through 2019, the sum of the respondent's average annual number of software products available for licensing and its average annual number of software products available for download by the public without a license. The variable avgLOC is the average lines of code for the responding lab's or facility's typical software product. The variable $d G O C O$ equals 1 if the responding lab or facility is government owned and contractor operated and is zero otherwise. The variable IPprotected $=1$ when there were copyrights or patents, and $=0$ when there was no copyright or patent protection.

Source: Authors' computations from "Software Copyright Impact Survey," OMB Control No. 0693-0033, Expiration Date: 07/31/2022

For the 16 respondents with complete observations for the model's variables, Table 11 shows the estimation of the simple cost model. The estimated model shows the expected annual software costs for a lab or lab facility as a function of the annual number of software products, available for licensing or for download by the public without license, and the average size of those products as measured by their lines of code. The annual cost of software products available for licensing or download is assumed to be zero if the number of such products is zero. Column (1) shows cost_19 as a function of total_products (the average annual number of software products available for licensing plus the average annual number of software products available for download by the public without a license) and avgLOC (the average lines of code for the responding lab's or facility's typical software product) used as a control for differences across the responding labs in the software developed. With costs measured in 2019 dollars, the estimated coefficient for total_products shows the marginal effect on costs from adding an additional software product available for licensing or available for download by the public without a license. At the margin, holding constant a product's size, for another

experience, it would be useful to develop a more detailed cost function that could identify the separable effects of copyrights and patents on costs. However, the sample of GOCO respondents is small, and their experience is primarily with copyrights. 


\subsubsection{Overview of the Agencies' Software Development and Management Costs for 2015-2019}

Respondents described their software costs over the entire period from fiscal year 2015 through fiscal year 2019. In the following tables, we show what the respondents who provided the information reported.

The Size of the Typical Software Product in Terms of Lines of Code. Each respondent was asked to estimate the average, maximum, and minimum number of lines of source code for the typical individual custom-developed software product developed by the respondent's laboratory/laboratories (or laboratory facility/facilities). Table 12 summarizes the information reported. Appendix E provides examples of custom software developed by GOGOs and GOCOs. For some, the estimated numbers of lines of code are reported.

Table 12. The Lines of Code (LOC) for the Typical Software Product

\begin{tabular}{|l|l|l|l|l|l|l|l|l|l|}
\hline \multicolumn{4}{|c|}{} & \multicolumn{5}{c|}{ percentiles $^{\text {th }}$} \\
\hline Variable & $n$ & mean & Std. Dev. & skewness & kurtosis & $25^{\text {th }}$ & $50^{\text {th }}$ & $75^{\text {th }}$ & $100^{\text {th }}$ \\
\hline Average LOC & 16 & 44,822 & 124,186 & 3.4 & 12.8 & 550 & 3,575 & 18,152 & 500,000 \\
\hline Maximum LOC & 16 & 722,010 & $2,486,116$ & 3.6 & 13.8 & 5,500 & 20,000 & 96,917 & $10,000,000$ \\
\hline Minimum LOC & 16 & 3,070 & 6,393 & 2.8 & 9.97 & 100 & 1,063 & 2,100 & 25,000 \\
\hline
\end{tabular}

Source: Authors' computations from "Software Copyright Impact Survey," OMB Control No. 0693-0033, Expiration Date: 07/31/2022

FTE for the Average Size Software Product (in Terms of Lines of Code). Each respondent was asked to estimate, for the average size software product (in terms of lines of source code), the average number of full-time equivalent (FTE) person-years required for its development, and also asked for a representative General Schedule (GS) rating. Table 13 shows the reported information.

Table 13. FTE and GS-rating for the Average Size Software Product

\begin{tabular}{|l|l|l|l|l|l|l|l|l|l|}
\hline \multicolumn{4}{|c|}{} & \multicolumn{4}{|c|}{ percentiles $^{\text {th }}$} \\
\hline Variable & $n$ & mean & Std. Dev. & skewness & kurtosis & $25^{\text {th }}$ & $50^{\text {th }}$ & $75^{\text {th }}$ & $100^{\text {th }}$ \\
\hline $\begin{array}{l}\text { Average Number of } \\
\text { FTE person-years }\end{array}$ & 16 & 3.69 & 9.78 & 3.5 & 13.5 & 0.3 & 0.75 & 2.5 & 40 \\
\hline Representative GS-rating & 13 & 12.85 & 1.07 & -0.54 & 2.2 & 12 & 13 & 14 & 14 \\
\hline
\end{tabular}

Source: Authors' computations from “Software Copyright Impact Survey," OMB Control No. 0693-0033, Expiration Date: 07/31/2022

Costs for Maintaining Software Available with or without a License. Respondents were asked about their organization's software management costs. The first such cost was the cost of maintaining software once developed. For software made available for download to the public with or without a license:

Over and above the cost of developing software that is released to the general public with or without a license, is there a significant annual cost to maintaining this software in terms of writing additional software or managing and administering the inventory once released? If so, please provide estimates of the average annual number of full-time equivalent (FTE) person-years required and a representative GS-rating. 
Table 14 shows the reported information.

Table 14. FTE and GS-rating for the Software Maintenance Costs

\begin{tabular}{|c|c|c|c|c|c|c|c|c|c|}
\hline & & & & & & \multicolumn{4}{|c|}{ percentiles } \\
\hline Variable & $n$ & mean & Std. Dev. & skewness & kurtosis & $25^{\text {th }}$ & $50^{\text {th }}$ & $75^{\text {th }}$ & $100^{\text {th }}$ \\
\hline $\begin{array}{l}\text { Average Number of } \\
\text { FTE person-years for } \\
\text { Writing Supporting } \\
\text { Software }\end{array}$ & 16 & 0.376 & 0.544 & 1.9 & 6.0 & 0.005 & 0.15 & 0.5 & 2 \\
\hline Representative GS-rating & 12 & 12.27 & 1.86 & -1.5 & 3.8 & 12.14 & 13 & 13 & 14 \\
\hline $\begin{array}{l}\text { Average Number of } \\
\text { FTE person-years for } \\
\text { Administering Software } \\
\text { Inventory }\end{array}$ & 16 & 0.226 & 0.345 & 1.5 & 3.8 & 0 & 0.075 & 0.375 & 1 \\
\hline Representative GS-rating & 10 & 11.67 & 2.40 & -1.0 & 2.7 & 11 & 12.5 & 13 & 14 \\
\hline
\end{tabular}

Source: Authors' computations from "Software Copyright Impact Survey," OMB Control No. 0693-0033,

Expiration Date: 07/31/2022

Costs for Managing IP and Licensing. With reference to licensed software, the respondents were asked about their organization's costs for managing IP and licensing for their software portfolio.

Internal to the laboratory/laboratories or facility/facilities for which you are responding, what is the average annual number of full-time equivalent (FTE) person-years (and representative GS-rating) dedicated to obtaining and maintaining intellectual property protection, and managing the licensing transactions for your software portfolio?

Table 15 shows the reported information.

Table 15. FTE and GS-rating for Costs of Managing IP and Licensing

\begin{tabular}{|l|l|l|l|l|l|l|l|l|l|}
\hline \multicolumn{4}{|c|}{ percentiles } \\
\hline Variable & $n$ & mean & Std. Dev. & skewness & kurtosis & $25^{\text {th }}$ & $50^{\text {th }}$ & $75^{\text {th }}$ & $100^{\text {th }}$ \\
\hline $\begin{array}{l}\text { Average Number of } \\
\text { FTE person-years }\end{array}$ & 16 & 0.357 & 0.592 & 1.6 & 4.6 & 0 & 0 & 0.75 & 2 \\
\hline Representative GS-rating & 8 & 14.125 & 0.835 & -0.22 & 1.7 & 13.5 & 14 & 15 & 15 \\
\hline
\end{tabular}

Source: Authors' computations from "Software Copyright Impact Survey," OMB Control No. 0693-0033, Expiration Date: 07/31/2022

Annuity Fees for Software Patents. Respondents were asked about the annuity fees for their organization's software portfolio.

For the laboratory/laboratories or facility/facilities for which you are responding, estimate the average annual annuity fees (paid to maintain all issued patents) required to maintain your software portfolio:

Table 16 shows the reported information. 
Table 16. Annuity fees for Software Patents

\begin{tabular}{|l|l|l|l|l|l|l|l|l|l|}
\hline \multicolumn{4}{|c|}{} & \multicolumn{4}{|c|}{ percentiles } \\
\hline Variable & $n$ & mean & Std. Dev. & skewness & kurtosis & $25^{\text {th }}$ & $50^{\text {th }}$ & $75^{\text {th }}$ & $100^{\text {th }}$ \\
\hline $\begin{array}{l}\text { Average annual cost of } \\
\text { annuity fees (\$) }\end{array}$ & 16 & 1,538 & 4,964 & 3.5 & 13.6 & 0 & 0 & 550 & 20,000 \\
\hline
\end{tabular}

Source: Authors' computations from "Software Copyright Impact Survey," OMB Control No. 0693-0033,

Expiration Date: 07/31/2022

Costs for External Legal Support for IP and Licensing of Software. Respondents were asked about their organization's costs for external legal support for managing the IP and licensing for their portfolio of software products.

External to the laboratory/laboratories or facility/facilities for which you are responding, what is the average annual cost of the legal support required for obtaining and maintaining intellectual property protection, and managing the licensing transactions, for your laboratory's software portfolio (including, if known, unreimbursed expense royalties)?*

* External legal costs include all annual expenses paid to private sector law firms in support of the agency's portfolio of software patents and copyrights.

Table 17 shows the reported information.

Table 17. External Legal Support Costs for IP and Licensing for Software Portfolio.

\begin{tabular}{|l|l|l|l|l|l|l|l|l|l|l|}
\hline \multicolumn{4}{|c|}{} & \multicolumn{4}{|c|}{ percentiles } \\
\hline Variable & $n$ & mean & Std. Dev. & skewness & kurtosis & $25^{\text {th }}$ & $50^{\text {th }}$ & $75^{\text {th }}$ & $100^{\text {th }}$ \\
\hline $\begin{array}{l}\text { Average annual cost of } \\
\text { external legal support }(\$)\end{array}$ & 16 & 11,750 & 30,827 & 2.3 & 6.5 & 0 & 0 & 0 & 100,000 \\
\hline
\end{tabular}

Source: Authors' computations from “Software Copyright Impact Survey," OMB Control No. 0693-0033, Expiration Date: 07/31/2022

\subsection{Counterfactual Software Copyright License \& Public Release Activity 2020- 2024}

Respondents were asked for their experience-based forecast of the 2020-2024 period assuming that the prohibition of copyrights for government-produced software is eliminated. In this section we provide an overview of the respondents' forecasts. Subsequently, we combine their forecasts with the estimated revenue and cost models, and from the combination provide predictions about how the elimination of the software copyright prohibition for GOGO laboratories and facilities would be expected to affect licensing revenues and costs. 


\subsubsection{Overview of the Respondents' Forecasts for 2020-2024 Given Elimination of the Copyright Prohibition for GOGO Laboratories or Laboratory Facilities}

Software Products Available. Each respondent was asked to estimate, assuming the elimination of the copyright prohibition for software produced by GOGO labs or lab facilities, the average annual number of software products that would be available for licensing from the lab/labs or lab facility/facilities for which the report was being made. Table 18 shows the respondents' forecast for the software products that would be made available. GOCO responses for the forecast average almost twice as many products as the GOGO responses. Comparing Table 18 with Table 3, we see a dramatic increase in the numbers of products available for both GOCO and GOGO respondents. The expected number jumps from 25 to 111 for GOCO respondents, and from 1 to 63 for GOGO respondents. Both increases are very large, but the relative increase for GOGO respondents, who would benefit most from the lifting of the copyright prohibition, is an order of magnitude larger than the increase for the GOCO respondents.

Table 18. Forecast of Average Annual Number of Software Products Available for Licensing if Copyright Prohibition Is Eliminated, 2020-2024

\begin{tabular}{|c|c|c|c|c|c|c|c|c|c|}
\hline \multicolumn{6}{|c|}{ GOCO } & \multicolumn{4}{|c|}{ percentiles } \\
\hline Variable & $n$ & mean & Std. Dev. & skewness & kurtosis & $25^{\text {th }}$ & $50^{\text {th }}$ & $75^{\text {th }}$ & $100^{\text {th }}$ \\
\hline $\begin{array}{l}\text { 5-year annual average for } \\
\text { number of products } \\
\text { available for licensing }\end{array}$ & 5 & 111.4 & 217.8 & 1.5 & 3.2 & 5 & 10 & 40 & 500 \\
\hline \multicolumn{6}{|c|}{ GOGO* } & \multicolumn{4}{|c|}{ percentiles } \\
\hline Variable & $n$ & mean & Std. Dev. & skewness & kurtosis & $25^{\text {th }}$ & $50^{\text {th }}$ & $75^{\text {th }}$ & $100^{\text {th }}$ \\
\hline $\begin{array}{l}\text { 5-year annual average for } \\
\text { number of products } \\
\text { available for licensing }\end{array}$ & 17 & 62.8 & 164.7 & 2.4 & 6.6 & 0 & 5 & 10 & 500 \\
\hline
\end{tabular}

Source: Authors' computations from "Software Copyright Impact Survey," OMB Control No. 0693-0033, Expiration Date: 07/31/2022

Software Products Licensed. Each respondent was asked to estimate, assuming the elimination of the copyright prohibition for software produced by GOGO labs or lab facilities, the average annual number of software products that would be licensed by the lab/labs or lab facility/facilities for which the report was being made. Table 19 shows the respondents' forecast for the software products that would be licensed. Comparing Table 19 with Table 5, we see the GOCO respondents anticipate somewhat more than a threefold increase in the numbers of products licensed, while the GOGO respondents, who would be directly affected by the elimination of copyright prohibition, anticipate an almost 60-fold increase from their average of less than one (0.6) product on average each year during 2015-2019. Although many of the GOGO respondents are reporting increases to what could be considered a modest number of products, for example in the range from 2 to 10, perhaps surprisingly the percentage increase for just these respondents is far more than the average for the sample as a whole because for many of them the percentage increase (from 0 to 2 to 10 ) is infinite. The three-fold increase anticipated by the GOCO respondents presumably reflects a growing market for software (as one respondent said: the "program is growing") and also greater awareness of the 
opportunities for using software created in the labs and facilities of Federal agencies (as one respondent providing a rationale for growth said: "increased awareness").

Table 19. Forecast of Average Annual Number of Licensed Software Products if Copyright Prohibition Is Eliminated, 2020-2024.

\begin{tabular}{|c|c|c|c|c|c|c|c|c|c|}
\hline \multicolumn{6}{|c|}{ GOCO } & \multicolumn{4}{|c|}{ percentiles } \\
\hline Variable & $n$ & mean & Std. Dev. & skewness & kurtosis & $25^{\text {th }}$ & $50^{\text {th }}$ & $75^{\text {th }}$ & $100^{\text {th }}$ \\
\hline $\begin{array}{l}\text { 5-year annual average for } \\
\text { number of products } \\
\text { licensed }\end{array}$ & 4 & 67.2 & 122.1 & 1.1 & 2.3 & 1 & 9.5 & 133.5 & 250 \\
\hline \multicolumn{6}{|c|}{ GOGO* } & \multicolumn{4}{|c|}{ percentiles } \\
\hline Variable & $n$ & mean & Std. Dev. & skewness & kurtosis & $25^{\text {th }}$ & $50^{\text {th }}$ & $75^{\text {th }}$ & $100^{\text {th }}$ \\
\hline $\begin{array}{l}\text { 5-year annual average for } \\
\text { number of products } \\
\text { licensed }\end{array}$ & 16 & 34.3 & 124.2 & 3.6 & 14.0 & 0 & 1.5 & 7 & 500 \\
\hline
\end{tabular}

Notes: Two of the 22 respondents who provided an estimate of the number of products available did not make an estimate of how many of their products available would actually be licensed.

*Includes one respondent reporting on multiple labs/facilities that were predominantly GOGO but included some GOCO activity.

Source: Authors' computations from "Software Copyright Impact Survey," OMB Control No. 0693-0033, Expiration Date: 07/31/2022

Licenses per Licensed Software Product. Each respondent was asked to estimate, assuming the elimination of the copyright prohibition for software produced by GOGO labs or lab facilities, the average annual number of times each licensed software product would be licensed. In the counterfactual scenario here where there is no copyright prohibition, these details about the number of times a product would be licensed become relevant for the GOGO respondents. Table 20 shows the respondents' forecast for the average number of times that a software product would be licensed. The one outlier is not a data-entry error, but instead a respondent who anticipates that the software created by the lab will have a lot of use, and given the type of software that the lab creates, the expectation is completely sensible. However, because the observation far greater than the others, we present the averages with and without it. 
Table 20. Forecast of Average Number of Times Each Licensed Software Product Would Be Licensed if Copyright Prohibition Is Eliminated, 2020-2024

\begin{tabular}{|l|l|l|l|l|l|l|l|l|l|l|}
\hline \multicolumn{7}{|c|}{ All Respondents } & & \multicolumn{3}{|c|}{ percentiles } \\
\hline Variable & $n$ & mean & $\begin{array}{l}\text { Std. } \\
\text { Dev. }\end{array}$ & skewness & kurtosis & $25^{\text {th }}$ & $50^{\text {th }}$ & $75^{\text {th }}$ & $100^{\text {th }}$ \\
\hline $\begin{array}{l}\text { 5-year annual average for number of } \\
\text { times } \\
\text { each product is expected to be } \\
\text { licensed }\end{array}$ & 19 & 558 & 2,289 & 4.0 & 17.0 & 0 & 2 & 10 & 10,000 \\
\hline $\begin{array}{l}\text { 5-year annual average for number of } \\
\text { times } \\
\text { each product is expected to be } \\
\text { licensed, } \\
\text { excluding the one outlier }\end{array}$ & 18 & 33.4 & 117.0 & 3.8 & 15.7 & 0 & 1.5 & 10 & 500 \\
\hline
\end{tabular}

\begin{tabular}{|c|c|c|c|c|c|c|c|c|c|}
\hline \multicolumn{6}{|c|}{ GOCO } & \multicolumn{4}{|c|}{ percentiles } \\
\hline Variable & $n$ & mean & $\begin{array}{l}\text { Std. } \\
\text { Dev. }\end{array}$ & skewness & kurtosis & $25^{\text {th }}$ & $50^{\text {th }}$ & $75^{\text {th }}$ & $100^{\text {th }}$ \\
\hline $\begin{array}{l}\text { 5-year annual average for number of } \\
\text { times } \\
\text { each product is expected to be } \\
\text { licensed }\end{array}$ & 4 & 6 & 7.62 & 0.91 & 2.1 & 1 & 3.5 & 11 & 17 \\
\hline \multicolumn{6}{|c|}{ GOGO* } & \multicolumn{4}{|c|}{ percentiles } \\
\hline Variable & $n$ & mean & $\begin{array}{l}\text { Std. } \\
\text { Dev. }\end{array}$ & skewness & kurtosis & $25^{\text {th }}$ & $50^{\text {th }}$ & $75^{\text {th }}$ & $100^{\text {th }}$ \\
\hline $\begin{array}{l}\text { 5-year annual average for number of } \\
\text { times } \\
\text { each product is expected to be } \\
\text { licensed }\end{array}$ & 15 & 705.2 & 2,575 & 3.5 & 13.0 & 0 & 1 & 10 & 10,000 \\
\hline $\begin{array}{l}\text { 5-year annual average for number of } \\
\text { times } \\
\text { each product is expected to be } \\
\text { licensed, } \\
\text { excluding the one outlier }\end{array}$ & 14 & 41.3 & 132.7 & 3.3 & 11.8 & 0 & 1 & 10 & 500 \\
\hline
\end{tabular}

Note: Among the 22 respondents who provided estimates of the number of products available, three did not provide a forecast for this item, including the two who did not provide a forecast for the number of licensed products, and then one additional respondent who reported a forecast for the number of licensed products, but did not have a forecast for the number of times each would be licensed. There is one clear outlier for the number of times that each individual licensed product would be licensed. That respondent forecasts that all of the lab's five products available would be licensed and that each of those licensed products would be licensed 10,000 times. Although far greater than the estimates from the other respondents, the estimate is completely understandable given the laboratory for which the respondent was reporting and the type of copyrighted software that it would be able to make available if the copyright prohibition were lifted. *Includes one respondent reporting on multiple labs/facilities that were predominantly GOGO but included some GOCO activity.

Source: Authors' computations from "Software Copyright Impact Survey," OMB Control No. 0693-0033, Expiration Date: 07/31/2022

Seats per License. Each respondent was asked to estimate, assuming the elimination of the copyright prohibition for software produced by GOGO labs or lab facilities, the average annual number of "seats per license" for the software products that would be licensed by the lab/labs or lab facility/facilities for which the report was being made. In the counterfactual scenario here where there is no copyright prohibition, these details about the number of seats per licensed product become relevant for the GOGO 
respondents. Table 21 shows the respondents' forecast for the software products that would be licensed and for which "seats per license" would be a relevant metric. Now that the question is relevant for potentially all of the GOGO respondents, the response to this question which was not of much interest for the 2015-2019 period, reveals a dramatic change if the copyright prohibition is eliminated.

\section{Table 21. Forecast of Average Annual Number of Seats per Licensed Software Product if Copyright Prohibition Is Eliminated, 2020-2024}

\begin{tabular}{|l|l|l|l|l|l|l|l|l|l|l|}
\hline \multicolumn{4}{|c|}{ All Respondents } & \multicolumn{3}{c|}{ percentiles } \\
\hline Variable & $n$ & mean & $\begin{array}{l}\text { Std. } \\
\text { Dev. }\end{array}$ & skewness & kurtosis & $25^{\text {th }}$ & $50^{\text {th }}$ & $75^{\text {th }}$ & $100^{\text {th }}$ \\
\hline $\begin{array}{l}\text { 5-year annual average of the number } \\
\text { of } \\
\text { "seats per license" (if this metric } \\
\text { applies) }\end{array}$ & 15 & 14.5 & 51.4 & 3.5 & 13.0 & 0 & 0 & 3 & 200 \\
\hline
\end{tabular}

\begin{tabular}{|c|c|c|c|c|c|c|c|c|c|}
\hline \multicolumn{6}{|c|}{ GOCO } & \multicolumn{4}{|c|}{ percentiles } \\
\hline Variable & $n$ & mean & $\begin{array}{l}\text { Std. } \\
\text { Dev. }\end{array}$ & skewness & kurtosis & $25^{\text {th }}$ & $50^{\text {th }}$ & $75^{\text {th }}$ & $100^{\text {th }}$ \\
\hline $\begin{array}{l}\text { 5-year annual average of the number } \\
\text { of } \\
\text { "seats per license" (if this metric } \\
\text { applies) }\end{array}$ & 3 & 2.33 & 2.52 & 0.24 & 1.5 & 0 & 2 & 5 & 5 \\
\hline \multicolumn{6}{|c|}{ GOGO* } & \multicolumn{4}{|c|}{ percentiles } \\
\hline Variable & $n$ & mean & $\begin{array}{l}\text { Std. } \\
\text { Dev. }\end{array}$ & skewness & kurtosis & $25^{\text {th }}$ & $50^{\text {th }}$ & $75^{\text {th }}$ & $100^{\text {th }}$ \\
\hline $\begin{array}{l}\text { 5-year annual average of the number } \\
\text { of } \\
\text { "seats per license" (if this metric } \\
\text { applies) }\end{array}$ & 12 & 17.5 & 57.5 & 3.0 & 10.1 & 0 & 0 & 2 & 200 \\
\hline
\end{tabular}

Note: Among the 22 respondents who provided estimates of the number of products available, seven did not provide a forecast for this item, including of the three who did not provide an estimate for the number of times each particular licensed product would be licensed, and then four additional respondents who had reported that item but then did not report an expected number of seats per license.

*Includes one respondent reporting on multiple labs/facilities that were predominantly GOGO but included some GOCO activity.

Source: Authors' computations from "Software Copyright Impact Survey," OMB Control No. 0693-0033, Expiration Date: 07/31/2022

Release Categories for Software Products. Each respondent was asked to estimate, assuming the elimination of the copyright prohibition for software produced by GOGO labs or lab facilities, the distribution of software products across seven release categories shown in Table 22.

Among the four GOCO respondents for Table 22, there is one who reports $0 \%$ for all seven release categories. Two of the remaining three GOCO respondents report percentages for the categories that sum to $100 \%$. The third does not respond as if the categories are mutually exclusive, and so the sum of its percentages across the seven release categories is greater than $100 \%$.

Among the 17 GOGO respondents for Table 22, there are three who report $0 \%$ for all seven release categories. Of the remaining 14 GOGO respondents, there are three that do 
not report the categories as mutually exclusive (i.e., the percentages sum to more than $100 \%$ ). For the remaining 11 GOGO respondents, each reports percentages across the categories that sum to $100 \%$.

The summary responses for all four GOCO respondents and for all 17 GOGO respondents are shown in Table 22. Table 23 shows the summary of the responses for the samples of GOCO and GOGO respondents who do not report all zeros for the seven release categories.

From the complete sample of respondents in Table 22, we see that the release category with the highest percentage on average is software copyrighted as open source and for the GOCO respondents the percentage of the products within that category is more than twice the percentage in any other category. For the GOGO respondents, the percent copyrighted as open source is about half as large as for the GOCO respondents. For the GOGO group, the "copyrighted-as-open-source" category is also the largest percentage across the seven categories, but it is half as likely to be a category characterizing their software in the counterfactual scenario in which they could copyright their software. The same result, although it is more pronounced, shows up in Table 23 with the samples that exclude respondents reporting all zeros for the percentages of their software in each of the seven release categories.

From Table 9, for the GOGO operations, $41 \%$ of the software products made available during the period 2015-2019 were released to the general public without copyright or copyleft restrictions, and therefore those products were clearly in the public domain. From Table 23, for the GOGO operations, that percentage falls to less than $11 \%$. Thus, however helpful copyrights may be for strengthening the effectiveness of making GOGO software available for others, there is a social cost - or unintended consequence - of eliminating the copyright prohibition. ${ }^{57}$ Namely, the proportion of public domain software is expected to decline by $30 \%(41 \%-11 \%)$. Considering the accounting for GOGO IP and release categories described in Table 4 and Table 9, from Table 23's accounting of the release attributes for GOGO software, the proportion of public domain software lost is transferred into the proportion taken by copyrighted software. Offsetting that relative decline is the very large increase in the number of software products licensed and, presumably, used productively. As we have seen by comparing Table 19 with Table 5, the GOGO respondents anticipate an almost 60-fold increase in the number of software products licensed if copyright is allowed; GOCO respondents expect about a 3-fold increase. Also, comparing Table 18 with Table 3, for products made available for licensing, a 72-fold increase is expected for GOGO respondents, and a 4.5-fold increase for GOCO respondents. Despite the increase in software made available and software licensed, the loss of public domain software may lessen productivity for some users of the agencies' publicly released software.

\footnotetext{
${ }^{57}$ On the loss of public domain software as a social cost or unintended consequence of eliminating the copyright prohibition, see Alfonso Gambardella and Bronwyn H. Hall, "Proprietary vs. Public Domain Licensing of Software and Research Products," National Bureau of Economic Research, Working Paper 11120, February 2005, http://www.nber.org/papers/w11120.
} 
Table 22. Approximate Percentage Distribution of Release Attributes for Software Products Available: All Responses

\begin{tabular}{|c|c|c|c|c|c|c|c|c|c|}
\hline \multicolumn{6}{|c|}{ GOCO } & \multicolumn{4}{|c|}{ percentiles } \\
\hline Variable & $n$ & mean & $\begin{array}{l}\text { Std. } \\
\text { Dev. }\end{array}$ & skewness & kurtosis & $25^{\text {th }}$ & $50^{\text {th }}$ & $75^{\text {th }}$ & $100^{\text {th }}$ \\
\hline Percent patented but not copyrighted & 4 & 12.5 & 25 & 1.2 & 2.3 & 0 & 0 & 25 & 50 \\
\hline Percent copyrighted but not patented & 4 & 25 & 46.7 & 1.1 & 2.3 & 0 & 2.5 & 50 & 95 \\
\hline Percent patented \& copyrighted & 4 & 0 & 0 & - & - & 0 & 0 & 0 & 0 \\
\hline Percent copyrighted as open source & 4 & 60 & 45.3 & -0.54 & 1.7 & 25 & 72.5 & 95 & 95 \\
\hline $\begin{array}{l}\text { Percent released to the general public or } \\
\text { other agencies for noncommercial use } \\
\text { (exclusive of open source) }\end{array}$ & 4 & 25 & 50 & 1.2 & 2.3 & 0 & 0 & 50 & 100 \\
\hline $\begin{array}{l}\text { Percent released to general public } \\
\text { without copyright or copyleft } \\
\text { restrictions }\end{array}$ & 4 & 0 & 0 & - & - & 0 & 0 & 0 & 0 \\
\hline Percent classified or export controlled & 4 & 1.25 & 2.5 & 1.2 & 2.3 & 0 & 0 & 2.5 & 5 \\
\hline \multicolumn{6}{|c|}{ GOGO* } & \multicolumn{4}{|c|}{ percentiles } \\
\hline Variable & $n$ & mean & $\begin{array}{l}\text { Std. } \\
\text { Dev. }\end{array}$ & skewness & kurtosis & $25^{\text {th }}$ & $50^{\text {th }}$ & $75^{\text {th }}$ & $100^{\text {th }}$ \\
\hline Percent patented but not copyrighted & 17 & 6.18 & 17.55 & 3.1 & 11.7 & 0 & 0 & 0 & 70 \\
\hline Percent copyrighted but not patented & 17 & 25.88 & 40.97 & 1.1 & 2.4 & 0 & 0 & 50 & 100 \\
\hline Percent patented \& copyrighted & 17 & 5.15 & 13.18 & 2.7 & 9.3 & 0 & 0 & 0 & 50 \\
\hline Percent copyrighted as open source & 17 & 28.82 & 41.93 & 0.90 & 2.0 & 0 & 0 & 50 & 100 \\
\hline $\begin{array}{l}\text { Percent released to the general public or } \\
\text { other agencies for noncommercial use } \\
\text { (exclusive of open source) }\end{array}$ & 17 & 10 & 14.90 & 1.4 & 3.95 & 0 & 0 & 20 & 50 \\
\hline $\begin{array}{l}\text { Percent released to general public } \\
\text { without copyright or copyleft } \\
\text { restrictions }\end{array}$ & 17 & 8.68 & 24.69 & 3.2 & 12.5 & 0 & 0 & 0 & 100 \\
\hline Percent classified or export controlled & 17 & 17.35 & 33.50 & 1.7 & 4.3 & 0 & 0 & 10 & 100 \\
\hline
\end{tabular}

*Includes one respondent reporting on multiple labs/facilities that were predominantly GOGO but included some GOCO activity.

Source: Authors' computations from “Software Copyright Impact Survey," OMB Control No. 0693-0033,

Expiration Date: 07/31/2022 
Table 23. Approximate Percentage Distribution of Release Attributes for Software Products Available: Smaller Selective Samples (without the respondents that reported zeros for all seven release categories)

\begin{tabular}{|c|c|c|c|c|c|c|c|c|c|}
\hline \multicolumn{6}{|c|}{ GOCO } & \multicolumn{4}{|c|}{ percentiles } \\
\hline Variable & $n$ & mean & $\begin{array}{l}\text { Std. } \\
\text { Dev. }\end{array}$ & skewness & kurtosis & $25^{\text {th }}$ & $50^{\text {th }}$ & $75^{\text {th }}$ & $100^{\text {th }}$ \\
\hline Percent patented but not copyrighted & 3 & 16.67 & 28.87 & 0.71 & 1.5 & 0 & 0 & 50 & 50 \\
\hline Percent copyrighted but not patented & 3 & 33.33 & 53.46 & 0.70 & 1.5 & 0 & 5 & 95 & 95 \\
\hline Percent patented \& copyrighted & 3 & 0 & 0 & - & - & 0 & 0 & 0 & 0 \\
\hline Percent copyrighted as open source & 3 & 80 & 25.98 & -0.71 & 1.5 & 50 & 95 & 95 & 95 \\
\hline $\begin{array}{l}\text { Percent released to the general public or } \\
\text { other agencies for noncommercial use } \\
\text { (exclusive of open source) }\end{array}$ & 3 & 33.33 & 57.74 & 0.71 & 1.5 & 0 & 0 & 100 & 100 \\
\hline $\begin{array}{l}\text { Percent released to general public } \\
\text { without copyright or copyleft restrictions }\end{array}$ & 3 & 0 & 0 & - & - & 0 & 0 & 0 & 0 \\
\hline Percent classified or export controlled & 3 & 1.67 & 2.89 & 0.71 & 1.5 & 0 & 0 & 5 & 5 \\
\hline \multicolumn{6}{|c|}{ GOGO* } & \multicolumn{4}{|c|}{ percentiles } \\
\hline Variable & $n$ & mean & $\begin{array}{l}\text { Std. } \\
\text { Dev. }\end{array}$ & skewness & kurtosis & $25^{\text {th }}$ & $50^{\text {th }}$ & $75^{\text {th }}$ & $100^{\text {th }}$ \\
\hline Percent patented but not copyrighted & 14 & 7.5 & 19.19 & 2.8 & 9.4 & 0 & 0 & 5 & 70 \\
\hline Percent copyrighted but not patented & 14 & 31.43 & 43.34 & 0.79 & 1.82 & 0 & 2.5 & 75 & 100 \\
\hline Percent patented \& copyrighted & 14 & 6.25 & 14.37 & 2.4 & 7.4 & 0 & 0 & 2.5 & 50 \\
\hline Percent copyrighted as open source & 14 & 35 & 43.94 & 0.59 & 1.6 & 0 & 2.5 & 85 & 100 \\
\hline $\begin{array}{l}\text { Percent released to the general public or } \\
\text { other agencies for noncommercial use } \\
\text { (exclusive of open source) }\end{array}$ & 14 & 12.14 & 15.65 & 1.1 & 3.3 & 0 & 5 & 25 & 50 \\
\hline $\begin{array}{l}\text { Percent released to general public } \\
\text { without copyright or copyleft restrictions }\end{array}$ & 14 & 10.54 & 27.00 & 2.9 & 10.0 & 0 & 0 & 2.5 & 100 \\
\hline Percent classified or export controlled & 14 & 21.07 & 36.01 & 1.4 & 3.3 & 0 & 0 & 25 & 100 \\
\hline
\end{tabular}

*Includes one respondent reporting on multiple labs/facilities that were predominantly GOGO but included some GOCO activity.

Source: Authors' computations from “Software Copyright Impact Survey,” OMB Control No. 0693-0033, Expiration Date: 07/31/2022

Growth Rate in Size (Lines of Code) of Software Products. Each respondent was asked to estimate, assuming the elimination of the copyright prohibition for software produced by GOGO labs or lab facilities, the average annual growth rate in the number of lines of code for their software products available for licensing:

Compared to the 2015-2019 period: Do you anticipate the average number of lines of source code for individual custom-developed software products available for licensing will grow, decline, or stay roughly the same? (Please choose one response and enter the \%.) (a) Average annual growth (\%), (b) Average annual decline (\%) (c) Remain the same (enter the number 0).

Table 24 shows average response as the simple average of responses (the positive percentages, negative percentages, and zeros) that the respondents reported. For all 21 respondents, the reported growth rates for product size averaged 9.6\%, with a minimum of $-5 \%$ and a maximum of $50 \%$. GOCO respondents reported growth rates for product size that averaged $1.2 \%$, while the GOGO respondents report growth rates that averaged $13 \%$. Perhaps as would be expected, the elimination of the software copyright prohibition for GOGO labs and lab facilities would cause those facilities to anticipate greater change in their software products than would be the case for the GOCO labs and lab facilities that already have the authorization to copyright their software products. 
Table 24. Average Annual Growth Rate in Lines of Code for Software Products

\begin{tabular}{|l|l|l|l|l|l|l|l|l|l|}
\hline \multicolumn{9}{|c|}{ GOCO } & \multicolumn{4}{c|}{ percentiles } \\
\hline Variable & $n$ & mean & Std. Dev. & skewness & kurtosis & $25^{\text {th }}$ & $50^{\text {th }}$ & $75^{\text {th }}$ & $100^{\text {th }}$ \\
\hline Average Annual Growth Rate & 6 & 1.17 & 4.26 & 0.044 & 2.05 & 0 & 0 & 5 & 7 \\
\hline \multicolumn{9}{|c|}{ GOGO* } \\
\hline Variable & $n$ & mean & Std. Dev. & skewness & kurtosis & $25^{\text {th }}$ & $50^{\text {th }}$ & $75^{\text {th }}$ & $100^{\text {th }}$ \\
\hline Average Annual Growth Rate & 15 & 13 & 16.88 & 1.13 & 3.03 & 0 & 10 & 20 & 50 \\
\hline
\end{tabular}

*Includes one respondent reporting on multiple labs/facilities that were predominantly GOGO but included some GOCO activity.

Source: Authors' computations from "Software Copyright Impact Survey," OMB Control No. 0693-0033, Expiration Date: 07/31/2022

Growth Rate in Revenues for Software Products. Each respondent was asked to estimate, assuming the elimination of the copyright prohibition for software produced by GOGO labs or lab facilities, the average annual growth rate in the revenues for their software products available for licensing:

Compared to the 2015-2019 period: Do you expect the average annual dollar amount of revenues generated per licensed software product (i.e., after removing the effects of inflation and thus using dollars of constant value) to grow, decline, or remain roughly the same? (Please choose one of the first three responses and enter the $\%$. Then provide your rationale in the fourth response area.) (a) Inflation-adjusted average annual growth (\%), (b) Inflation-adjusted average annual decline (\%), (c) Remain the same (enter the number 0), (d) Please provide a general rationale for your estimate.

Table 25 shows average response as the simple average of responses (the positive percentages, negative percentages, and zeros) that the respondents reported. For all 21 respondents, the reported revenue growth rates averaged $10.4 \%$, with a minimum of $0 \%$ and a maximum of $100 \%$. GOCO respondents reported growth rates for revenue growth that averaged $1.6 \%$, while the GOGO respondents report growth rates that averaged $13.1 \%$. Just as with the anticipated growth rates in software product size as measured with lines of code, the GOGO respondents anticipate a much larger growth rate in their revenues than do the GOCO respondents. Again, that is to be expected given that the GOCO respondents are the ones for whom the copyright prohibition would be lifted. However, as the qualitative responses about the rationale for the estimates makes clear, there are some GOGO respondents who are not anticipating charging any fees for the use of their software.

Responses for the revenue growth rate rationale included the following. First, for the GOCO respondents, the responses were as follows. One respondent who expected revenue growth said the rationale was the "program is growing." And another anticipating growth said the rationale was "increased awareness." Two respondents anticipate that revenues per product would remain about the same. One said, "We're a small shop with limited software products, government facing with little intention of selling our software back to the government. Significant growth is not expected." The other said, "The copyright disclosure numbers are about the same."

Second, for the GOGO respondents the qualitative responses about the rationale for their growth projections were as follows. From GOGO respondents who anticipated growth in 
revenues, one respondent stated, "Our workforce is growing $10 \%$ a year. I cannot release much info due to [security reasons]." Another reported, "Right now we have nothing. This effort will move [our organization] closer to understanding the value of software written at [its facilities]." Yet another simply said, "growth in software as an R\&D product". Another respondent said, "Currently there is almost no revenue generated from software products. This might change if copyright restrictions are lifted." From the GOGO respondents who did not anticipate any growth in revenues, one respondent simply said, "Open Source, no charge." Another said, "They will always be freely available products." Another respondent said, "There is no licensed software." Another said, "[Our lab] has no plans, at this time, to develop any software. Our lab works on processes and equipment [for internal use]." And another respondent said, "Don't intend to charge for software as this is counterproductive to getting people to use it."

Thus, although there are a significant number of respondents who do not anticipate revenue growth per licensed software product, there are clearly many who do, with the average response shown in Table 25. Note well that the question here is about the growth in revenue per licensed product. From the preceding tables we know that considerable growth in the numbers of licensed products is anticipated, and here in Table 25 we can see that for many respondents, revenue per licensed product is also expected to grow if the copyright prohibition is lifted.

Also observe that although there are some GOGO respondents who are not anticipating charging any fees for the use of their software, nonetheless, lifting the software copyright prohibition would be expected to increase use of software if the copyright protection made users of open source software more willing to contribute to its development without concern that other users would appropriate the developments and then incorporate them in proprietary software for which fees were charged. As one GOGO respondent stated:

I am glad that someone is asking the question about lifting the restriction on copyrighting government employee created software. I'd like to present a different case why it would be so valuable. I'm a scientist. I want to be able to collaborate with other scientists in all sectors - commercial, academic, government, NGO etc. Part of how I collaborate is by developing software that helps us to advance our science. Typically, I start the project and give away the code. Other people find the code *almost* does exactly what they want. So, they make a small change or addition. Often, they want to contribute the change back to the project so that others can benefit but they find the lack of a copyright a problem. They don't want to contribute back without some basic copyright protections. So, they don't and their enhancement remains proprietary. I don't get to benefit and nor does anyone else. What I'd like to do is make the code available with some well understood but permissive license - I like the "MIT license" - so other people feel comfortable collaborating. I benefit because my product has been improved and they benefit because they get the benefit of all my effort. Being able to license our code using a permissive Open Source license would actually enhance reuse and collaboration - in other words enhance its value to the citizens of the United States.

In a related vein, the IP attorney for the software group at a different responding GOGO facility wrote: 
Two basic benefits [from eliminating the copyright prohibition]. (1) Gov employee produced software can be licensed to commercialization partners who could then make improvements to tech data or software and then protect their investment better. This reduces uncertainty. When certainty as to ability to get RoI increases, then so does investment. (2) Contractors have been known to take Gov employee produced designs or software and then make marginal changes then try to sell this Government employee produced recorded information back to the Gov without making any real private investment. If the Gov had copyright protection, it could file a lawsuit against the company and force them to disgorge their unearned profits from sale of Gov employee produced recorded information. ${ }^{58}$

Table 25. Average Annual Growth Rate in Revenues for Software Products

\begin{tabular}{|l|l|l|l|l|l|l|l|l|l|}
\hline \multicolumn{9}{|c|}{ GOCO } & \multicolumn{4}{|c|}{ percentiles } \\
\hline Variable & $n$ & mean & Std. Dev. & skewness & kurtosis & $25^{\text {th }}$ & $50^{\text {th }}$ & $75^{\text {th }}$ & $100^{\text {th }}$ \\
\hline Average Annual Growth Rate & 5 & 1.6 & 2.30 & 0.68 & 1.75 & 0 & 0 & 3 & 5 \\
\hline \multicolumn{9}{|c|}{ GOGO* } \\
\hline Variable & $n$ & mean & Std. Dev. & skewness & kurtosis & $25^{\text {th }}$ & $50^{\text {th }}$ & $75^{\text {th }}$ & $100^{\text {th }}$ \\
\hline Average Annual Growth Rate & 16 & 13.1 & 26.8 & 2.5 & 8.2 & 0 & 0 & 15 & 100 \\
\hline
\end{tabular}

*Includes one respondent reporting on multiple labs/facilities that were predominantly GOGO but included some GOCO activity.

Source: Authors' computations from "Software Copyright Impact Survey," OMB Control No. 0693-0033, Expiration Date: 07/31/2022

\subsection{Predictions of the Effects of Allowing Copyright Protection for Software Created by GOGO Laboratories and Laboratory Facilities}

In this section, we juxtapose the respondents' forecasts and the simple revenue and cost models. From the juxtaposition we develop overall predictions about how the elimination of the software copyright prohibition for GOGO laboratories and facilities would be expected to affect licensing revenues and costs. From the estimated effects for the respondents to our survey, we estimate the effects across all Federal agencies by using information about the proportion of all Federal agency software activity taken by the respondents.

\footnotetext{
${ }^{58}$ Of course, the observer here is discussing what could be done if copyright protection is allowed. The observation is about what could happen in the counterfactual scenario that allows copyright of Government Works software. Government works software cannot be copyrighted, and therefore one would not find evidence that the government has brought a lawsuit to claim infringement of the copyrights that it does not possess. However, copyright infringement cases have been prosecuted by GOCO laboratories operating under the authorities granted to them by the agencies for whom they operate the laboratories. For example, see, https://www.govinfo.gov/content/pkg/USCOURTS-idd-4_13-cv-00442/pdf/USCOURTS-idd-4_13-cv00442-2.pdf. So, perhaps, in the event that the restrictions on Government Works are lifted, more copyright infringement cases would be prosecuted.
} 


\subsubsection{Prediction of Licensing Revenues for the GOCO and GOGO Laboratories and Facilities Providing 2020-2024 Forecasts Assuming Copyrights Are Allowed}

From Table 6, for all of the software licensing revenue reported by the survey respondents over 2015-2019, the annual revenue in constant 2019 U.S. dollars averaged $\$ 82,931$ for the $8 \mathrm{GOCO}$ respondents that provided the revenue data. The annual revenue in 2019 dollars averaged $\$ 2,645$ for the 28 GOGO respondents and 1 predominantly GOGO respondent that provided the revenue data. Based on what we have learned from studying the respondents' survey responses, how would we expect those licensing revenues to change over the next five years if the copyright prohibition on copyrights for software produced by GOGO labs and lab facilities is lifted?

To answer, we combine the respondents' forecasts for products licensed, release categories, and growth in revenues per licensed product with our simple estimated model of licensing revenue. The answer that we find for the forecast for 2020-2024 under the assumption that the copyright prohibition is lifted is as follows. The average annual revenue in 2019 dollars for GOCO respondents is forecast to be $\$ 201,677$. The average annual revenue in 2019 for the GOGO respondents is forecast to be $\$ 135,333$. Thus, compared with the actual annual revenues for 2015-2019, the forecast for the expected value of annual licensing revenues is 2.43 times as great (an increase of 243\%) for GOCO labs or lab facilities, and it is 51.2 times as great (an increase of $5100 \%$ ) for GOGO labs or lab facilities. Table 26 summarizes the forecasts for 2020-2024, including the confidence intervals for the estimates, and the comparisons with the actual revenues for 2015-2019. 
Table 26. Average Annual Revenue for Software Products for a GOCO or GOGO Respondent: Actual versus Forecast in 2019 dollars

\begin{tabular}{|c|c|}
\hline \multicolumn{2}{|l|}{ GOCO } \\
\hline Variable & \\
\hline $\begin{array}{l}\text { Average Annual Revenue 2015-2019 } \\
\text { (from Table 6) }\end{array}$ & $\$ 82,931$ \\
\hline $\begin{array}{l}\text { Average Forecast Annual Revenue 2020-2024 } \\
\text { if GOGO copyright prohibition eliminated } \\
n=5\end{array}$ & $\begin{array}{l}\$ 201,677 \\
(\$ 154,773 \text { to } \$ 248,581)\end{array}$ \\
\hline \multicolumn{2}{|l|}{ GOGO* } \\
\hline Variable & \\
\hline $\begin{array}{l}\text { Average Annual Revenue 2015-2019 } \\
\text { (from Table 6) }\end{array}$ & $\$ 2,645$ \\
\hline $\begin{array}{l}\text { Average Forecast Annual Revenue } 2020-2024 \\
\text { if GOGO copyright prohibition eliminated } \\
\mathrm{n}=18\end{array}$ & $\begin{array}{l}\$ 135,333 \\
(\$ 107,500 \text { to } \$ 163,166)\end{array}$ \\
\hline
\end{tabular}

Note: In parentheses with each forecast is the $95 \%$ confidence interval that uses the standard error of the forecast for the mean of the forecasts. That larger standard error rather than the standard error of the prediction (i.e. fitted value) is the appropriate one in the present context. The smaller standard error of the prediction would show a tighter distribution of the random variable (the prediction for the dependent variable) that would result if within-sample observations of the explanatory variables were used, while the larger standard error of the forecast is appropriate since we are using the out-of-sample 2020-2024 projections for the explanatory variables. The standard error of the mean of the forecasts is the square root of the product of (1) the reciprocal of the square of the number of respondents in the subsample and (2) the sum, over the respondents in the subsample, of the squared standard errors of the forecast for each respondent. The $95 \%$ confidence interval ranges from two standard errors below the mean to two standard errors above the mean.

*Includes one respondent reporting on multiple labs/facilities that were predominantly GOGO but included some GOCO activity.

Source: Authors' computations from "Software Copyright Impact Survey," OMB Control No. 0693-0033, Expiration Date: 07/31/2022

The opportunities would be the same for the GOGOs given that they can copyright their software, but notice that their average annual revenues are still less than those for GOCOs. That is because we have the observations that do not anticipate licensing software, and more generally, the GOGOs anticipate licensing less software than the GOCOs, as we saw in the overview tables for their forecasts for 2020-2024. That is, despite the dramatic increase in the mean number of licensed products for the GOGO respondents, the number is still considerably less than for the GOCO respondents. The GOGO respondents on average had practically no licensed products for 2015-2019, and then anticipate the dramatic increase if the copyright prohibition is lifted, but the number of licensed products anticipated is nonetheless less than what the GOCO respondents anticipate.

To derive the forecasts in Table 26, we began with the information described in Section 2.6.1 for the respondents' expectations for the 2020-24 period if the copyright prohibition for government created software is eliminated. Respondents reported about their expectations, should copyrights become obtainable, for their software products available, for products licensed, and for the types of intellectual property protection obtained 
(implicit in the report of software release types). We use those expectations with the model of licensing revenues, described in Section 2.4.1 and estimated in Appendix C, to provide the forecasts shown in Table 26 about the likely effects on licensing revenues of eliminating the copyright prohibition. We turn now to the detailed explanation of the forecasts.

GOGO respondents especially were understandably cautious about providing their forecasts for products and IP in the counterfactual situation that copyrights for their software could be obtained. The result is that some respondents would provide responses to some questions, but then leave others blank. In some cases, the blanks and the resulting missing data may be because the respondent considered the answer was implied by other responses. In other cases, it could simply be that the respondent was uncertain about what the right answer would be-uncertain about what will happen over the next five years if the copyright prohibition is lifted. In a few cases, the most accurate projections, and also the most conservative projections, of what will happen require filling in a few of the blanks to add a few more observations to be used for the projections. It is a conservative approach because the observations added result in lower projections of licensing revenues for the set of respondents, and hence lower expected revenues when the results are extrapolated to the level of all the software activity for all Federal agencies. The reason that completing the missing data for a handful of observations lowers the projections is because on the whole, the additional observations are cases where absolutely no software is projected to be available for licensing. Using these observations is not only more conservative, it also allows more accurate projections. Those respondents anticipating no licensing of software are those where software production has been for internal use only. It is those respondents who may have found completing the survey somewhat frustrating, because it was asking for projections about something that they did not anticipate doing. Some of these respondents completed all the necessary questions for use in the projections, but some, perhaps in their frustration with the questions that did not seem pertinent to their circumstances, did not. To leave them out of the projections would bias the findings toward much higher licensing revenues that would actually be anticipated.

For the foregoing reasons, we have for the projections filled in a few incomplete responses. The tables in Section 2.6.1 show the reported numbers, i.e., the forecasts that the respondents made. For the projections that we make in this section, both to be conservative and also to be more accurate in our projections, we have "filled in the blanks" in the following cases.

First, there are two cases where the respondents answered the question about the number of products expected to be available for 2020-2024, but then did not complete the question about the distribution of software products across the software release categories. For our projection model for revenues, we do not need all of the information about the categories, but simply need to know about whether there will be IP protection. For these two cases, it was possible to use the two respondents' answers to the two multipart questions about intellectual property and about release categories during 2015- 
2019, as well as the collection of their other responses, to ascertain the appropriate setting for the variable IPprotected during the period 2020-2024.

Second, for one case, a respondent provided the forecast of the number of products expected to be available over 2020-2024 assuming the elimination of the copyright prohibition, but then left blank the forecast of the number of products that would be licensed. In the context of all of the respondent's answers, it appeared that there would be licensed products, but the number was not forecast. For this one respondent, for the observation to use in our projection, we filled in the missing expected number of licensed products with the respondent's reported number of products available for licensing multiplied by the proportion - on average in the sample of reported 2020-2024 forecasts — of licensed products to available products.

Third, for two cases where the respondents had reported zero products available and also zero products licensed and also, consistently, no intellectual property for 2015-2019, the respondents completed the 2020-2024 forecast for product release types with all zeros, again indicating no intellectual property. However, they left blank the forecasts for products available and products licensed. The zeros for the release categories and the full context of all of their responses for 2020-2024 make it clear that for these two respondents again there would be no products available for licensing and no products licensed. These are cases where the respondents do a lot of software work for their organizations' internal use, but they have not, and do not anticipate, products to license. As explained above, the conservative and also more accurate approach is to fill in the missing data for the 2020-2024 forecast and enter 0 for products available and for products licensed for these two observations.

With the set of forecasts in hand, we turn now to the predictions. We provide predictions for the GOCO respondents, and for the GOGO respondents. The predictions can then be compared with the actual licensing revenues during 2015-2019.

First, we use the simple estimated model — specification (2) of Table C.1 - of revenues for GOCO respondents; the model is estimated for the actual 2015-2019 experience, with revenue in 2019 dollars as a function of the number of software products licensed and the dummy variable to indicate IP protection. Then we use the estimated model to predict the average annual licensing revenues for the next five years, 2020-2024, assuming that the copyright prohibition for GOGO software is eliminated. With the discussion, in Section 2.4.1 and Appendix C, of the revenue models estimated in Tables C.1, C2, and $\mathrm{C} 3$ of Appendix $\mathrm{C}$, we concluded that if copyright protection is allowed, the potential revenues for the GOGO operations can be predicted with the estimated GOCO model since the difference in the functions estimated for the 2015-2019 period is because of the availability of copyright protection for the GOCOs and the lack of it for the GOGOs, and because of good fortune in the distribution of types of IP protection in the two samples.

To make the predictions for the GOCO respondents, we use the estimated model with the projected values for the explanatory variables provided by the GOCO respondents. To make the predictions for the GOGO respondents, we use the estimated model with the 
explanatory variables' projected values provided by those respondents. There are two reasons that the average projected annual revenues for 2020-2024 shown in Table 26 are lower for the GOGO respondents than for the GOCO respondents. First, we know that some GOGO respondents will choose not to make products available for licensing, and that will result in lower projected 2020-2024 annual revenues on average for the GOGO respondents. Some GOGO respondents not offering products for licensing will plan to offer products for download without a license and without any charge for their use. The second reason that the average of the projected 2020-2024 annual revenues for the GOGO respondents is less than for the GOCO respondents is that, although on average the numbers of licensed products for GOGO respondents are expected to increase dramatically, the mean annual average number of products licensed for the GOGO respondents is, despite the large percentage increase, still considerably less than the number for the GOCO respondents.

For both samples, in addition to the predicted value for annual licensing revenue for each respondent, we calculated the standard error of the forecast for each respondent. We then multiplied the predicted value for annual revenue in 2020-2024 (as predicted based on the 2015-2019 experience for the relationship between revenue and the number of products) for each respondent by the sum of 1 and the respondent's projected growth rate (as a proportion) in the revenue per software product for 2020-2024 as compared with 20152019. The standard error of the forecast for each respondent is also multiplied by the sum of 1 and the projected growth rate. ${ }^{59}$ For the GOCO and the GOGO samples, we then compute the average of the respondents' predicted annual licensing revenues and also the standard error of the forecast for that average.

It is important to emphasize that the predicted licensing revenues are at best rough projections of what might happen in the counterfactual situation where copyrighting Government Works software is allowed. In projecting the revenues for the counterfactual situation, we are careful to include GOGO respondents who do not anticipate copyrighting and licensing products even if allowed to do so. Hence, for such respondents, the predictions provide good estimates of actual revenues in the counterfactual situation, but underestimate potential revenues should the GOGO respondents take advantage of copyright to realize revenues to the extent that GOCO respondents do. Potential revenues for such respondents are underestimated because they choose not to copyright and offer licensed products and collect revenues, and the projections reflect that. On the other hand, the projection of the revenues is indeed a projection of potential revenues rather than actual revenues for those GOGO respondents who report that they will copyright and license software projects. For such respondents

\footnotetext{
${ }^{59}$ The forecast using the model estimated for 2015-2019 is a random variable; denote it as $x$. Its standard error is the estimate of that random variable's standard deviation, and that standard deviation is the square root of the variance of the random variable. The forecast for the 2020-2024 period is ax, where $\mathrm{a}=1+$ the projected growth rate. With $\mathrm{E}$ denoting the mathematical expectation operator, the variance of $\mathrm{a} x$ is: $\mathrm{E}(\mathrm{a} x-\mathrm{E}(\mathrm{a} x))^{2}=\mathrm{E}(\mathrm{a}(x-\mathrm{E}(x)))^{2}=\mathrm{E}\left(\mathrm{a}^{2}(x-\mathrm{E}(x))^{2}\right)=\mathrm{a}^{2} \mathrm{E}(x-\mathrm{E}(x))^{2}=\mathrm{a}^{2} \operatorname{Var}(x)$.

Thus, the standard deviation of the forecast for 2020-2024 is the square root of $\mathrm{a}^{2} \operatorname{Var}(x)$, alternatively denoted $\mathrm{a}^{2} \sigma^{2}$, and so the standard deviation is a $\sigma$. Thus, the standard error for the forecast for the 20202024 period, which is the estimate of the standard deviation for the forecast for the 2020-2024 period, is the product of the standard error of $x$ multiplied by 1 plus the projected growth rate.
} 
the projection is of their potential revenues because the forecasting equation assumes that they will take advantage of the revenue-generating opportunities to the same extent as the GOCO respondents do. In fact, many may choose not to take similar advantage to generate licensing revenue from an ability to copyright the software. In that sense, the forecasted revenues will be potential revenues, and the actual revenues received are expected to be even less than what is forecast. So, to summarize, the projection of the expected licensing revenues of the GOGO respondents in the counterfactual situation where they can copyright their software is a very rough estimate. Nonetheless, it is a rough estimate well worth making and describing in order to develop some initial understanding about what might happen if copyright is allowed for Government Works software. Moreover, the understanding developed makes clear that the forecasted licensing revenues greatly understate the value of the licensed software to those who use it.

\subsubsection{Projected Costs Associated with the Projected Revenues}

In Section 2.5.1, in column (1) of Table 11, we show the results for estimating a very simple cost function for the production of software products available for licensing or download. In Table 11, annual costs in constant 2019 dollars are estimated as a function of the respondent's total software products available and the average lines of code for its typical software product. As shown in Table 11, neither the type of laboratory or facility (GOCO or GOGO) nor the qualitative variable for intellectual property added significantly to the simple model. We use the simple model to predict for 2020-2024 the annual software costs corresponding the predicted annual revenues (shown in Table 26) assuming elimination of the copyright prohibition.

Table 27 shows the projected average annual costs for the software products made available for licensing or download by the government laboratories and facilities. The cost projections in Table 27 correspond to the revenue projections shown in Table 26. The number of software products and the lines of code for the typical product are the explanatory variables, and the expectations for those variables during 2020-2024 are used with the estimated equation shown in column (1) of Table 11 to predict each respondent's average annual costs for software products available for licensing or download. Each respondent provided an estimate of the number of software products it would have available in 2020-2024 if the copyright prohibition is lifted. Also provided is an estimate of the size (in terms of lines of code) of its typical software product for 2015-2019, and also provided is the expected growth from 2015-2019 to 2020-2024 in the size of the typical software product. As with the revenue projections, for a few cases appropriate substitutions for missing data were made in the interest of both being conservative and being accurate as explained in the discussion of the revenue projections. 
Table 27. Average Annual Costs for Software Products Available for Licensing or Download: Actual versus Forecast in 2019 dollars

\begin{tabular}{|l|l|}
\hline Variable & \\
\hline $\begin{array}{l}\text { Average Annual Costs 2015-2019 } \\
\text { (from Table 10) }\end{array}$ & $\$ 1,273,945$ \\
\hline $\begin{array}{l}\text { Average Forecast Annual Cost 2020-2024 } \\
\text { if GOGO copyright prohibition eliminated } \\
\mathrm{n}=23\end{array}$ & $\begin{array}{l}\$ 18,800,000 \\
(\$ 14,029,264 \text { to } \\
\$ 23,570,736)\end{array}$ \\
\hline $\begin{array}{l}\text { Overestimate of average forecast annual costs 2020-2024 incurred } \\
\text { because software products are made available to others } \\
\mathrm{n}=23\end{array}$ & $\$ 1,310,360$ \\
\hline
\end{tabular}

Note: In parentheses with the forecast is the $95 \%$ confidence interval that uses the standard error of the forecast for the mean of the forecasts. That larger standard error rather than the standard error of the prediction (i.e. fitted value) is the appropriate one in the present context. The smaller standard error of the prediction would show a tighter distribution of the random variable (the prediction for the dependent variable) that would result if within-sample observations of the explanatory variables were used, while the larger standard error of the forecast is appropriate since we are using the out-of-sample 2020-2024 projections for the explanatory variables. The standard error of the mean of the forecasts is the square root of the product of (1) the reciprocal of the square of the number of respondents and (2) the sum, over the respondents in the sample, of the squared standard errors of the forecast for each respondent. The $95 \%$ confidence interval ranges from two standard errors below the mean to two standard errors above the mean. Source: Authors' computations from "Software Copyright Impact Survey," OMB Control No. 0693-0033, Expiration Date: 07/31/2022

The forecast for the cost of the software products that are made available increases because many more products will be made available. However, just a small portion of the annual estimated cost of $\$ 18,800,000$ would be because of the expected increase in the amount of software made available to others. Most of the costs for the software would be incurred whether or not it is made available for licensing. The software is developed for internal use by the agencies, and if copyrighting the software is allowed, more of it will be made available. But, the additional costs of making the software available would be the costs of obtaining the copyrights and managing the licensing process.

The part of the projected costs that would be because of making software available in the new IP regime with copyrights allowed for the GOGO software is conservatively overestimated to be $\$ 1,310,360$. That amount is $6.97 \%$ of the projected costs, and is based on the fact that for the subset of the respondents that did have IP costs for their software products available during 2015 through 2019, the proportion of their annual software cost for the products available that was due to obtaining and maintaining IP and managing licensing of software was $6.97 \%$ of the software costs. That is a conservative overestimate of the costs associated with copyrighting software, because the $6.97 \%$ also includes the IP-related costs incurred because of software patents. Moreover, some of the IP-related costs would be incurred for the software portfolio even if software products were not made available for licensing but instead used solely in support of the agencies' missions. Most of the software costs are associated with the production and maintenance 
of the software, and those costs are incurred whether or not the software is copyrighted and licensed. ${ }^{60}$

\subsubsection{Comparison of Projected Costs and Projected Revenues.}

Producing software products is expensive, but to understand the costs of making software available for licensing or for download without a license one cannot simply compare the revenue projections in Table 26 with the full costs shown in Table 27 for the software. That is not the appropriate comparison because the costs of producing the products are primarily the production and maintenance costs for the software, and those costs are incurred primarily to have the products to use in accomplishing the agencies' missions, not to have the products available for licensing. Annual costs for the products are justified by the need for the products to accomplish the agencies' missions, and of course those costs will be considerably more than any annual licensing revenues from making the software that is produced for the agencies' internal needs also available to others who might find it useful.

Moreover, if one wanted to compare revenues with production costs, the reported costs for software development should be capitalized over the useful lifetime of the software. The useful commercial lifetime for the software developed in the labs of the Federal agencies can reasonably be estimated to be 10 years. ${ }^{61}$ For purposes of comparison with the annual revenues, the software development costs, the first of our six cost items that are summed to have the annual software costs, would then be capitalized over a 10-year lifetime of the software. The average annual software costs during the period 2015-2019, i.e., the average for the 16 respondents for cost_19, equals $\$ 1,273,945$, and the proportion

${ }^{60}$ Recall cost_19 was computed based on the number of software products available for licensing or download without a license and equals the sum of each respondent's 2015-2019 annual averages for the cost of (1) software development, (2) supporting software to maintain developed software, (3) administrative support for managing developed software, (4) licensing administration, (5) annuity fees for software patents, and (6) external legal support expenses for IP protection and licensing for the software portfolio. The IP costs are the sum of items (4), (5), and (6). Conservatively, for the proportion of the projected costs using the model of cost_19 (but evaluated at the new values for the explanatory variables that the respondents forecast for 2020-2014 given that copyright of GOGO software is allowed) that is due to the IP costs, we use the proportion of IP costs in total software costs during the 2015-2019 period for those respondents that reported IP costs. The reported IP costs are observed for respondents with different sizes for their IP-protected software portfolios, and the sum of their IP costs divided by the sum of their software costs provides the benchmark for the proportion of software costs taken by IP costs. Thus, $6.97 \%$ is the cost-weighted average of the IP cost as a proportion of total software costs for the respondents that had IP costs. That follows because $\sum_{i}\left(s_{i} / t_{i}\right)\left(t_{i} / \sum_{i} t_{i}\right)=\sum_{i} s_{i} / \sum_{i} t_{i}$, where $s_{i}$ is the $i^{\text {th }}$ respondent's sum of the IP costs — cost items (4), (5), and (6) - and $t_{i}$ is the ith respondent's sum of all costs - cost items (1) through (6).

61 "Studies have shown the average software program lifespan over the last 20 years to be around 6-8 years. Longevity increases somewhat for larger programs, so that for extremely large complex programs (i.e., over a million Lines of Code - LOC) the average climbs as high as 12-14 years. This increased longevity for large programs is related directly to the huge cost and inconvenience to an organization of replacing them. Nonetheless, 12-14 years is not very long when one considers the risk and the investment of time and money required to develop and maintain a 1M+ LOC program. Over the lifetime, such programs can easily cost $\$ 10$ 's or $\$ 100$ 's of millions." Mitopia Technologies, Inc., https://mitosystems.com/software-evolution/, accessed August 29, 2020. 
of the annual software costs that is due to the software development costs is 0.8812 or $88.12 \%$. Thus, the amount of the software development costs is $\$ 1,122,563$.

Capitalizing (at the OMB mandated 7\% annual rate of return for Federal investment projects) the development costs over a 10-year useful life for the software yields the annual production costs of $\$ 159,853 .{ }^{62}$ Thus, for comparison with the annual licensing revenues, we have annual costs of $\$ 159,853+(\$ 1,273,945-\$ 1,122,563)=\$ 311,235$. However, the annual production costs and also the annual software maintenance costs (so our cost items (1), (2), and (3)) would be incurred whether or not the software is made available for licensing, because it is developed for an agency's internal use. The portion of the annual 2015-2019 software costs that is incurred because the software has IP protection and is made available to others is a subset of $\$ 88,794=0.0697 \times \$ 1,273,945$. Similarly, for a comparison to the projected 2020-2024 licensing revenues, the relevant 2020-2024 annual costs are not the $\$ 18,800,000$ in annual costs as computed with the sum of all the cost items, and moreover they are not the costs using the capitalized annual production costs, but instead they are just a subset of the annual costs of obtaining and managing the intellectual property, i.e., the sum of cost items (4), (5), and (6), and that sum is $1,310,360$.

Thus, a simple comparison of the annual licensing revenues with the reported annual the software costs is misleading for three reasons. First, the licensing revenues will understate the commercial value to the users of the software that the agencies make available for licensing or download. As we have seen, much of the software is made available without charge, and many respondents' say that freely available software will continue to be the rule even if copyright is allowed. The copyright protection would, as respondents have reported, allow more software to be used and to be used more effectively, but much software will still be available without charge. Second, the software development costs should be capitalized over the useful lifetime of the software. Third, the software is certainly costly to produce, but it is produced for the agencies' internal use in accomplishing their primary missions. That value from the software is not reflected in the licensing revenues at all. The software produced is used by the agencies to accomplish their primary missions, and the costs are incurred to support that use. Then, essentially the same software can be made available for others to use, and the additional costs of making it available would be relatively small and not the full costs the agencies incur in producing the software for internal use. As reported just above, the additional costs of making the software available are conservatively estimated to be less than $6.97 \%$ of the full costs for the software.

Thus, for the sample of 23 respondents, from Table 26, the projected average annual licensing revenue is $\$ 201,677$ for the 5 GOCO respondents, and it is $\$ 135,333$ for the 18 GOGO respondents. The projected average annual cost $(n=23)$ that is incurred because of making licensing their software products available - that is, the cost that would not be

$62 \$ 1,122,563=\$ 159,853 \times\left(1 /(1.07)^{1}+1 /(1.07)^{2}+1 /(1.07)^{3}+1 /(1.07)^{4}+1 /(1.07)^{5}+1 /(1.07)^{6}+1 /(1.07)^{7}\right.$ $\left.+1 /(1.07)^{8}+1 /(1.07)^{9}+1 /(1.07)^{10}\right)$. For the $7 \%$ discount rate, see U.S. Office of Management and Budget (OMB), Circular number A-94, Guidelines and Discount Rates for Benefit-cost Analysis of Federal Programs (Washington D.C.: Government Printing Office, 1992). 
incurred if the costs of managing licensing were avoided - is an amount less than $\$ 1,310,360$.

Comparing the simple model for costs in Table 11 and the simple model for revenues in specification (2) of Table C. 1 of Appendix C, based on the average experience of GOCO respondents for 2015-2019, we estimate just below that the average revenue of a copyrighted software product is $\$ 5,908$ while the average cost of that product is $\$ 297,487$ (and capitalizing the development costs over the product's useful commercial lifetime reduces that amount considerably as we have illustrated). However, just $6.97 \%$ of those costs, or $\$ 20,735$, is the rough overestimate of the part of the costs that would not have been incurred if the product was not copyrighted and licensed. The gap between a product's average cost and its licensing revenue is not surprising at all, given that the software is produced for use by the laboratory or laboratory facility and then made available, often free of any charge, for others who find it useful for their own work. The software is not developed solely or even at all for its ability to generate licensing revenues. Recall the comments from respondents that were discussed with the forecast growth rates shown in Table 25-in particular, "Don't intend to charge for software as this is counterproductive to getting people to use it." Nonetheless, the value of distributing such software, making it available for licensing or download without a license, is potentially quite large, outweighing the costs of producing it, because of the economy-wide impact that distributing the software has, and we return to an estimation of that impact in Section 2.8. Here we shall explain the estimated gap between licensing revenues and the costs for producing the software products.

To understand the estimated gap, begin with specification (2) of Table C.1 in Appendix $\mathrm{C}$, where using the estimated coefficients, annual licensing revenue is estimated to be $\$ 164$, plus $\$ 2,565$ multiplied by the number of licensed products, plus $\$ 70,042$ if the respondent has IP protection for its software. From Table 2, during 2015-2019, average annual number of licensed products is 21 for the respondents who are able to copyright their software, i.e., the GOCO respondents. Also, from Table 2, 57\% of the GOCO respondents had IP protection for their software. Using the estimated licensing revenue model, the expected value of the annual revenue from a copyrighted software product (the average revenue for copyrighted software products), using the mean number of products for the sample, is estimated to be $\$ 5,908=(164+70042+2565 \times 21) / 21$. The average cost of such a product is much more as we now describe, but over $90 \%$ of the costs for the product are in their entirety incurred not to make it available for licensing, but instead for the agencies' internal uses of the software to support their primary missions. Moreover, much of the remaining costs would be incurred for IP-related costs of the software portfolio even if there were no licensing and the software was used solely in support of the agencies' missions.

From Table 11, the annual cost for software products is estimated to be $\$ 256,976$ multiplied by total products available, plus 18.98 multiplied by the size of the typical software product in terms of lines of code. For the sample of respondents, from Table 10, the average size is 44,822 lines of code. Thus, while the annual revenue from a copyrighted product is estimated to be $\$ 5,908$, the annual average cost for the product is 
estimated to be $\$ 297,487=((256976 \times 21)+(18.98 \times 44822)) / 21$. With the costs of skilled software engineers who develop the product, the maintenance and support costs for the software, and the costs of the obtaining and maintaining IP protection, the estimated cost should not be surprising. Moreover, $93 \%$ of the cost is in its entirety incurred not to provide IP protection for the product and make it available for licensing, but to have the product to support the agencies' primary missions. The part of the average cost incurred to make an IP-protected product available for licensing is estimated to be less than $\$ 20,735 .^{63}$ Because that figure includes the costs of patenting software as well as the costs of copyrights, and because some IP-related costs for the software portfolio would be incurred to support the agencies' missions even if there were no licensed software, it is a conservative overestimate of the expected impact on the average cost of a copyrighted software product that is made available to others. Thus, the estimate of about $\$ 21,000$ is an overestimate of the part of the costs for the software product that would not have been incurred if the product was not copyrighted and made available, and there is not enough information to make a more refined estimate. ${ }^{64,65}$

The foregoing estimates - for the expected annual revenues of $\$ 5,908$ for a licensed software product and for expected annual copyright-and-licensing costs of less than $\$ 20,735$ - are derived from our forecasting models of licensing revenues and costs. The estimates provide a reliable summary of the information about revenues and costs because they are based in the respondents' observed 2015-2019 experience, and because they are evaluated at the means for the explanatory variables. In contrast, the comparison of Table 26 and Table 27 is for the counterfactual scenario, with the estimates derived by using the estimated equations for revenues (specification (2) of Table C.1 in Appendix C) and costs (Table 11) that were based on the 2015-2019 experience, but evaluated using the respondents' projections for numbers of products and their typical size during 20202024 assuming copyright is allowed. It is very important to note that those projections for the annual numbers of products are in some cases two orders of magnitude higher (for example, 500 rather than 5) than what actually occurred during 2015-2019. The result is

\footnotetext{
${ }^{63}$ To have a good estimate of the revenue per product, we evaluate the simple revenue function at the mean number of licensed products in the sample used to estimate the function. We have used that same number of products in the cost function in order to have an estimate of the corresponding cost per product.

However, observe that if we instead estimated the cost per product at the mean (or equivalently the median as seen in Table 10) for the number of products in the sample used to estimate the cost function, and (for consistency since the mean and the median are the same, but the lines-of-code variable is highly skewed) use the median of the lines of code, the cost per product is essentially the same. Namely, $\$ 290,903=$ $((256976 \times 2)+(18.98 \times 3575)) / 2$. Then the overestimate of the part of the costs that is due to making copyrighted products available to others would be $6.97 \%$ of $\$ 290,903$, or $\$ 20,276$, as compared with $\$ 20,735$.

${ }^{64}$ Asking directly for such detail in the information gathered in the survey would of course not have worked. The level of detail as it is created challenges for the respondents. However, knowing that, the survey and the research design were planned to allow separating the costs that could be avoided if software products were not copyrighted and licensed. The original plan was to estimate a detailed cost function that broke out the marginal impacts on costs of copyrighted versus patented software conditional on whether the software was licensed or not. That plan could not be executed given the limited number of GOCO laboratories and facilities responding to the survey with complete responses.

${ }^{65}$ For strategic reasons, the agencies might want to copyright software even if they did not plan to license it. For example, with the copyright, the agency would avoid the risk that a vendor would want to charge the agency for essentially the same software that the agency's labs or facilities had created.
} 
that our estimated equations based on the 2015-2019 experience may not be good predictors of what will happen to revenues and costs in the counterfactual circumstances for 2020-2024. There is good reason to think that both the projection of revenues and the projection of costs are too conservative-i.e., the projected revenues are too low and the projected costs are too high.

The revenue projections are conservative because the effect of IP protection had to be estimated as a shift in the function. The alternative to estimating the shift in the revenue function if the respondent has IP protection for its software is to estimate different slope effects for software with IP protection as well as the shift effect. There is not enough data to estimate that model - or, stated differently, if one tries to estimate it with the limited amount of data available, one gets the same result as what we find in the model of specification (2) of Table C. 1 in Appendix C, both in the size and significance of the two explanatory variables for the number of products and the IP protection shift effect, and then additionally the slope effect of IP is wholly insignificant both in absolute size and in statistical significance. ${ }^{66}$ Thus, with the revenue model estimated (and even the one with the insignificant IP slope effect estimated), if the number of products jumps dramatically, as is the case for the forecast if copyrights are allowed for the GOGO respondents, then the estimated effect for the IP protection that was made with the experience during 20152019 is diluted - as the number of products increases, the estimated $\$ 70,000$ effect of IP protection is divided over far more products. As just discussed, in the estimating sample, the sample average number of products is 21 , but the sample average number in the counterfactual forecasts is much greater (67 for GOCO respondents and 34 for GOGO respondents, with several respondents anticipating numbers of licensed products much higher than those averages) as shown in Table 19. However, the limitation in the functional form because the data were insufficient to estimate a slope effect as well as a shift effect for IP will not be an important limitation for most of the GOGO respondents. For all but a few GOGO respondents, the functional-form limitation is not an important one because even in the counterfactual situation the numbers of licensed products that they forecast are less than the mean number of licensed products for the GOCO respondents in the sample used to estimate the forecasting equation.

Turning to the cost forecasts, the costs that are forecasted using the model estimated with the experience in 2015-2019 may be too high because, with the dramatic anticipated jump in licensed products for 2020-2024, there may be pronounced economies of scale that would not appear in the cost equation estimated for the experience in 2015-2019. Moreover, the forecasted costs are for products that will primarily be used to support the agencies' primary missions, and so they are not intended to be weighed against the licensing revenues generated when the products are made available for use by others.

\footnotetext{
${ }^{66}$ For additional discussion of difficulties posed by limited information, see Section 1.4 about the constraints on gathering detailed information in general, Section 2.4.1 about the restrictions imposed on the revenue function because of the distribution of IP within the GOCO and the GOGO samples, and Section 2.5.1 about the restrictions imposed on the cost function because of the limited number of GOCO respondents who provided complete data.
} 
In sum, because of the expected dramatic increase in the numbers of products to be made available, the projected revenues may be too low and the projected costs may be too high. After projecting the software effects from our sample to the entire group of Federal agencies, we return to the potential economy-wide benefits-benefits that far exceed those captured by licensing revenues - that would be generated by the greater availability of the software if the copyright prohibition is eliminated.

\subsubsection{Projection of Effects on the Software Activity of All Federal Agencies}

Recall that we estimated expected annual revenue from a copyrighted software product, using the mean number of products for the sample of respondents, to be $\$ 5,908$, and the expected part of average cost that is incurred to copyright the product and make it available for licensing is, as explained above, overestimated to be something less than $\$ 20,735$, again at the average values of the explanatory variables for the sample of respondents. However, for our projections of revenues and costs, we begin with the predicted revenues and predicted costs for the individual respondents. That is because the values of the explanatory values for the respondents are not at the means - some respondents will have more products available, others less, and some will have larger products as measured by lines of code, while others have smaller products. Thus, the values for revenues and costs that are projected to the Federal agency level will depend on the actual distribution across respondents of their forecasts for the number of products, growth rates in revenue for the typical product, size of the products, and growth rates in the size of the products, as well as on the proportions of their parent agencies taken by the respondents.

Table 26 shows the average annual software licensing revenues that are forecasted for 2020-2024 for 23 respondents to the Software Copyright Impact Survey. From the averages reported in Table 26, the sum of the forecasted annual licensing revenues for the 23 respondents is $\$ 3,444,379 .{ }^{67}$

Because we have cast a wide net, looking into the agencies to find places where the agencies may be creating software products that could be made available to others, we use information about the IT employment for the laboratories or facilities of the respondents and about the IT employment of their parent agencies to extrapolate from the respondents' activities to the activities of the agencies. To extrapolate the forecasts to the parent agencies of the 23 respondents, we use the detailed employment information that is provided by the U.S. Office of Personnel Management (OPM) in its FedScope data. ${ }^{68}$ The data provide the employment of various types for each Federal agency and its component organizations. To get what will be a very rough estimate of the portion of its parent agency's software work that is taken by the laboratory or laboratory facility (or laboratories or laboratory facilities) for which a respondent reports, we use FedScope's reported number of IT management employees for each agency as whole and for the organizations within it.

${ }^{67} \$ 3,444,379=\$ 201,677 \times 5+\$ 135,333 \times 18$.

${ }^{68} \mathrm{https}$ ://www.fedscope.opm.gov 
From the FedScope menu, we selected "STEM and Health Occupations," then "STEM Occupations," then "Technology Occupations," and then "Information Technology Management." 69 So for example, if a respondent from NASA reports for the Ames Research Center, from FedScope we have that the number of "IT management" employees for NASA is 476, and that the number is 41 for the Ames Research Center. Thus, the rough estimate of the proportion of NASA's software activity that is done by the Ames Research Center would be 0.086 or $8.6 \%$. For another example, if a DoD respondent reported on the software activity for Defense Microelectronics Activity, in FedScope we find Defense Microelectronics Activity as a part of the Department of Defense activity not separately provided under Department of the Air Force, Department of the Army, and the Department of the Navy. The "IT management" employment for the most current quarter is 7411 for the Department of Defense not including the Air Force, the Army, or the Navy. The "IT management" employment for Defense Microelectronics Activity is 23. So, the estimate of the proportion of the total DoD IT activity (apart from the activity in the Air Force, Army, and Navy) is $23 / 7411=0.0031$ or $.31 \%$.

In most cases, we have multiple respondents within a single agency. For example, among the 23 respondents used for Table 26, there are multiple respondents from two of the armed forces departments that are listed separately in OPM's FedScope data. Also, there are multiple respondents from DOC, DOE, DOT, and HHS. In these cases of multiple respondents for an agency, for many cases each respondent represented a different organizational part of the parent agency. In these cases, where we have multiple respondents from a parent agency, for a set of multiple respondents with the same parent agency, we add their shares of the parent's IT employment to have an estimate of their collective share of the parent agency's software activity. For such a set of multiple respondents, we also sum their forecasted licensing revenues to have the forecasted revenues for the set. Then to estimate the parent agency's forecasted licensing revenues, we divide the sum of the forecasted licensing revenues for the respondents that belong to the parent by the sum of their shares of the parent's IT employment.

When the FedScope data do not break down an agency's component organizations in sufficient detail to find the IT employees for a respondent's organization, we use the information for the subset of the agency containing the respondent's organization. For example, the total IT employment as reported by FedScope for HHS as a whole is 3249. For NIH within HHS, the reported IT employment is 718, and for FDA within HHS the reported IT employment 470. A single respondent from a part of NIH, absent additional information would conservatively be assigned the overestimated proportion 0.221 , but multiple respondents reporting on different parts of NIH within HHS would together, as the sum of their shares of HHS software activity, be assigned the proportion 0.221 or

\footnotetext{
${ }^{69} \mathrm{https} / / / \mathrm{www}$. fedscope.opm.gov/ibmcognos/bi/v1/disp?b_action=powerPlayService\&m_encoding=UTF8\&BZ=1AAABpu3eKwh42o1OwW6CQBD9mR3Ug2Z2EAsHDiwLkYOgwqWnhuJqmsJiFjz4983Cwfb W9zKZycx7L_OUxaasinOSyXAYe6MyuQSiL19yLgN3J4X thXoCY8LN8DAE37i7tItEK0c602ic7w Rt U_BEqbXo9Kj0DptW8vyoAnYIu67hS4cnGsm_ 6poaPpLu3 bNTelyAJ4HS_3z5K3_pgLAySl_AcPmuar Me_7XtK2t3ZBlv4iLPk7jKijyPDkn4D6sjTuEVkXFE5BwZY8g8ZITMkrHopnTzBEIga47aFjA49INNjB GzNmnR21GZQADBuQDuQikONAnUDAv_GvBJgC5Vv4LfOI0zQ9NNb8x4wcrtG_w
} 
22.1\%. A respondent reporting on FDA's software activity would be assigned the proportion of 0.145 or $14.5 \%$. The result is a very conservative extrapolation. The predicted amount of licensing revenues for the parent agency will often be too small because the proportion used to extrapolate the respondents' forecasted revenues is too large.

In some cases, Internet search uncovered information that allowed refining the estimated proportion used to extrapolate a respondent's forecast. So for example, a respondent was a part of the Air Force's Material Command. The Air Force's total IT management employment reported in FedScope is 8453, and its Material Command has IT management employment reported as 1847 by FedScope. Internet information about the respondent showed that it was one of six specialized centers assigned to the Material Command, and for a rough approximation its IT employment is estimated as a sixth of the IT employment for the Material Command. In the case of another respondent that was just a part of one of the parent agency's organizations identified in FedScope, Internet search revealed the particular software group exactly as named by the respondent, and the information for its IT employment was thereby found and could be used instead of the IT employment of the organization, identified in FedScope, of which it was a part.

Given the 23 respondents for which forecasts could be estimated, the foregoing extrapolation process provided very rough forecasts for the annual 2020-2024 licensing revenues for HHS, DOT, VA, NASA, DOC, DOE, DoD apart from the branches of the armed forces separately reported by FedScope, Department of the Air Force, Department of the Navy, and GSA. The sum of these agency-wide forecasts totals $\$ 44,238,828$, extrapolated from the forecasts for the 23 individual respondents for which the sum of the forecast annual licensing revenues was $\$ 3,444,379$ as reported in Table 26 .

From FedScope, the IT employment in the agencies represented by the 23 respondents takes $51.4 \%$ of the total IT employment for all Federal agencies. ${ }^{70}$ Thus, if the software copyright prohibition is eliminated, the forecast of the annual 2020-2024 licensing revenues for all Federal agencies is $\$ 86,067,759=\$ 44,238,828 / 0.514$. Table 28 shows the overall forecast for annual licensing revenues for the 23 respondents in Table 26, for their parent agencies, and finally for all Federal agencies.

\footnotetext{
${ }^{70}$ From FedScope, the sum of the IT employment for the agencies represented by the 23 respondents is 43,776. The sum of IT employment for all Federal agencies (summing over the FedScope reports for the cabinet level agencies, the large independent agencies, the medium independent agencies, and the small independent agencies) is 85,167 . So, the Federal agencies in our sample of respondents take the proportion $0.514=43776 / 85167$ of the IT employment at all Federal agencies.
} 
Table 28. Forecast Annual Licensing Revenues in 2019 dollars for Software Products Available for Licensing or Download in 2020-2024 if the Copyright Prohibition is Eliminated

\begin{tabular}{|l|l|}
\hline Group for the Forecast & $\begin{array}{l}\text { Forecast of Annual } \\
\text { Licensing Revenues }\end{array}$ \\
\hline $\begin{array}{l}\text { For 23 Respondents } \\
\text { (from Table 26) }\end{array}$ & $\$ 3,444,379$ \\
\hline $\begin{array}{l}\text { For the Parent Agencies } \\
\text { of the 23 Respondents }\end{array}$ & $\$ 44,238,828$ \\
\hline For All Federal Agencies & $\$ 86,067,759$ \\
\hline
\end{tabular}

Source: Authors' computations from "Software Copyright Impact Survey," OMB Control No. 0693-0033, Expiration Date: 07/31/2022

Summarizing, across all Federal agencies, if copyrights are allowed for GOGO software, the software made available over the next five years is expected to generate $\$ 86$ million in annual licensing revenues, a pronounced increase over the annual licensing revenues generated over the preceding five years. The pronounced increase that is projected is largely driven by the expected increase in the GOGO licensing revenues. From Table 26, the average annual software licensing revenues for the GOGO respondents are expected to increase by 51 times or $5100 \%$, while the average for the GOCO respondents is expected to increase by 2.43 times or $243 \% .{ }^{71}$ Moreover, because (1) the software is developed for the agencies' internal use in support of their missions, and (2) the costs are largely incurred in the production and maintenance of the software, the costs of the software would largely be incurred whether or not the software is made available for others to use. As discussed earlier, the additional costs of obtaining and maintaining copyrights is expected, (conservatively overestimated because all IP-related costs are included, and because IP-costs for the software portfolio will be incurred even if the software is used exclusively to support agencies' missions and there is no licensed software) to be less than about $6.97 \%$ of the total costs of the software. Most importantly from an evaluation perspective, the $\$ 86$ million from making the software available for others to use is only a small part of the economy-wide value that is created for users outside the agencies. The next subsection provides an estimate of that economy-wide value. Before turning to the estimate of economy-wide economic impact of the software, we provide the overestimate of the agencies' costs for making the software available. From our earlier estimates, we know that the overestimate, or upper bound for the additional costs will exceed the $\$ 86$ million in revenue.

Turning to the costs of making available the large number of software products expected to be made available if copyright protection is allowed, we estimated in Table 27 that on average for the 23 respondents for which the projection was made, an overestimate of those annual costs (incurred because of making the software available to others) would be $\$ 1,310,360$ over the years 2020-2024. Using the same procedure that we used to extrapolate the expected licensing revenues for those 23 respondents, we estimate the

\footnotetext{
${ }^{71}$ The $95 \%$ confidence intervals, shown in Table 26, for the projected average revenues cover a relatively small range even using the conservative standard errors of the forecast.
} 
sum of the annual costs (that is an overestimate of the costs for making the products available) for their 10 parent agencies (HHS, DOT, VA, NASA, DOC, DOE, DoD apart from the branches of the armed forces separately reported by FedScope, Department of the Air Force, Department of the Navy, and GSA) would be $\$ 151.8$ million. Remember that this figure is the cost, projected from the responding sample to their parent agencies, of obtaining IP protection and making available for licensing almost 60 times as many software products for the GOGO respondents and about three times as many for the GOCO respondents. Recall that from FedScope, the IT employment in the agencies represented by the 23 respondents takes $51.4 \%$ of the total IT employment for all Federal agencies. Thus, if the software copyright prohibition is eliminated, the upper bound forecast of the annual 2020-2024 additional costs incurred for making the products available is for all Federal agencies $\$ 295.3$ million $=\$ 151.8$ million/0.514. Although a substantial sum, and one that exceeds the $\$ 86$ million in additional revenues expected to be generated, as we have emphasized, the expected revenues will not even come close to the benefits to the users of the software, and much of the IP-related costs would be incurred even if there were no licensed software products and the software is used solely in support of agencies' missions.

Summarizing the information that compares licensing revenues with the costs for IP protection and licensing, we have the following. For an individual software product, evaluating the licensing revenue model and the cost model at the average number of software products for the GOCO respondents over the period 2015 through 2019 for which the models were estimated, we found that the average revenue for the typical software product was about $\$ 6000$, while the part of its average cost that was due to obtaining and maintaining IP and licensing the product was about $\$ 21,000$. As explained, that cost estimate is an overestimate of the contribution of IP and licensing (to the typical product's average cost) that would be due to making copyrighted software products available to others. So, an overestimate of the ratio of the cost per product to the revenue per product is $3.5(\$ 21,000 / \$ 6,000)$. After extrapolating from the costs and revenues for the respondents to the costs and revenues for all Federal agencies, the projected 20202024 overestimated ratio of IP and licensing costs to revenue is 3.4 (295.3 million in IP and licensing costs divided by $\$ 86.1$ million). However, as we have discussed, the projection of licensing revenues is just a rough estimate, and, more importantly, even if it were a perfect estimate, it would far underestimate the value of the software to the economy.

The $\$ 86.1$ million projection of the annual licensing revenues is just a rough estimate of what the actual revenues from Federal agencies' software might be in the counterfactual situation where copyright for Government Works software is allowed. As an estimate of potential revenues should the GOGO respondents take advantage of copyright to realize revenues to the extent that GOCO respondents do, the projection is an underestimate because, in projecting the revenues for the counterfactual situation, we are careful to include respondents who do not anticipate copyrighting and licensing products even if allowed to do so. Such respondents choose not to copyright and offer licensed products and collect revenues, and the projections reflect their actual expected revenues of zero. On the other hand, the projection of the revenues is indeed a projection of potential 
revenues rather than actual revenues for the respondents who report that they will copyright and license software projects. For such respondents it is a projection of the potential revenues because the forecasting equation assumes that they will take advantage of the revenue-generating opportunities to the same extent as the GOCO respondents do. In fact, many may choose not to take similar advantage to generate licensing revenue from an ability to copyright the software. In that sense, the forecasted revenues will be potential revenues, and the actual revenues received are expected to be even less than what is forecast. In all, it is important to emphasize that the projection of $\$ 86.1$ million in licensing revenues is surely a very rough estimate. The rough estimate is worth making and describing in order to develop an initial understanding about what might happen and, even more importantly, to develop understanding that the licensing revenues, whatever they actually would turn out to be, vastly understate the value of the Federal agencies' software to the economy.

We turn now to an estimate of the potential magnitude of that value. In the next section, we estimate that the potential annual economy-wide benefits from the use of the software would, based on the U.S. economy's performance in 2019 , be $\$ 4.3$ billion in additional output for the economy because the use of the agencies' software would increase the productivity of those using the software.

\subsection{Assessment of Potential Economy-Wide Effects of Federal Agencies' Software}

Software enables a large amount economic activity beyond the activity of producing the software itself. What would be the expected impact, on the U.S. economy as a whole, of the software produced in the laboratories and laboratory facilities of the U.S. Federal agencies if the copyright prohibition is eliminated for software produced by the agencies' GOGO laboratories and laboratory facilities? If the copyright prohibition is lifted, we have conservatively estimated that over the next five years the annual licensing revenues generated from the agencies' software that would be made available for licensing or download would be $\$ 86$ million. What would be the economy-wide impact from the dissemination of the software that would generate those revenues? The projected annual licensing revenues greatly understate the value of the software to those using it, in part because much of the agencies' software is made available without any charge. Because much of the Federal agencies' software would be made available without charge, to develop an answer about its likely contribution to economy-wide economic value, we combine information about the economy-wide impact for the software industry with information about the software activities of the Federal agencies.

The software produced by the software industry makes a direct contribution to the nation's output. Additionally, over and above that direct contribution to output, the software contributes to productivity gains throughout the economy. The economy-wide productivity gains from software result because of the software's contribution to capital deepening from the accumulation of information-technology capital and because of software's contribution to multifactor productivity growth. Appendix B reviews the assessment of those productivity effects beyond the direct contribution of the software 
industry to economy-wide output, GDP, i.e., value added. ${ }^{72}$ As detailed in Appendix B, in addition to the direct contribution of the software industry to GDP, it is estimated that software contributes $15 \%$ of the annual growth in the nation's output. We use that benchmark estimate to provide an assessment of the potential economy-wide impact of the Federal agencies' software if copyright is allowed and the anticipated increase in their software that is made available to others occurs.

Application of the Benchmark to the Federal Agencies' Software Operations. The software created by the laboratories and laboratory facilities of the Federal agencies covers a wide range of applications. Hence, the estimated economic impact for the software industry can reasonably be applied to the Federal agencies' software. We use the benchmark estimate for the software produced by the software industry to provide an estimate of the potential economy-wide impact of the agencies' software above and beyond its contribution to the economy's output that is made by the software operations of the agencies as they accomplish their missions. So what we are interested in is the induced impact because the use of the agencies' software increases the productivity of those outside the agency who use software. The argument is that the indirect or induced impact of the agency's software will become important if copyright is allowed and we then have the anticipated 60-fold increase in the amount of GOGO software that is licensed to others.

However, the difficult part of such an application is that the revenues from the agencies' software will, as compared with the situation for the software industry as a whole, vastly understate the amount of the agencies' software that is used downstream. Because of that downstream use, the software increases productivity in the economy beyond the direct effects of the use of the software by the Federal agencies. The reason - that the licensing revenues will understate the use of the software as compared to the relationship between revenues and use for the software industry as a whole - is that, as we have reported, many software managers for the Federal agencies quite deliberately make the software available as a public service without charge and intend to continue doing so even if the copyright prohibition for government-created software is eliminated.

Recall from the discussion of Table 25, the comments of the GOGO respondents who did not anticipate any growth in revenues per software product. Three of the 16 GOGO respondents made it quite clear that they did not intend to charge for the software that

\footnotetext{
${ }^{72}$ The Bureau of Economic Analysis in its glossary of terms with its latest news releases emphasizes that GDP, the economy-wide measure of output, $i$ s value added: "Gross domestic product (GDP) or value added is the value of the goods and services produced by the nation's economy less the value of the goods and services used up in production." Bureau of Economic Analysis, U.S. Department of Commerce, News Release, July 6, 2020, "Gross Domestic Product by Industry, First Quarter 2020," p. 4, https://www.bea.gov/data/gdp/gdp-industry. Value added is the measure of output that is used when describing economy-wide output and the contributions to economy-wide output made by individual industries. "Value added is a measure of output after accounting for the intermediate inputs used in production. As such, it is also a measure of an industry's contribution to GDP." Mary L. Streitwieser, Measuring the Nation's Economy: An Industry Perspective - A Primer on BEA's Industry Accounts, Bureau of Economic Analysis (BEA), www.bea.gov, U.S. Department of Commerce, Revised May 2011, p. 7.
} 
they made available, copyrighted on not. One said, "Open Source, no charge." Another said, "They will always be freely available products." And the third said, "Don't intend to charge for software as this is counterproductive to getting people to use it." Moreover, even respondents that do not say they will not charge for distributed software will typically have a significant proportion of their software, copyrighted or not, available without charge or for a fee far less than it would be possible to obtain if it were marketed by a private sector firm.

Because the forecasted potential licensing revenues of $\$ 86$ million vastly underestimate the value of the Federal agencies' software, to evaluate the economy-wide impact of the agencies' software we need to find a way to assess its value. Our respondents' expectations support the belief that the elimination of copyright prohibition for government produced software would be accompanied by a dramatic increase in the amount of the Federal agencies' software that would be made available for others to use. Recall that, if the software copyright prohibition is lifted, for the upcoming five-year period the GOGO respondents predicted about a 60 -fold increase in the amount of software that would be made available for licensing, and the GOCO respondents also expected about a three-fold increase. Arguably, if the copyright prohibition is eliminated and the dramatic increase in licensed software products does occur for the Federal agencies' laboratories, the economy-wide effects of the agencies' software will, given appropriate adjustment for the scale of the activity, be similar to the effects that have been observed for the software industry as a whole. Under the assumption that the agencies' software, once the protections of copyright law are available, will realize such commercial potential, we use the benchmark estimates developed for the software industry to forecast the potential economy-wide effects of the Federal agencies' software if the copyright prohibition is eliminated.

Appendix B's benchmark estimate is that $15 \%$ of the annual growth in the nation's output is because software increases the productivity of the organizations that use it. For the development of the benchmark estimate, the number of employees in the software industry totaled 2.34 million. ${ }^{73}$ The corresponding total number of IT employees in all Federal agencies as reported by FedScope was $79,850 .{ }^{74}$

\footnotetext{
${ }^{73}$ As explained in Appendix B, the benchmark estimate uses 2012 data, and the employment number is documented in Robert J. Shapiro, "The U.S. Software Industry as an Engine for Economic Growth and Employment," September 2014, Sonecon, https://sonecon.com/docs/studies/Report_for_SIIAImpact_of_Software on the Economy-Robert_Shapiro-Sept2014-Final.pdf, p. 13.

${ }^{74}$ FedScope provides the IT employment for all Federal agencies for 2014, 2015, 2016, 2017, and 2018. The employment increases every year, and the average increase is 886 . The IT employment for all the agencies totaled 81,622 in 2014, and extrapolating back using the average yearly change, the estimated IT employment for 2012 is 79,850 .

https://www.fedscope.opm.gov/ibmcognos/bi/v1/disp?b_action=powerPlayService\&m_encoding=UTF8\&BZ=1AAABpu3eKwh42o1OwW6CQBD9mR3Ug2Z2EAsHDiwLkYOgwqWnhuJqmsJiFjz4983Cwfb W9zKZycx7L_OUxaasinOSyXAYe6MyuQSiL19yLgN3J4X thXoCY8LN8DAE37i7tItEK0c602ic7w Rt U_BEqbXo9Kj0DptW8vyoAnYIu67hS4cnGsm_ 6poaPpLu3 bNTelyAJ4HS_3z5K3_pgLAySl_AcPmuar Me 7XtK2t3ZBlv4iLPk7jKijyPDkn4D6sjTuEVkXFE5BwZY8g8ZITMkrHopnTzBEIga47aFjA49INNjB GzNmnR21GZQADBuQDuQikONAnUDAv_GvBJgC5Vv4LfOI0zQ9NNb8x4wcrtG_w
} 
The relative size, estimated as the ratio of the employment amounts, of the Federal agencies' software operations as compared with the total software operations for the economy is $0.034=79,850 / 2,340,000$. That estimate of the agencies' relative size is an underestimate, because FedScope's reported number of IT employees uses a narrow definition of an IT employee while the employment figure from the Bureau of Economic Analysis for the total employment in the software industry includes employees working in the industry that would not be classified as IT workers for purposes of the FedScope report of employees by type of employment. Because our estimate is an underestimate of the relative size of the Federal agencies' software operations as compared with the economy-wide software activity, our estimate of the potential economy-wide impact for the agencies' software products is a conservative underestimate.

To estimate the potential downstream productivity effect of the Federal agencies' software for the economy as a whole, we use the productivity benchmark of 0.15 multiplied by the growth in economy-wide value added to have the induced productivity effect for the software industry as a whole. We then multiply that by the Federal agency's software operations' size, as measured by employment, relative to the size of the software industry.

The induced output effect from the agencies' software would be the agencies' proportion, 0.034, of the total induced effect of software on the output in the economy. That total induced effect would be 0.15 multiplied by the growth in output which, over the year 2018 to 2019 was $\$ 847.5$ billion as gross domestic product increased from $\$ 20,580.2$ billion to $\$ 21,427.7$ billion. ${ }^{75}$ Thus the estimate of the potential annual induced productivity effect for the Federal agencies' software operations is $\$ 4.3$ billion $=0.034 \mathrm{x}$ $0.15 \times$ x $\$ 847.5$ billion. The potential $\$ 4.3$ billion economy-wide impact is an induced effect because the use of the Federal agencies' software would increase the productivity of the industries where the software was used. ${ }^{76}$

The potential \$4.3 billion economy-wide impact is based on the most recent year for which the U.S. economy's growth in value added is reported. Until the U.S. economy has recovered from the pandemic of 2020, we cannot expect the growth in the U.S. economy to be as much as it was from 2018 to 2019, and consequently, the software

\footnotetext{
${ }^{75}$ Bureau of Economic Analysis, U.S. Department of Commerce, News Release, July 6, 2020, "Gross Domestic Product by Industry, First Quarter 2020," p. 9, Table 5, https://www.bea.gov/data/gdp/gdpindustry.

${ }^{76}$ In addition to the induced productivity, or "downstream" effect of the agencies' software, there is the "upstream" employment effect from the Federal agencies' demand for inputs that are used in their software operations. Applying the benchmark employment multiplier of 1.5 derived from the input-output tables (see Appendix B), to the direct employment effect of the 86,053 IT employees for all Federal agencies in 2019 , the combined direct and indirect employment effects from the agencies' software operations sum to 129,079 employees. (FedScope reports that the total IT employment for the agencies in 2018 was 85,167. Extrapolating to 2019 using the average yearly change over the years 2014-2018 reported by FedScope gives estimated IT employment of 86,053 for the agencies in 2019.) To the direct effect of providing 86,053 jobs, there is an induced effect of 43,026 $=0.5 \times 86,053$ employees that are hired in the upstream industries to produce goods and services purchased by the Federal agencies to support their software operations.
} 
industry's contribution to positive economic growth cannot be expected to be what we observed for the most recent year of data.

\section{Conclusion}

This report has used the responses to a survey of the Federal agencies' GOCO and GOGO laboratories and facilities to develop projections for the economic impact of the agencies' software products if the copyright law is changed so that Federal agencies are allowed to copyright the software that is created in their GOGO laboratories and facilities. The projections are:

- As compared with the annual numbers of licensed software products for the last five years, over the next five years, if copyright protection is allowed, the averaged forecasts of the survey respondents suggest that the annual number of licensed software products by the agencies' laboratories and facilities will increase by almost 60 times for GOGO operations and by about 3 times for GOCO operations. Respondents explained that copyright protection would make the use of the released software more effective because users would be willing to contribute to its development for commercial use and share their work with others. Both commercial users and the government would be protected from users who otherwise might claim proprietary interests in the developed software and even sell it back to its originators.

- Across all Federal agencies, if copyrights are allowed for GOGO software, the software made available over the next five years is expected, based on a very simple forecasting model, to generate $\$ 86$ million in annual licensing revenues, a pronounced increase over the annual licensing revenues generated over the preceding five years. The increase that is projected for the next five years is largely driven by the expected increase in the GOGO licensing revenues. The annual licensing revenues for the GOGO software are, on average for the respondents, again based on the very simple model, expected to increase by 51 times or $5100 \%$, while GOCO licensing revenues on average for the respondents, are expected to increase by 2.43 times or $243 \%$. Because the software is developed for the agencies' internal use in support of their missions, and because the costs are largely incurred in the production and maintenance of the software, the costs of the software would largely be incurred whether or not the software is made available for others to use. The $\$ 86$ million from making the software available for others vastly understates the value that the software would create for others using it, because the software developed for internal agency use is made available as a public service rather than as a profit-maximizing endeavor, and indeed much of the software would be made available without charge.

- We estimate that if the copyright prohibition for government produced software is eliminated, the potential annual contribution from making Federal agencies' software available to others would be an addition to the U.S. economy's output of $\$ 4.3$ billion because the use of the Federal agencies' software would increase the productivity of the industries where the software is used. The projection is based 
on the most recent year, 2019, for which the requisite data are available from the U.S. Bureau of Economic Analysis. Thus, for the near term, as the economy recovers from the unanticipated shock of the pandemic of 2020, the projection based on 2019 data should be taken as no more than an illustration of the potential for a significant economy-wide impact from Federal agencies' software.

- Although this report's assessment supports the view that the Government Works software made available for others to use would create far more value for the economy as a whole than the additional IP-related costs incurred by the Federal agencies, it should be emphasized that based on the projections from the information provided by the respondents to the Software Copyright Impact Survey, the agencies would probably incur costs of making the products available that exceed the licensing revenues anticipated. Based on the information provided by respondents to the survey, making a copyrighted software product available for licensing would on average contribute about $\$ 6,000$ to expected annual licensing revenues while it would add an amount less than $\$ 21,000$ to expected average cost for a software product. The $\$ 21,000$ includes IP-related costs that would be incurred even if there were no licensing of products and the software were used solely in support of the agencies' missions. It is thus an overestimate of the part of the costs for the software product that would not have been incurred if the product was not copyrighted and made available. The software is produced for use by the laboratory or laboratory facility and then made available, often free of any charge, for others who find it useful for their own work. The software is not developed solely or even at all for its ability to generate licensing revenues, and many respondents indicate that they expect to make software available without charge even if copyright protection is allowed.

- Although the availability of copyright protection would strengthen the effectiveness of making GOGO software available for others, there is a social cost — perhaps an unintended consequence — of eliminating the copyright prohibition. Namely, the proportion of public domain software-released to the general public without copyright or copyleft restrictions - is expected to decline by $30 \%$. Offsetting that relative decline is the very large increase in the number of software products licensed and, presumably, used productively. GOGO respondents on average anticipate an almost 60 -fold increase in the number of software products licensed if copyright is allowed; GOCO respondents on average expect about a 3-fold increase. Also, for products made available for licensing, on average a 72-fold increase is expected for GOGO respondents, and a 4.5-fold increase for GOCO respondents. Despite the increase in software made available and software licensed, the loss of public domain software may lessen productivity for some users of the agencies' publicly released software. That possibility and its importance should be the subject of future research.

One of the GOGO respondents wrote about the potential for an economy-wide impact from the large increase in licensed government software that is anticipated if copyright 
protection for software created by the government is allowed. The GOGO respondent observed:

I really believe greater ability to protect and distribute government created software would be a boon to both private industry and the [Federal agency]. ... [Let me describe] the nature of the software work done [in organizations like mine]. Typically [the agency's] contractors give software maintenance duties to the government after they develop a system or give those duties to the government in a few years after maintenance becomes less lucrative. This means the majority of the total software work done [in organizations like mine] entails updates that fix bugs, provide new features, or enable systems to work in new environments. This is not to say traditional software development does not occur, it does but usually in regard to tools and software that support these [agency] contractor systems. With that said, I am certain that government created ... software is an untapped resource for [the agency]. I tried working on this problem for the past few years. ... The assumption ... is that nothing of public value comes out of [organizations like mine] since most of their software work is maintenance work on classified systems. The truth is that many of these ... systems have commercial versions that experience the same problems. Many of these software updates, with a little repackaging, could find their way into commercial systems. Also, many [of the agency's] contractor systems were developed entirely with government money making them additional candidates to be publicly shared and licensed by the government as long as export controls and classification levels are accounted for. Last those supporting systems developed $100 \%$ by government employees are the low hanging fruit of sharing software. As I write this, [my organization's] first software license for internally developed software is being written and there are many more software items that are good candidates.

Allowing greater copyright protection on government software would help drive a culture change where more of the software that [organizations like mine] create is shared with the public. Licensing software is motivating for [software] engineers, but also encourages better knowledge shared with industry and open source groups. We don't need to reinvent the wheel every time we create software.

The results of the study suggest that to effectively realize the potential for the economywide productivity-enhancing economic impact of copyrighted, licensed software from the Federal agencies, additional management resources will be needed. After providing information about an agency's limited number of software license agreements and limited royalty income, one respondent observed, "[Our agency does not] really have the tracking and management systems in order to do much official technology transfer with this type of technology. This is probably an area where the USG doesn't need a separate tech transfer office at each agency to make things work better. I would like to see a "mega distribution platform" housed at NIST to deal with it better." Appendix D provides examples of how Federal agencies are conducting outreach concerning custom software technologies. One agency, the General Services Administration (GSA) maintains such a "mega-distribution platform," but it is focused on custom software that is developed as "open source." 
In conclusion, based on the projections developed from the responses of the GOCO and GOGO respondents to the Software Copyright Impact Survey, changing the copyright law to allow copyright protection for GOGO Government Works software is expected to have a positive economic impact on the U.S. economy. However, because the survey asked the respondents at the agencies for information about their software activities that have not previously been tracked and reported systematically, providing responses to the survey was a challenge for many respondents. The report should be considered as only an exploratory first look to develop new information about the agencies' software activities and thereby to describe the potential economy-wide impact for allowing copyright for government-works software. 
Appendix A. Software Copyright Impact Survey (OMB Control No. 0693-0033, Expiration Date: 07/31/2022)

The Software Copyright Impact Survey was attached as a separate PDF file in the original report to preserve its formatting and complete contents. For the GCR report, the Software Copyright Impact Survey is appended at the end of the PDF file of GCR 21028. 


\section{Appendix B. Economy-Wide Impact of the Software Industry}

For software production in general, apart from the direct economic effects from the revenues generated and employment provided by the software production itself, the literature about the software industry has documented both downstream effects on the productivity of the users of the software and upstream effects of increased demand for the products that are used in software production. To provide an assessment of the probable economy-wide impact of the forecast of increased software available from the Federal agencies' labs and lab facilities if copyright prohibition is eliminated, we first explain the literature's development of two benchmarks. The first benchmark is for the downstream effect on the productivity of users of the Federal agencies' software. The first benchmark will allow forecasting the potential economy-wide productivity effect of the agencies' software made available for licensing or downloading without a license. The second benchmark is for the upstream effect on employment because of the demands for inputs used in the Federal agencies' software operations. The second benchmark will allow projecting the effect of the agencies' software activity on economy-wide employment.

The Definition of the Software Industry Used to Develop the Benchmarks. The software industry is typically defined as a combination of industry categories. For example, Shapiro defines the industry as a combination of industrial classification industries:

The ... software industry [is defined as the] operations of companies in three subindustries: computer systems design and related services; software publishing; and data processing, hosting and information services. The computer systems design industry (NAICS code 5415) covers companies that write, modify, test, and provide support for software, and so would include enterprise software companies such as IBM, HewlettPackard, and Oracle, as well as IT consulting companies like Accenture. The software publishing industry (NAICS code 5112) covers companies that produce and distribute computer software, including the development, publishing and installation of software, as well as providing support for software customers. This sub-industry is comprised of 1) prepackaged software produced by companies such as Apple and Microsoft (25.6 percent of software publishing); 2) custom software built by companies such as IBM and Hewlett Packard (37.6 percent); and 3) software developed by companies in-house for their own use (36.8 percent). Finally, the data processing, hosting, and other information services industry (NAICS codes 518 and 519) covers companies that provide web-based software, infrastructure and data storage, as well as search engines, social networks, auction sites, and web publishing companies. Services included under this designation include web-based platforms and applications, cloud computing services, and streaming services. The companies include Google, eBay, Salesforce, and Netflix. ${ }^{77}$

\footnotetext{
${ }^{77}$ Robert J. Shapiro, "The U.S. Software Industry as an Engine for Economic Growth and Employment," September 2014, Sonecon, https://sonecon.com/docs/studies/Report_for_SIIAImpact of Software on the Economy-Robert_Shapiro-Sept2014-Final.pdf.
} 
The definition is essentially the same as used in a 2016 report from BSA | The Software Alliance that commissioned The Economist Intelligence Unit (EIU) to assess the economic impact of the software industry.

The modern definition of the software industry used in the study reflects recent technological advancements in the software industry - from one that focused on tangible and packaged software products to one that includes software related services like the cloud based software as a service (SaaS), cloud storage and computing, mobile app development and hosting. As a result, the EIU analysis has defined the US software industry to include the following software sub-industries: NAICS 5112: Software Publishers; NAICS 5415: Computer Systems Design and Related Services; NAICS 518: Data Processing, Hosting and Related Services; NAICS 519130: Internet Publishing and Broadcasting and Web Services. ${ }^{78}$

The Benchmark for the Downstream Economy-wide Productivity Effect. In a sophisticated study, Byrne, Oliner, and Sichel estimate the contribution of software to the $1.56 \%$ growth in labor productivity over the period from 2004 to 2012 . They estimate that the productivity effect of software contributed $0.24 \%$ in percentage points to the $1.56 \%$ of the growth in labor productivity. Of software's contribution of percentage points to the $1.56 \%$ total, $0.16 \%$ was from software's contribution to the capital deepening from the accumulation of IT capital, and $0.08 \%$ was software's contribution to multifactor productivity growth. ${ }^{79}$ Shapiro observes that software's contribution to labor productivity growth is then $0.154=0.24 / 1.56$, or $15.4 \%$, and then observes that since real nonfarm business output grew $1.6 \%$, software accounted for about $15 \%$ of that growth in output from 2004 to 2012. Labor productivity growth explained $97.5 \%(1.56 / 1.6)$ of the growth in output; and $15.4 \%$ of that $97.5 \%$ of the growth in output was explained by software. Thus, $0.154 \times .975 \times 1.6 \%=0.24 \%$ of the $1.6 \%$ growth in output is contributed by software, and therefore software contributed 0.15 or $15 \%$ of the growth in output $(0.24 \% / 1.6 \%=0.15) .{ }^{80}$ Shapiro observes that software value added in 2012 was $\$ 425$ billion; that was the direct contribution to GDP. ${ }^{81}$ Also, in addition to the direct contribution of the software industry to GDP, it contributed to productivity gains throughout the economy. Using the foregoing analysis, Shapiro observes that software's contributions to the productivity gains were $15 \%$ of the growth in output from 2011 to 2012, and that amounted to $\$ 101$ billion. ${ }^{82}$ Thus, Shapiro concludes, "All told, the

\footnotetext{
78 BSA | The Software Alliance, "The \$1 Trillion Economic Impact of Software," with data from The Economist Intelligence Unit, June 2016, https://softwareimpact.bsa.org.

${ }^{79}$ David M. Byrne, Stephen D. Oliner, and Daniel E. Sichel, "Is the Information Technology Revolution Over?" 2013-36, Finance and Economics Discussion Series, Divisions of Research \& Statistics and Monetary Affairs, Federal Reserve Board, Washington, D.C., March 2013, Table 1, "Contributions to Growth of Labor Productivity in the Nonfarm Business Sector,” p. 22. Shapiro, op cit., Table 5, p. 10 shows and works with these facts from Byrne, Oliner, and Sichel.

${ }^{80}$ Shapiro, Ibid., p. 10.

${ }^{81}$ Value added is the measure of output that is used when describing economy-wide output and the contributions to economy-wide output made by individual industries. See the discussion of GDP, i.e., value added, and the definitions, provided in Section 2.8 of this report, from the Bureau of Economic Analysis.

${ }^{82}$ Careful reading of Shapiro's analysis, op. cit., will not find an explicit statement of the $15 \%$ being applied to the growth in output from 2011 to 2012. It is certainly implicit, however, and it is the
} 
software industry in 2012 contributed $\$ 526$ billion to GDP $-\$ 425$ billion $+\$ 101$ billion - or 3.2 percent of GDP." 83 Hence, based on the experience during a period when the impact of software was considerably less than it was during the 1995-2004 period, and hence a period yielding a conservative estimate for the productivity effect, in addition to the annual value added contributed directly, software has a large indirect productivity effect on the entire economy. The benchmark effect is the direct effect of value added provided by the software industry plus the indirect effect of value added from other industries throughout the economy because their use of the software increases their productivity. The benchmark tells us that the indirect effect is estimated by multiplying 0.15 times the growth in value added for the economy.

The circa 2012 benchmark for the economy-wide productivity effect of software is an appropriate one because the effect has been based on the experience over the 2004-2012 period, when the effects of software were grounded in the reality of the period after the mid-1990s to early 2000s outsized impact of information technology, and at the same time the output share of software was large. As Byrne, Oliner, and Sichel observe:

As for the separate contributions from the use of IT (capital deepening) and from efficiency gains in the production of IT, the patterns are similar, with the contributions over 2004-2012 well off from the rapid pace during 1995-2004 and a little below the contribution from 1974 to 1995 . The slowdown in the contribution from the production of IT reflects both a slower pace of advance of MFP in each IT sector and a sizable step-down in the current-dollar output share of the industries producing computer hardware, communication equipment, and semiconductors. This drop reflects substantial movement of IT manufacturing from the United States to foreign locations. Indeed, as shown in figure 1, the share of current-dollar nonfarm business output represented by the production of computer hardware, communication equipment, and semiconductors has fallen more than 70 percent from its peak in 2000. In contrast, the output share of the software industry was higher from 2004 to 2012 than in either of the earlier periods. ${ }^{84}$

The Benchmark for the Upstream Economy-wide Employment Effect. For software's economy-wide impact that is from the upstream effect of increased demand for the products and services used as inputs for the software industry, Shapiro uses the InputOutput tables from the Bureau of Economic Analysis. The approach is also used in the 2016 report from BSA using EIU research.

Shapiro explains the analysis that produces the benchmark for the upstream effect that we apply to the Federal agencies' software activity.

Input-output analysis relies on a series of statistics issued regularly by the Bureau of

appropriate procedure, and it is what was done in the report. We verified the procedure used by using the historical data from the Bureau of Economic Analysis archival files. Although the data have been revised, the result is essentially the same as what Shapiro reports.

${ }^{83}$ Ibid., p. 1.

${ }^{84}$ Byrne, Oliner, and Sichel, op. cit., p. 9. 
Economic Analysis tracking the commodity outputs produced by each industry, called the "Make" tables, and the commodity inputs used by each industry to produce its output, called the "Use" tables. ... I-O analysis can track and estimate an industry's indirect effects on output, employment and income generated by its purchases of intermediate inputs from other industries or supply chains....

We define the software industry here as the ... NAICS categories which, according to the Bureau of Labor Statistics, employ the largest number of software developers and programmers: 1) computer systems design industry (NAICS code 5415); software publishing (NAICS code 5112); and data processing, hosting, and information services (NAICS codes 518 and 519). As noted earlier, the Bureau of Economic Analysis reports that the output of these three categories in 2012 totaled $\$ 425$ billion. Further, the Bureau of Labor Statistics reports that these sub-industries in 2012 employed 2.34 million workers, and they earned a total of $\$ 308.4$ billion.

To estimate the software industry's indirect employment impact across other industries, we begin with the BEA "Use" table to calculate the amount of each commodity consumed by software companies as intermediate inputs, and the BEA "Make" table identify the source of these intermediate inputs by industry. Next, we aggregate the industry totals to estimate the value of goods and services consumed by the software industry on an industry-by-industry basis. We find that that in order to produce its $\$ 425$ billion in output in 2012, U.S. software companies consumed $\$ 212$ billion in goods and services produced by other industries. Further, we estimate that this economic demand from the software industry supported 1.1 million jobs in other industries, including 145,000 workers in the accommodation and food services industry, 364,000 workers in the administrative services industry (office administration, clerical services, security, cleaning, and waste disposal services), and 181,000 jobs in the professional, scientific, and technical services industry.

Based on these data, we calculate that every ten jobs in the software industry supported five more jobs in other industries - that is, the software industry had an employment multiplier of about 1.5 in $2012 .{ }^{85}$

Other Effects. Software industry associations have used the foregoing approaches that generate a value-added multiplier and an employment multiplier to describe the economy-wide impact of the software industry. They have also in some cases added another effect, namely an induced effect "... associated with the consumption by workers employed by the software industry: Their earnings create additional demand for goods and services, which in turn require employment to satisfy that demand." 86 However, we agree with Shapiro that such estimates are difficult to determine because if the employees were not working in the software industry, presumably they would be earning incomes in another occupation. ${ }^{87}$

\footnotetext{
${ }^{85}$ Shapiro, op. cit., pp. 12-13.

${ }^{86}$ Shapiro, op. cit., p. 13. BSA, op. cit., provides an example where such induced effects are estimated and discussed.

${ }^{87}$ Shapiro, op. cit., p. 13.
} 


\section{Appendix C. Estimated Licensing Revenue Functions}

In this appendix, we discuss and present the simple revenue model that we use to describe, for the sample of GOCO respondents, the relationship between licensing revenues and the number of licensed software products and their IP protection. In the report, we use the simple model to describe the average revenue for licensed software products with and without IP protection, and we also use the model to provide a forecast of what might be expected if the Government Works software of GOGOs could be copyrighted. In the report we provide a full discussion of those applications of the simple revenue model. Here in the appendix we focus on the technical details of why the very simple model is appropriate, and we compare the results obtained with the simple model to what is found when instead a more elaborate model is used. We show in this appendix that the simple model - that is easily explained and readily understood by a general audience - actually yields the same predictions and statistical inferences as the more elaborate model. Everything that we do with the simple model can be replicated with the more elaborate one, but the elaborate one is not one that can be readily understood by a general audience.

In the simple model, observed licensing revenues are determined by the number of licensed software products, by whether or not the products have IP protection, and by random error, as specified in equation (1).

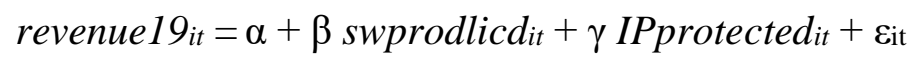

The variable revenue $19_{i t}$ denotes the $i^{\text {th }}$ respondent's software licensing revenue in constant 2019 dollars for fiscal year $t$. The variable swprodlicd ${ }_{i t}$ denotes for the $i^{\text {th }}$ respondent, the annual number of licensed software products in fiscal year $t$. The variable IPprotected ${ }_{i t}=1$ when there were copyrights or patents, and $=0$ when there was no copyright or patent protection. The variable $\varepsilon_{i t}$ denotes the independently distributed random error with expected value equal to zero. In the classical, normal Ordinary Least Squares (OLS) model that random error is assumed to be normally distributed. Therein lies the problem that we need to address in this appendix.

Table 2 showed and discussed the asymmetry and peakedness of the distributions for the variables across the different GOGO and GOCO respondents. As observed with the discussion of Table 2, when estimating the model of the licensing revenues, it is the distribution of the random error that must be addressed.

The first point about the disturbances in the model is that their mean is zero. The second point is that the variance in the error may not be the same for each observation. The very different situations for the respondents - differences that cause their different outcomes for the variables - suggests that the error in the model's estimated equation may be heteroskedastic, that is, the error variance may differ across the observations. For that reason, we estimate the OLS models shown in the tables of this appendix with robust standard errors. (Although, as it turns out, whether estimated with robust standard errors or not, the results are essentially the same.) 
For our estimates of the model using simple regression and allowing for different error variances to be unbiased, we need only the assumption that the expected value for randomly distributed disturbances is zero. That is the key for our very exploratory use of the model. We hope for unbiased estimates for the model's coefficients, and then we can use the estimated model to predict what would happen if copyright protection were allowed for the GOGO respondents. Observe that while the mean for the licensing revenues in the GOCO and GOGO samples is positive as shown in Table 2, the mean for our observations of the errors - i.e., our observations of the residuals in the regression models that we estimate - is zero. For example, among the models estimated in this appendix, it turns out that the key model for our predictions is specification (2) in Table C.1 (that will be presented after we have explained a bit more about why the simple model that will be shown in Table C. 1 is appropriate). For that specification, the mean (estimated with double precision) of the model's residuals is -0.00000000000477 ($4.77 \times 10^{-12}$ ). However, while the mean of the residuals is zero, the distribution is skewed and more peaked than the normal distribution.

To compare the distributions of the licensing revenues, the dependent variable in the model, with the distribution of the residuals for the estimated model, we show appropriate histograms. The histogram in Figure C.1 shows the density for the licensing revenues for the GOCO respondents whose data is used in specification (2) in Table C.1. The density metric has scaled the height of the histogram's bars so that the sum of their areas equals 1 (as would be the case for a probability distribution for the continuous variable, licensing revenues). The licensing revenues have been divided into five "bins" with each bin having width $\$ 130,901.29$. Observe that $5 \times \$ 130,901.29=\$ 654,506.4$ which is the maximum in the sample for licensing revenue. The range of revenues for the five bins begins at 0.0 , the minimum revenue reported by the GOCO respondents, and the range ends at $\$ 654,506.4$, the maximum revenue reported. For comparison, superimposed on the histogram is an appropriately scaled normal density. The overlaid normal distribution has the same mean and standard deviation as the GOCO respondents' data for licensing revenues in constant dollars of 2019. 
Figure C.1. Histogram of Licensing Revenue in Constant Dollars of 2019 Overlaid with the Normal Density Having the Same Mean and Standard Deviation

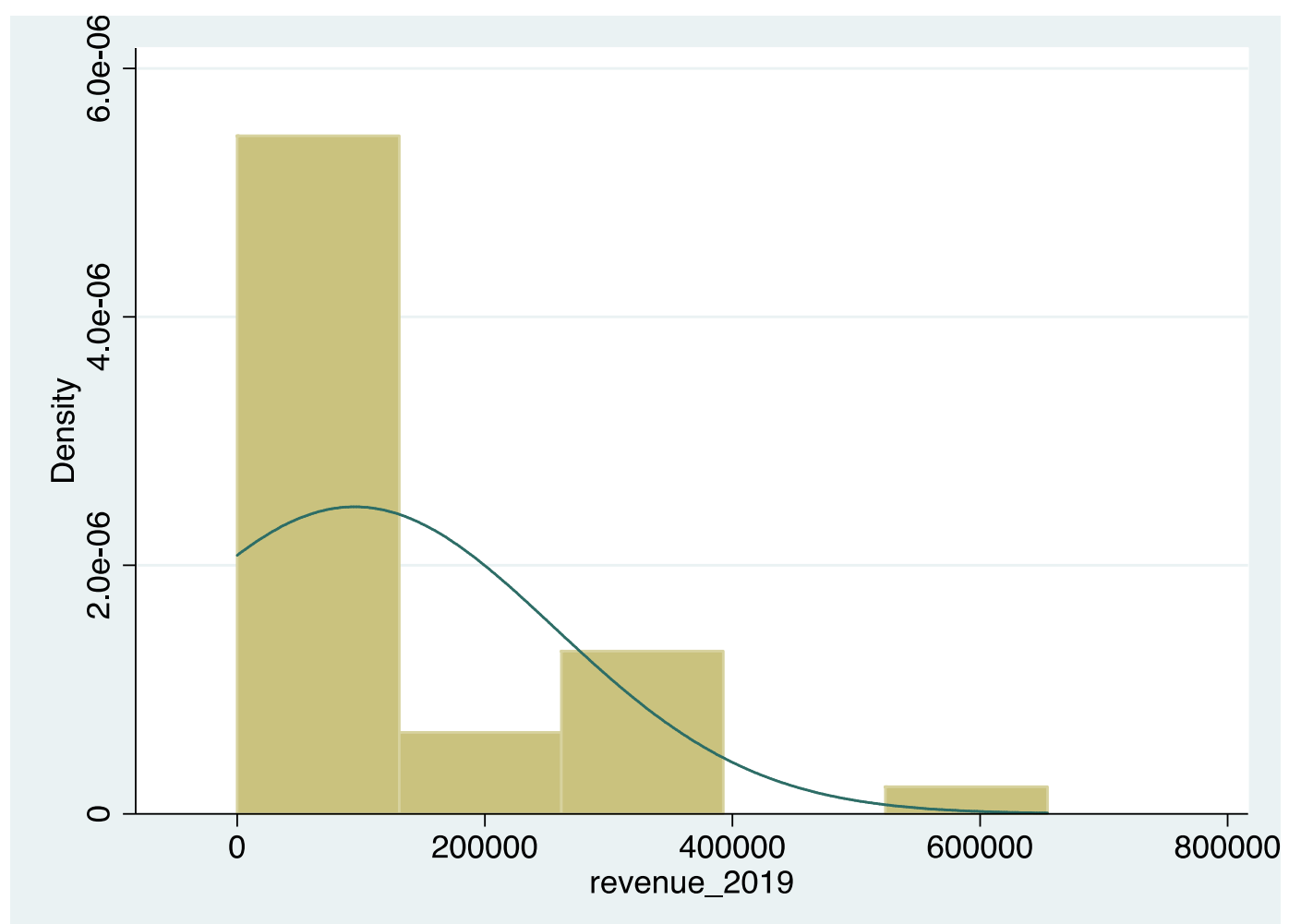

The histogram in Figure C.2 shows the density for the residuals for the estimation of specification (2) in Table C.1. As in Figure C.1, the density metric has scaled the height of the histogram's bars so that the sum of their areas equals 1 (as would be the case for a probability distribution for the residuals, a continuous variable). The residuals have been divided into five "bins" with each bin having width $\$ 89,834.845$. Observe that the width of each bin has divided into five equal parts the range of the residuals from the minimum value of $-\$ 116,209.9$ to the maximum value of $=\$ 332,964.4$, since $5 \times \$ 89,834.845=$ $449,174=\$ 332,964.4-(-\$ 116,209.9)$. Again, for comparison, superimposed on the histogram is an appropriately scaled normal density. The overlaid normal distribution has the same mean and standard deviation as the residuals for specification (2) in Table C.1. 
Figure C.2. Histogram of Residuals for Specification (2) in Table C.1 Overlaid with the Normal Density Having the Same Mean and Standard Deviation

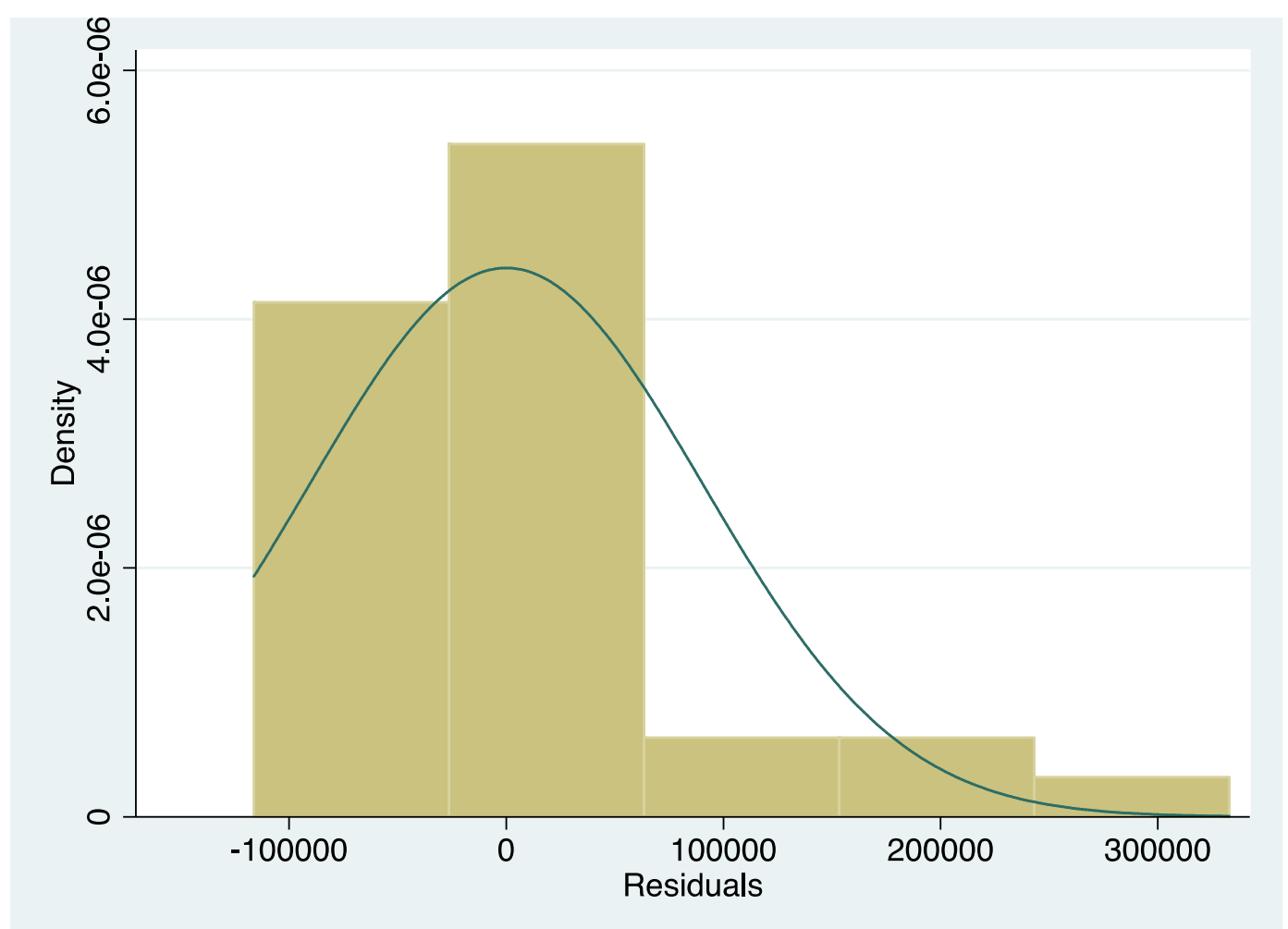

Although the mean for the residuals is zero; and the estimated coefficients are unbiased for randomly distributed errors, the distribution of the residuals from the usual regression model with the software survey data is not normal. Thus, the inferential statistics that accompany our unbiased estimated coefficients for equation (1) will not necessarily provide the same inferences as what would be shown by a different type of estimating model that accounted for the skewness in the randomly distributed errors as indicated by the distribution of the residuals. However, the OLS regression model typically provides good inferences with samples for which the regression disturbances with mean zero are not normally distributed. Moreover, we shall show that for our sample, OLS provides essentially the same inferences as the formal Tobit model that accounts for the limited dependent variable that is "left-censored" at zero. ${ }^{88}$

A well-known example for which OLS and the appropriate formal statistical model for the limited dependent variable provide similar inferences is the case where the dependent variable is a qualitative ("dummy") variable - that is, either a 0 or a 1, indicating whether or not an event occurs. The so-called "linear probability model" which simply regresses

\footnotetext{
${ }^{88}$ See G. S. Maddala, Limited-Dependent and Qualitative Variables in Econometrics (Cambridge, U.K.: Cambridge University Press, 1983) for the exposition of the Tobit model.
} 
the $0-1$ dependent variable on the explanatory variables, will often provide the same inferences as a formal probit model that estimates the probability of the event. When compared to the probit model's results, the estimated coefficients from the ordinary least squares estimator predict the same probabilities and the statistics reach the same conclusions about the statistical significance of the model and its estimated effects. Link and Scott (2009) provide a carefully documented example. Comparing their probit model's estimates (Table 4, p. 273) with the linear probability model's estimates (Table A3, p. 279), Link and Scott conclude (p. 274): “[T]he simple linear probability model (i.e. ordinary least squares (OLS)) yields essentially the same conclusions, although of course the assumptions making ordinary least squares appropriate are not satisfied." 89

For another example of the robustness of the OLS estimator, Marchenko and Genton (2010) develop a maximum-likelihood estimator that assumes skewed distributions for the disturbances rather than the symmetric normal distribution. They compare OLS estimates with skewed residual error with the estimates from the skewed distribution estimator and find that coefficient estimates and inferential conclusions are similar. ${ }^{90}$ For the Marchenko and Genton example, the residuals for the OLS regression model are somewhat skewed, with a longer left tail, and they are more peaked than the normal distribution (Marchenko and Genton, Figure 4, p. 524). The residuals for specification (2) in Table C.1 (the key model for the prediction of licensing revenue) are also more peaked than the normal distribution, and also skewed, but with a longer right tail. In the Marchenko and Genton example, despite the distribution of the OLS regression's residuals being somewhat skewed and more peaked than the normal distribution, the normal regression model provides similar inferential conclusions (p. 531).

Given the small number of respondents for our model, in our exploratory look at the relationship between licensing revenues and the number of licensed software products with or without IP protection, we use the OLS estimator rather than work with maximumlikelihood estimators that ideally require large numbers of observations (and, with smaller samples, may not even be estimable because they may not converge to a maximum likelihood). For both our descriptions and predictions, we use the estimates from the OLS regression model. The simple model is expected to provide good inferences about the descriptive relationship between licensing revenue and the explanatory variables. Moreover, discussing and explaining the OLS model's results is much easier than discussing the results of the formal model — the Tobit model — designed to deal with a limited dependent variable that, like licensing revenue, is left-censored at zero. ${ }^{91}$ In fact, after presenting and discussing the OLS model, we show that the Tobit model yields similar inferential results to what we find with the OLS model.

\footnotetext{
${ }^{89}$ A. N. Link and J. T. Scott, "Private Investor Participation and Commercialization Rates for Governmentsponsored Research and Development: Would a Prediction Market Improve the Performance of the SBIR Programme?" Economica, Volume 76, Issue 302 (April 2009).

${ }^{90}$ Yulia V. Marchenko and Marc G. Genton, "A Suite of Commands for Fitting the Skew-Normal and Skew-t Models,” The Stata Journal, Vol. 10, No. 4 (2010), pp. 507-539, at p. 531.

${ }^{91}$ An example of a full discussion of an application of the Tobit model is provided in J. T. Scott and T. J. Scott, "Innovation Rivalry: Theory and Empirics," Economia e Politica Industriale-Journal of Industrial and Business Economics, Vol. 41, No. 1 (March 2014), pp. 25-53.
} 
For the seven GOCO respondents with complete observations for the three variables, Table C. 1 shows the estimation of the simple revenue model. Column (1) shows the licensing revenues as a function of the number of licensed software products, swprodlicd. With the revenues measured in constant dollars of 2019, the estimated coefficient for swprodlicd shows the marginal effect on revenue from adding an additional licensed product. At the margin, for another product the annual licensing revenues increase by $\$ 2,884$. The estimated constant term is large, $\$ 33,389$ in constant dollars, and significantly different from zero. Thus, the slope of the ray from the origin to the total revenue function's value, at a given number of licensed products, shows a relatively large average revenue per product for the licensed software products of the GOCO respondents. As shown in the specification in column (2), that large constant term is explained by the presence of intellectual property protection. Adding the variable IPprotected to the specification, the coefficient estimated for swprodlicd is $\$ 2,565$ and the estimated coefficient for IPprotected is $\$ 70,042$, reflecting the advantage, for the observations in the sample, of having an appropriate combination of IP protection of copyrights, patents, or both. With the addition of the control for the presence of intellectual property protection from copyrights or patents, the estimated constant term is small and not significantly different from zero. That change from what we observed in column (1) where, before the addition of IPprotected we found a constant term that was large and significantly different from zero, tells us that the high average revenues associated with the licensed software products reflect the IP protection of copyrights or patents. For the GOCO observations, the IP protection is coming mostly from copyright protection, although there are some respondents that report patents for their software as well as copyrights. The GOCO respondents providing the three variables used in the revenue model report, on average, that $19 \%$ of their licensed software had copyright protection while $3 \%$ of their licensed software had patent protection.

Rather than report the t-statistics directly, we have followed current practice in the economics journals and reported the coefficient, its standard error, and the p-value for the conservative two-tailed test of the coefficient's statistical significance against the null hypothesis. Dividing the estimated coefficient by the standard error gives the t-statistic that some readers might want to see. Observing whether the $|t|>2$ provides a quick test for statistical significance. In that case, if the null hypothesis that the estimated coefficient is zero is true, then the probability that the t-statistic would have a higher absolute value (denoted as probability $>|\mathrm{t}|$ or $\mathrm{p}\rangle|\mathrm{t}|$ ) is the two-tailed $\mathrm{p}$-value, and, given the number of degrees of freedom for our model, it would be about 0.05 for $|t|>2$, i.e. about 0.025 in each tail of the distribution for the t-statistic against the null hypothesis. Thus, an estimated coefficient for which $\mathrm{p}\rangle|\mathrm{t}|=0.000$ means the probability in the two tails of the $t$ distribution is $<0.0005$. So the estimated coefficient is highly statistically significant. Note, for example, that the $\mathrm{p}$-value for the estimated coefficient on swprodlicd it in specification 2 of Table C. 1 is 0.000 , and the t-statistic (the ratio of the estimated coefficient to its standard error) is 4.90. For specification 2 in Table C.1, we see that both explanatory variables have estimated coefficients that are statistically significant. 
Table C.1. The Software Licensing Revenue Model for the GOCO Observations: Least-Squares Estimates, Dependent Variable revenue $19_{\text {it }}$

\begin{tabular}{|c|c|c|}
\hline Variable & (1) & (2) \\
\hline \multirow[t]{3}{*}{ swprodlicd $_{i t}$} & 2884.1 & 2564.6 \\
\hline & $(515.2)$ & $(523.6)$ \\
\hline & {$[0.000]$} & {$[0.000]$} \\
\hline \multirow[t]{3}{*}{ IPprotected $_{i t}$} & -- & 70042.4 \\
\hline & & $(26287)$ \\
\hline & & [0.012] \\
\hline \multirow[t]{3}{*}{ Intercept } & 33388.9 & 164.0 \\
\hline & (13174) & $(323.1)$ \\
\hline & {$[0.016]$} & {$[0.615]$} \\
\hline R-squared & 0.647 & 0.686 \\
\hline F-statistic & 31.3 & 21.3 \\
\hline$($ probability $>F)$ & $(0.0000)$ & $(0.0000)$ \\
\hline$n$ & 35 & 35 \\
\hline \multicolumn{3}{|c|}{$\begin{array}{l}\text { Notes: The variable revenue } 19_{i t} \text { denotes the } i^{\text {th }} \text { respondent's software licensing revenue in constant } 2019 \\
\text { dollars for fiscal year } t \text {. The variable } \text { swprodlicd }{ }_{i t} \text { denotes for the } i^{\text {th }} \text { respondent the annual number of } \\
\text { licensed software products in fiscal year } t \text {. The variable IPprotected } d_{i t}=1 \text { when there were copyrights or } \\
\text { patents, and }=0 \text { when there was no copyright or patent protection. } \\
\text { Robust standard errors in parentheses, probability }>|t| \text { in brackets. } \\
\text { The F-statistic degrees of freedom for column }(1) \text { is } \mathrm{F}(1,33) \text { and for column }(2) \text { is } \mathrm{F}(2,32) \text {. } \\
\text { Source: Authors' computations from "Software Copyright Impact Survey," OMB Control No. 0693-0033, } \\
\text { Expiration Date: } 07 / 31 / 2022\end{array}$} \\
\hline
\end{tabular}

For the 26 GOGO respondents with complete observations for the three variables, Table C. 2 shows the estimation of the simple revenue model. Column (1) shows the licensing revenues as a function of the number of licensed software products, swprodlicd. With the revenues measured in constant dollars of 2019, the estimated coefficient for swprodlicd shows the marginal effect on revenue from adding an additional licensed product. At the margin, for another product the annual licensing revenues increase by $\$ 3,167$. The estimated constant term is $\$ 1,317$ in constant dollars. Thus, the slope of the ray from the origin to the total revenue function's value, at a given number of licensed products, shows, compared with the situation for the GOCO respondents, a relatively small average revenue per product for the licensed software products of the GOGO respondents. As shown in the specification in column (2), both the estimated coefficient for swprodlicd and the estimated constant term in the first specification are explained by the presence of intellectual property protection. Adding the variable IPprotected to the specification, the coefficient estimated for swprodlicd falls to $\$ 1,977$, and the estimated constant term falls to $\$ 460$. The estimated coefficient for IPprotected is $\$ 6,648$, reflecting the advantage, for the observations in the GOGO sample, of having IP protection of copyrights, patents, or both, but the value of the IP protection actually obtained for the typical software product is clearly an order of magnitude less for the GOGO sample, where copyright protection, excepting internationally protected products and products transferred to the labs, cannot be obtained. Thus, the average revenues associated with the licensed software products of the respondents in the GOGO sample reflect the lack of IP protection as compared with the respondents in the GOCO sample. For the GOGO observations, the IP protection observed is coming mostly from some patent protection, 
although there are some exceptions for software transferred to the lab or software protected internationally. The 26 GOGO respondents that provided the data used in the revenue model report, on average, that $3 \%$ of their licensed products had copyright protection, while $12 \%$ had patent protection.

Table C.2. The Software Licensing Revenue Model for the GOGO Observations: Least-Squares Estimates, Dependent Variable revenue 19 ${ }_{i t}$

\begin{tabular}{|c|c|c|}
\hline Variable & $(1)$ & (2) \\
\hline \multirow[t]{3}{*}{ swprodlicd $_{i t}$} & 3167.4 & 1977.1 \\
\hline & $(1280.6)$ & (1250.3) \\
\hline & {$[0.015]$} & [0.116] \\
\hline \multirow{3}{*}{ IPprotectedit $_{\text {it }}$} & & 6647.8 \\
\hline & -- & (6154.3) \\
\hline & & [0.282] \\
\hline \multirow[t]{3}{*}{ Intercept } & 1316.9 & 459.6 \\
\hline & (863.3) & (198.4) \\
\hline & [0.130] & [0.022] \\
\hline R-squared & 0.0539 & 0.0850 \\
\hline F-statistic & 6.12 & 2.78 \\
\hline$($ probability $>$ F) & $(0.0147)$ & $(0.0660)$ \\
\hline$n$ & 130 & 130 \\
\hline
\end{tabular}

Notes: The variable revenue $19_{i t}$ denotes the $i^{\text {th }}$ respondent's software licensing revenue in constant 2019 dollars for fiscal year $t$. The variable swprodlicd ${ }_{i t}$ denotes for the $i^{\text {th }}$ respondent the annual number of licensed software products in fiscal year $t$. The variable IPprotected $_{i t}=1$ when there were copyrights or patents, and $=0$ when there was no copyright or patent protection.

Robust standard errors in parentheses, probability $>|t|$ in brackets.

The F-statistic degrees of freedom for column (1) is $\mathrm{F}(1,128)$ and for column (2) is $\mathrm{F}(2,127)$.

Source: Authors' computations from "Software Copyright Impact Survey," OMB Control No. 0693-0033, Expiration Date: 07/31/2022

Note that in comparison with the $\mathrm{R}^{2}$ of 0.686 for the GOCO specification (specification 2 in Table C.1), the relatively low $\mathrm{R}^{2}$ for the GOGO specification is telling us formally what we already knew - namely there is a lot of "noise" (error variance) in the revenue data for the GOGO sample. Although relatively small, the $\mathrm{R}^{2}$ is statistically significant as seen by the F-statistic for the significance of the model as a whole. The F-statistic can in fact be derived from the $\mathrm{R}^{2}$ and the number of observations, $n$, and the number of explanatory variables, $k$. Written in terms of the $\mathrm{R}^{2}$, the F-statistic equals $((n-k) /(k-$ $1))\left(R^{2} /\left(1-R^{2}\right)\right){ }^{92}$ Also, observe that the coefficient for the explanatory variable swprodlicd it is statistically significant for a two-tailed test. The coefficient for the explanatory variable IPprotected $d_{i t}$ is not significant at conventional levels, but is significant for a one-tailed test at the $15 \%$ level (given the a priori expectation that the coefficient would be positive, a one-tailed test would not be inappropriate, although it is less conservative). Both coefficients are smaller than for the GOCO specification-just as we would expect.

\footnotetext{
${ }^{92}$ Jan Kmenta, Elements of Econometrics, (New York: The Macmillan Company, 1971), p. 367.
} 
Table C. 3 shows what happens when to the 26 GOGO respondents with complete observations for the three variables we add the additional observation that was predominately for GOGO operations, but that also included some GOCO operations. Column (1) shows the licensing revenues as a function of the number of licensed software products, swprodlicd. With the revenues measured in constant dollars of 2019, the estimated coefficient for swprodlicd shows that for each additional licensed product, the annual licensing revenues increase by $\$ 3,312$, which as we would expect is somewhat higher than the $\$ 3167$ estimated before the addition of the mixed case including some GOCO labs and lab facilities. The estimated constant term \$1,256 about the same as the $\$ 1,317$ estimated before the addition of the mixed case. As shown in the specification in column (2), both the constant term and the coefficient on swprodlicd in the column (1) specification are again explained to an extent by the presence of intellectual property protection. Adding the variable IPprotected to the specification, the coefficient estimated for swprodlicd drops to $\$ 2095$, and the estimated constant term drops to $\$ 443$. The estimated coefficient for IPprotected is $\$ 6,215$, capturing the advantage, for the observations in the sample, of having an appropriate combination of IP protection of copyrights, patents, or both. If a dummy variable for the additional respondent (reporting for several labs and facilities that are predominantly GOGO, but some are GOCO) that has been added to the estimation in Table C.3, the variable never has a significant effect and the other results seen in Table C. 3 remain essentially the same.

\section{Table C.3. The Software Licensing Revenue Model for the GOGO Observations Plus the Mixed Case: Least-Squares Estimates, Dependent Variable revenue $19_{\text {it }}$}

\begin{tabular}{lcc}
\hline Variable & $(1)$ & $(2)$ \\
\hline swprodlicdit & 3312.0 & 2094.7 \\
& $(891.1)$ & $(1148.5)$ \\
IPprotectedit & {$[0.000]$} & {$[0.070]$} \\
& & 6215.3 \\
Intercept & -- & $(5840.3)$ \\
& 1255.9 & {$[0.289]$} \\
& $(878.3)$ & 442.8 \\
R-squared & {$[0.155]$} & $(200.2)$ \\
F-statistic & & $0.029]$ \\
(probability > F) & 0.0799 & 0.107 \\
$n$ & 13.8 & 6.46 \\
\hline
\end{tabular}

Notes: The variable revenue $19_{i t}$ denotes the $i^{\text {th }}$ respondent's software licensing revenue in constant 2019 dollars for fiscal year $t$. The variable swprodlicd ${ }_{i t}$ denotes for the $i^{\text {th }}$ respondent the annual number of licensed software products in fiscal year $t$. The variable IPprotected $_{i t}=1$ when there were copyrights or patents, and $=0$ when there was no copyright or patent protection.

Robust standard errors in parentheses, probability $>|t|$ in brackets.

The F-statistic degrees of freedom for column (1) is $\mathrm{F}(1,133)$ and for column (2) is $\mathrm{F}(2,132)$.

Source: Authors' computations from "Software Copyright Impact Survey," OMB Control No. 0693-0033, Expiration Date: 07/31/2022 
Comparing the results for Tables C.1, C.2, and C.3, and knowing (see the discussion in the body of the report at Table 2) that the IP protection for the GOCO respondents is almost entirely from copyrights, while the IP protection for the GOGO respondents is almost entirely from patents, the difference between the revenue functions for GOGOs and GOCOs appears to be because of the availability of copyright protection for the GOCOs and the lack of it for the GOGOs. Thus, the revenue function estimated for the GOCO respondents provides a model of what we could expect for the potential revenues for the GOGO respondents, given their forecasts for their number of licensed products, if copyright protection is allowed.

The OLS model that we use gives similar inferential results to what is found if instead the formal Tobit model is used to handle the limited dependent variable. The OLS model that we use for predictions is specification (2) in Table C.1, and Table C.4 compares the key findings for that model with what is found if the Tobit model is used.

Table C.4. Comparison of OLS and Tobit Estimates of the Software Licensing Revenue Model for the GOCO Observations: Dependent Variable revenue $19_{\text {it }}$

\begin{tabular}{|c|c|c|}
\hline Variable & $\begin{array}{c}\text { OLS specification (2) } \\
\text { Table C. } 1\end{array}$ & Tobit regression \\
\hline \multirow[t]{3}{*}{ swprodlicdit $_{\text {in }}$} & 2564.6 & 2615.0 \\
\hline & (523.6) & (454.8) \\
\hline & {$[0.000]$} & {$[0.000]$} \\
\hline \multirow[t]{3}{*}{ IPprotectedit $_{\text {it }}$} & 70042.4 & 147871.6 \\
\hline & $(26287)$ & $(47514.0)$ \\
\hline & {$[0.012]$} & {$[0.004]$} \\
\hline \multirow[t]{3}{*}{ Intercept } & 164.0 & -82868.1 \\
\hline & $(323.1)$ & $(37420.8)$ \\
\hline & {$[0.615]$} & {$[0.034]$} \\
\hline \multirow[t]{2}{*}{$\begin{array}{l}\text { Model Statistic (degrees of freedom) } \\
\text { [probability }>\text { model statistic] }\end{array}$} & $\begin{array}{c}\mathrm{F}(2,32)=21.3 \\
{[\text { probability }>\mathrm{F}=}\end{array}$ & $\begin{array}{c}\text { LR chi-squared }(2)= \\
38.7\end{array}$ \\
\hline & $0.0000]$ & $\begin{array}{l}\text { [probability > chi- } \\
\text { squared }=0.0000]\end{array}$ \\
\hline $\begin{array}{l}\text { Mean for the } 35 \text { observations of the } \\
\text { model's prediction for the annual licensing } \\
\text { revenues during } 2015-2019^{*}\end{array}$ & $\$ 94,779$ & $\$ 104,656$ \\
\hline$n$ & 35 & 35 \\
\hline
\end{tabular}

Notes: The variable revenue $19_{i t}$ denotes the $i^{\text {th }}$ respondent's software licensing revenue in constant 2019 dollars for fiscal year $t$. The variable swprodlicd $_{i t}$ denotes for the $i^{\text {th }}$ respondent the annual number of licensed software products in fiscal year $t$. The variable IPprotected $_{i t}=1$ when there were copyrights or patents, and $=0$ when there was no copyright or patent protection.

Standard errors in parentheses, probability $>|t|$ in brackets.

*The $95 \%$ confidence interval for the mean of the model's predictions shows that the model makes reliable predictions even when the forecast uses out-of-sample values for the explanatory variables (see Table 26). Source: Authors' computations from "Software Copyright Impact Survey," OMB Control No. 0693-0033, Expiration Date: 07/31/2022

The estimated coefficient for the continuous variable for the number of licensed products can be compared directly in the two models. The estimated effect of the variable is almost the same- each estimate rounds to $\$ 2,600$. Because of the transformation used in the 
Tobit model to formally account for the limited dependent variable, the estimated constant term and the estimate for the qualitative variable for IP protection differ from those estimates in the OLS model, but the differences are offset in the predictions of licensing revenue that we are interested in. For the Tobit model's maximum likelihood prediction of expected licensing revenues, if the linear combination of the variables plus normally distributed error is less than or equal to zero, the licensing revenue is predicted to be zero; if the linear combination plus error exceeds zero, the licensing revenue is predicted to be the expected value of the given linear combination plus the error. The levels of statistical significance for the coefficients of the two explanatory variables and for the model statistics are essentially the same for the OLS and the Tobit regressions. We can directly compare the expected value of the average annual revenues predicted by the two models, and the prediction is the reason we are interested in the model. That is, we want the model to predict annual revenues for the counterfactual circumstances where copyright of Government Works software is allowed. We see that the two models reach similar conclusions. Thus, the OLS model predicts that on average during the period 2015-2019 the annual revenues for the GOCO respondents are \$94,779 in constant dollars of 2019, while the Tobit model that has reformulated the problem to treat the leftcensoring of the data predicts that the average annual revenues are $\$ 104,656$ in constant dollars of 2019. The two estimates differ by about $10 \%$. The average OLS prediction is the average of the OLS fitted values. Denoting the actual value of the dependent variable as $y$, the fitted value as $\hat{y}$, and the OLS residual as $e$, the average of the OLS fitted values is $(1 / n) \sum_{i} \hat{y} i=(1 / n) \sum_{i}\left(y_{i}-e_{i}\right)=(1 / n) \sum_{i} y_{i}$ because the sum of the least squares residuals is zero. Thus, the OLS model's mean estimate of expected annual licensing revenue during the period 2015-2019 equals the actual mean for annual licensing revenue reported by the respondents and shown in Table 2. As seen in Table 2, the actual average of the annual revenue in constant 2019 dollars for the GOCO sample was $\$ 94,779$.

In all, we see that the simple OLS model and the Tobit model - that formally deals with the issue that 11 of the observations have no licensing revenue - reach similar inferences. Most importantly for the purposes of using the simple revenue model for predictions, the two models yield similar predictions for the dependent variable. 


\section{Appendix D. Examples of the Custom Software Outreach ("Marketing") Practices of Federal Laboratories}

As discussed throughout this report, Federal agencies are enabled and, to variable extents, motivated to share and transfer the software developed for agency missions within their laboratories. Their approaches are similar even though the licensing arrangements they employ vary. Obviously, GOCO laboratories can license copyrights whereas, for the most part, GOGO laboratories cannot. But beyond that, licensing arrangements vary according to technology "release type" (discussed in Sections 1.4; 2.4.2, Tables 8 and 9; and 2.6.1, Tables 22 and 23, of this report) and other factors specific to the technology at issue.

That said, four agencies exemplify the approaches Federal agencies take to "getting the word out" and making their custom-software readily available to users: NASA, NIH, USDA, and DOE.

NASA features outreach ("marketing") for custom software. They maintain a website NASA SOFTWARE <https://software.nasa.gov> — that allows potential external users to search for software applications in the following 15 technology categories: aeronautics, autonomous systems, business systems and project management, crew and life support, data and image processing, data servers processing and handling, design and integration tools, electronics and electric power, environmental science, materials and processes, operations, propulsion, structures and mechanisms, systems testing, and vehicle management.

Dozens of individual software projects are listed in each technology category and each software product is described along with its "release type" - general public, government purpose, open source, U.S. only, U.S. and foreign - and points of contact.

In addition, like other Federal agencies with substantial R\&D capabilities, NASA maintains a more general technology transfer website <https://technology.nasa.gov> that allows searches for licensing opportunities using key words. Entering "software" as a search term returns 326 items.

Most of NASA's laboratories are government operated (GOGO). One, the Joint Propulsion Laboratory (JPL), is contractor operated (GOCO). JPL, too, features software licensing opportunities <https://ott.jpl.nasa.gov/index.php?page=software> declaring that, "Caltech elects ownership of copyrights to all JPL developed software" and that they "grant the U.S. Government and its contractors a license to use the software at no cost" on the basis of a "government use" license.

The approach taken by NIH is less software-specific than that of NASA but it too involves their technology transfer website $\langle$ https://www.ott.nih.gov $>$ and keyword searching for licensing opportunities <https://www.ott.nih.gov/opportunities > Entering "software" as an unrestricted search terms returns 1,642 items. Entering "software" as a 
search term and restricting the "technology" category to "software" returns 64 items. (Examples of NIH custom software technology are described in Appendix E.)

The USDA, too, organizes access to licensing opportunities through its Office of Technology Transfer website <https://www.ars.usda.gov/ott/office-of-technology-transfer/>. Like NIH, USDA does not focus on software per se. And, rather than a "search engine" approach, USDA identifies categories of "available technologies"

<https://www.ars.usda.gov/ott/available-technologies/>: animal protection \& production; bioenergy \& environment; crop production \& protection; food processing \& products; materials \& methods; and biological materials. Each category features descriptions of specific technology projects, characterizations of associated benefits, application areas, and points of contact.

The DOE also organizes a range of collaborative approaches to technology transfer, including copyright licensing, through an elaborate website interface <https://www.labpartnering.org/about> that creates Internet access to individual DOE experts, identifies the capabilities of numerous facilities, and technology summaries. The "Technology Summaries" page includes a multi-dimensional filter that allows general searching of more than 1400 technology summaries.

According to the DOE's Laboratory Partnering Service (LPS) website:

"It delivers a myriad of information to provide access to a portfolio of investment opportunities. The LPS enables fast discovery of expertise and serves as a conduit between the investor and the innovator, by providing multi-faceted search capabilities across numerous technology areas and the national laboratories."

The LPS website offers no specific focus on software (as the NASA portal does) but entering "software" as a search term results in 283 informative project summaries across the DOE laboratories. (An example of DOE/INL custom software technology is described in Appendix E.)

Finally, as discussed in Section 1.3 of this report, the technology transfer offices of agencies whose R\&D laboratories are predominantly government-operated have paid very uneven attention to software technologies per se. NASA's focus on the transfer of software technology appears to be exceptional. For government-operated labs that have paid less attention to software specifically, according to one agency expert, "more informal aspects of marketing are probably more important for software licensing -activities related to the inventor/developer," including their publications and presentations at conferences. Many Federal employee inventors also post information or links to their software on their individual laboratory web sites. This practice appears true of contractor-operated laboratories as well. In addition to centralized, Internet-accessed "collaboration" portals, time dedicated to publications and conference presentations are likely an important vehicle for communicating ("marketing") internally-developed technologies, including custom software technology. 
The General Services Administration's (GSA) Code.gov program office is worth mention as a Federal government-wide vehicle to provide access to Federal agency custom-software. It is exclusively focused on Open Source software, indicating that some form of copyright property protection is afforded its software projects. Nonetheless, its mission is expanding access to Open Source custom software developed by Federal agencies and, "to become the primary platform where America shares its code." 93 The Federal Source Code Policy requires agencies to provide an inventory of their customdeveloped code to support government-wide reuse and make Federal open source code easier to find.$^{94}$ Agencies are required to publish their inventories using a standard metadata schema and to make those inventories available on their agency websites. Using these inventories, Code.gov provides a platform to search Federally funded open source software and software available for government-wide reuse. ${ }^{95}$ Currently, Code.gov's inventory contains 6854 open source software repositories (<https://code.gov/browseprojects? \&page $=1 \&$ size $=10 \&$ sort=a-z $>$ ), searchable by programming language, agency, copyright license, and release type ("open source" and "government-wide reuse").

\footnotetext{
${ }^{93} \mathrm{https}$ ://open.gsa.gov/api/codedotgov/

${ }^{94}$ Executive Office of the President, Office of Management and Budget, Memorandum for the Heads of Departments and Agencies, "Federal Source Code Policy: Achieving Efficiency, Transparency, and Innovation through Reusable and Open Source," August 8, 2016.

${ }^{95} \mathrm{https}: / /$ code.gov/federal-agencies/compliance/inventory-code
} 


\section{Appendix E. Examples of the Custom Software Developed in Federal Laboratories}

\section{Predict the Behavior of Blackbody Heated Surfaces software (NASA/AFRC) ${ }^{96}$}

Understanding of the radiation that emits from a heated surface is important in many areas of science and engineering. Thus, researchers at NASA's Armstrong Flight Research Center developed a set of computer functions for predicting the behavior of heated surfaces written in Microsoft@ Visual Basic ${ }^{\circledR}$ for Applications (VBA) software that incorporates functions specific to Microsoft Excel® software.

The software enables the calculation of important derivative and integration functions over a range of blackbody wavelengths. ${ }^{97}$ Because it is based on widely available computer software tools from the Microsoft suite it can be integrated with other engineering software.

In addition to aerospace applications, this software is useful for researchers developing new materials and other technologies in a wide range of applications, including: thermal management (for application to integrated circuits, computer chassis, remote sensors); heat shields (for application in automotive, appliances, safety equipment); insulation (for application in architecture, textiles and clothing); energy storage (for applications in collecting and storing thermal energy); infrared surveillance; and earth science (for understanding the composition of clouds, volcanoes, etc.).

Currently this custom software product is freely available from the NASA's Armstrong Flight Research Center website.

\section{Source Lines Counter (SLiC) version $4.0^{98}$}

Source lines of code is a software metric used to measure the size of a computer program for comparative purposes. ${ }^{99} \mathrm{SLiC}$ has been used in a variety of projects and missions at JPL. It is the official code counter endorsed by the Software Quality Improvement (SQI) project for its metrics collections effort across JPL. It is SQIs most requested software product. SLiC provides data for cost models used during all major JPL pre-Phase A software estimation activities as well as cost validation activities throughout project lifecycles. SLiC is used to gather metrics for the JPL State of Software report to measure process trends in flight projects and multi-mission ground system services.

The tool is used mostly by NASA centers, U.S. Government contractors and NOAA. $\mathrm{SLiC}$ can be used by any organization to measure software size. Since it has wide-

\footnotetext{
96 https://software.nasa.gov/software/DRC-015-017

${ }^{97}$ A blackbody is defined as a perfect absorber for all incident radiation. < https://en.wikipedia.org/wiki/Black_body>

98 https://software.nasa.gov/software/NPO-45962-1

${ }^{99}$ https://en.wikipedia.org/wiki/Source_lines_of_code
} 
ranging support for the logical statement standard used in cost estimation, it may also be of use to those using the popular public-domain COCOMO cost model. Any software project that wishes to track development size metrics for a variety of languages not supported by COTS tools may also find SLiC useful. ${ }^{100}$

The size of this custom software is about 4,000 lines of code, about the median for the survey sample discussed in this report. ${ }^{101}$ The average for the typical software product from the survey sample is approximately 45,000 lines of code, but the distribution is highly skewed, and the median is 3,575 lines of code. ${ }^{102}$

This software is only available for use by Federal employees and contractors to the Federal government working on projects where this tool would be applicable.

\section{Detected Emitter Display Tool ${ }^{103}$}

This custom software was created to assist with testing passive radar detection systems used by many aircraft. ${ }^{104}$ Previously, testing was slow and cumbersome. There was no way to visualize how emitters were being detected by the equipment in a simulated environment. This software tool allowed quick testing of emitter identification errors and errors related to emitter locations.

The software was written in C\# and became integral to the Air Force Life Cycle Management Center's testing process. Its utility to external organizations has never been examined. It could be useful to aircraft that use passive detection systems.

The size of this custom software is estimates to be 1000 lines of code. ${ }^{105}$ From Table 12 in Section 2.5.2, the size of this software product is the median for the minimum lines of code for their products as reported by the respondents to the survey. This software is not to be protected by a license.

\section{Computer-Aided Diagnostic for Use in Multiparametric MRI for Prostate Cancer (NIH/ NIHCC) ${ }^{106}$}

Researchers at the National Institutes for Health Clinical Center (NIHCC) have developed computer-aided diagnostics (CAD) that may further improve the already

\footnotetext{
${ }^{100}$ Personal communication with Brian Morrison, Joint Propulsion Laboratory, October 5, 2020.

101 Ibid.

${ }^{102}$ See Table 10. Descriptive Statistics for the Respondents with Complete Data for the Model of Software Development and Maintenance Costs. For more detail, see Table 12. The Lines of Code (LOC) for the Typical Software Product.

${ }^{103}$ Personal communication with Christopher Young, Air Force Life Cycle Management Center, October 5, 2020.

${ }^{104}$ So-called electronic support measures (ESM) gather intelligence through passive "listening" to electromagnetic radiations of military interest. < https://en.wikipedia.org/wiki/Electronic_warfare_support_measures>

${ }^{105}$ Christopher Young, op cit.

106 https://techtransfer.cancer.gov/availabletechnologies/e-183-2016
} 
superior capabilities of multiparametric magnetic resonance imaging (MRI) for detection and imaging of prostate cancer. This system produces an accurate probability map of potential cancerous lesions in multiparametric MRI images that is superior to other systems and may have multiple product applications.

The system uses specialized algorithms trained against the results of conventional information from hand drawn contours, recorded biopsy results, and normal cases from randomly sampled patient images weighted for lesion size. This CAD system produces a more accurate probability map of potential cancerous lesions in multiparametric MRI images.

The CAD system may be used in several applications and settings including, cloud-based prostate cancer screening, use in under-resourced clinical settings with few or underexperienced radiologists, integration into a work station or a picture archiving and communication system (PACS), or serve as standalone software to be used on existing systems.

This technology is currently available for licensing and co-development partnerships.

\section{Convolutional Neural Networks for Organ Segmentation (NIH/ NIHCC) ${ }^{107}$}

Computer automated segmentation of high variability organs and disease features in medical images is uniquely difficult. The pancreas, for example, is a small, soft, organ with low uniformity of shape and volume between patients. Because of the lack of uniform image patterns, there are few features that can be used to aid in automated identification of anatomy and boundaries. High variability anatomical features are currently analyzed and determined only by trained physicians who can read the images and there is a shortage of trained physicians relative to the amount of image data generated. Computer automation has been difficult to achieve but could improve image analysis capabilities and lead to better diagnostics, disease monitoring, and surgical planning for many diseases.

Researchers at the National Institutes of Health Clinical Center (NIHCC) have developed a technology that trains a computer to read and segment certain highly variable images features by employing Holistically-Nested Convolutional Neural Network (HNNs) and deep learning. The resulting biomarkers are far more precise.

The Training methods may be generalizable to enable automation of segmentation for many high variability image structures, such as tumors and diseased organs.

This technology is currently available for licensing and co-development partnerships.

\section{Human Research Information System (NIH/ NIHCC) 108}

\footnotetext{
${ }^{107} \mathrm{https}$ ///techtransfer.cancer.gov/availabletechnologies/e-056-2017

${ }^{108} \mathrm{https} / / /$ techtransfer.cancer.gov/availabletechnologies/e-266-2014
} 
Human Research Information System (HuRIS) software automates all major functions of a clinical-research entity. The system is designed for commercial healthcare providers, community treatment centers, and clinical research facilities. HuRIS is an intelligent electronic environment for the collection, organization and retrieval of information in clinical/scientific decision support which enables data and resource sharing in real time among authorized users at NIHCC clinics.

At the core of this informatics infrastructure reside the clinical charts and research records of participants compiled over the entire history of their study participation, and sometimes across multiple studies. The resulting information can be accessed, ondemand, by doctors writing medication orders or nurses recording participants' vital signs as well as researchers conducting data analysis or completing reporting requirements.

HuRIS has potential commercial applications across the spectrum of medical care information management systems, including clinical research, pharmacies, biospecimens tracking, laboratories, and behavioral modification and addiction treatment.

This technology is available for licensing.

\section{Battery Diagnostic Software (INL/DOE) ${ }^{109}$}

Researchers at DOE's Idaho National Laboratory developed an advanced software diagnostic tool to assess batteries currently in use. Known as CellSage (or Cell's Age), this technology characterizes battery performance, diagnoses the health of a battery, and predicts how much longer it will be able to function under specific conditions or scenarios. ${ }^{110}$

The CellSage software tool closes knowledge gaps in understanding how to measure, monitor, and manage complex battery systems used in a wide variety of applications. ${ }^{111}$ Prior to INL's more sophisticated approach, battery diagnostics tend to be chemistry or application specific. They correlated simple measurements of voltage, current, and temperature with empirical trends of aging. As such the less sophisticated approaches could not accurately predict battery aging trends outside these specific diagnostics. CellSage software provides a more complete picture of battery health metrics such as kinetic performance, capacity loss, conductance fade, power loss, and ancillary quantities. The tool expands understanding of how specific battery chemistries react to usage conditions and environments.

CellSage's computational architecture uses Fortran at its core, making it easily converted to a number of other scientific computing languages. It runs on most standard laptop and desktop systems. CellSage software can be used in electric vehicles and for applications

\footnotetext{
${ }^{109}$ https://www.labpartnering.org/success-story/0b1e5b9e-b112-4c77-ab7f-1e90ac26c055

110 Ibid.

${ }^{111} \mathrm{https}$ //www.ridgetopgroup.com/wp-content/uploads/CellSage-Document.pdf
} 
in the military, space, medicine, electric utilities, telecommunications, and some consumer electronics. ${ }^{112}$

The size of this custom software is estimated to be between 9,000 and 10,000 lines of code. ${ }^{113}$ The average for the typical software product from the survey sample discussed in this report was approximately 45,000 lines of code, but the distribution is highly skewed. The median is 3,575 lines of code, and the $75^{\text {th }}$ percentile is 18,152 lines of code. ${ }^{114}$ This software is patented, copyrighted, and was licensed in 2017.

${ }^{112}$ Ibid.

${ }^{113}$ Personal correspondence with Ryan Bills, Idaho National Laboratory, October 7, 2020.

${ }^{114}$ See Table 10. Descriptive Statistics for the Respondents with Complete Data for the Model of Software Development and Maintenance Costs. For more detail, see Table 12. The Lines of Code (LOC) for the Typical Software Product. 


\section{Introduction}

NIST's Return on Investment (ROI) Initiative supports the President's Management Agenda goal of modernizing federal government practices to further fuel the nation's engines of innovation by maximizing the transfer of Federal investments in science and technology to the private sector.

The ROI Initiative is the culmination of a broad-ranging and inclusive review of policies and practices that constrain technology commercialization. One of these constraints is the regulatory prohibition of copyright protection on software developed by federal agency employees (Title 17, Section 105, of the United States Code).

This survey is part of a NIST-sponsored study to assess the future economic benefits of eliminating the prohibition of copyright protection for software developed in government-operated federal laboratories. Contractor-operator federal laboratories are included because of their extensive experience with copyrighted software.

The survey covers two time periods, 2015-2019 and 2020-2024. Based on your informed judgement, we want to obtain, for the laboratory or facility (or laboratories or facilities) that you are responding for, estimates of the approximate number of software products (and associated revenue) that have been subject to copyright protection in federal laboratories (either because the lab is contractoroperated or because of exceptions that apply to government-operated labs), and the number of software products without copyright protection that could be available for copyright protection if the prohibition was eliminated. We will use the information you provide to estimate the net economic benefits of such a policy action. Please answer all questions to the best of your ability. The information provided will be used to estimate costs and revenues as functions of numbers and types of software products. Individual responses will not be attributed to you, the survey respondent, or the specific laboratory or facility with which you are associated. Issues concerning specific survey questions should be directed to David Leech <david.leech@starpower.net>.

Disclaimer: By design, the data entry fields in this survey form are not intended for the insertion of sensitive personally identifiable information (SPII)—nor are they intended for any proprietary business identifiable information (BII). Please take Federal best practice precautions in not inserting any data that is not explicitly requested.

Note: This collection of information contains Paperwork Reduction Act (PRA) requirements approved by the Office of Management and Budget (OMB). Notwithstanding any other provisions of the law, no person is required to respond to, nor shall any person be subject to a penalty for failure to comply with, a collection of information subject to the requirements of the PRA unless that collection of information displays a currently valid OMB control number. Public 
reporting burden for this collection is estimated to be thirty (30) minutes per response, including the time for reviewing instructions, searching existing data sources, gathering and maintaining the data needed and completing and reviewing the collection of information. Send comments regarding this burden estimate or any aspect of this collection of information, including suggestions for reducing this burden, to the National Institute of Standards and Technology, Attn: Nicole Gingrich <nicole.gingrich@nist.gov>; Phone: 301-975-8034. 


\section{OMB Control No. 0693-0033}

Expiration Date: 07/31/2022

\section{Software Copyright Impact Survey}

\section{Section 1}

\section{Laboratory Identification, Agency Affiliation, and Operator Type}

1. Identify the laboratory/laboratories (or laboratory facility/facilities) for which you are responding.

2. Name the parent federal agency of which your laboratory/laboratories (or laboratory facility/facilities) is/are a part.

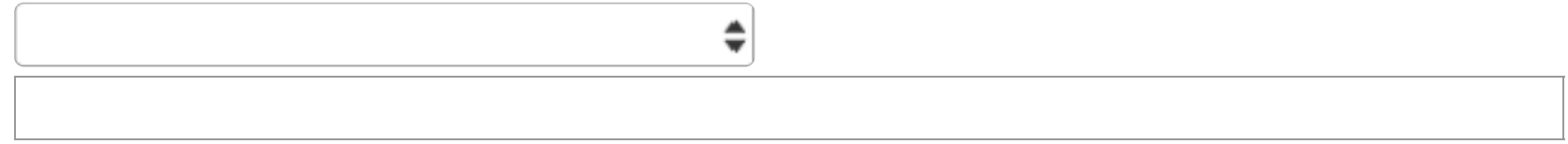

3. Is/Are the laboratory/laboratories (or laboratory facility/facilities) you are responding for considered government-operated or contractor-operated? (Choose one, or if you are responding for multiple laboratories or facilities and they are not all considered to be in the same operation category, please list each in the "other" box and identify each as GOGO or GOCO.)

$\square$ Government Owned Government Operated (GOGO)

Government Owned Contractor Operated (GOCO)

Other (please specify) and identify as either GOGO or GOCO.

If answering for multiple labs or facilities, from this point on just respond to each question for the collection of those labs or facilities. 


\section{OMB Control No. 0693-0033}

Expiration Date: 07/31/2022

\section{Software Copyright Impact Survey}

\section{Section 2}

\section{Software Licensing \& Public Domain Software Release Activity 2015-2019}

(in the laboratory/laboratories or laboratory facility/facilities for which you are responding)

\section{For fiscal years, FY15-FY19:}

4. For the FY15-FY19 period as a whole, approximate the percentage of the two custom-developed software* product categories that your laboratory/laboratories (or laboratory facility/facilities) contributed to your parent Federal agency's (\{\{ Q2 $\}\})$ total output in those categories:

${ }^{*}$ Custom-developed computer software refers to software developed by agency employees as part of their official duties and software written as part of a federal contract or otherwise fully funded by the federal government. It includes computer software projects, modules, plugins, scripts, middleware, and application programing interfaces (APIs).

Percent of parent federal agency

$$
\begin{aligned}
& \text { Software exclusive of } \\
& \text { open source } \\
& \text { Open source software }
\end{aligned}
$$

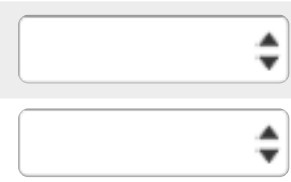

5. How many custom-developed software products made by your laboratory/laboratories or facility/facilities were made available for licensing? (For GOGO labs it is understood that copyrighted software products transferred to federal agencies or protected outside the U.S. are available to be licensed.)

Number available for licensing (numerical only please):

FY15
FY16
FY17
FY18
FY19


6. Estimate the approximate percentage distribution of the kinds of intellectual property protection applied to software products available for licensing:

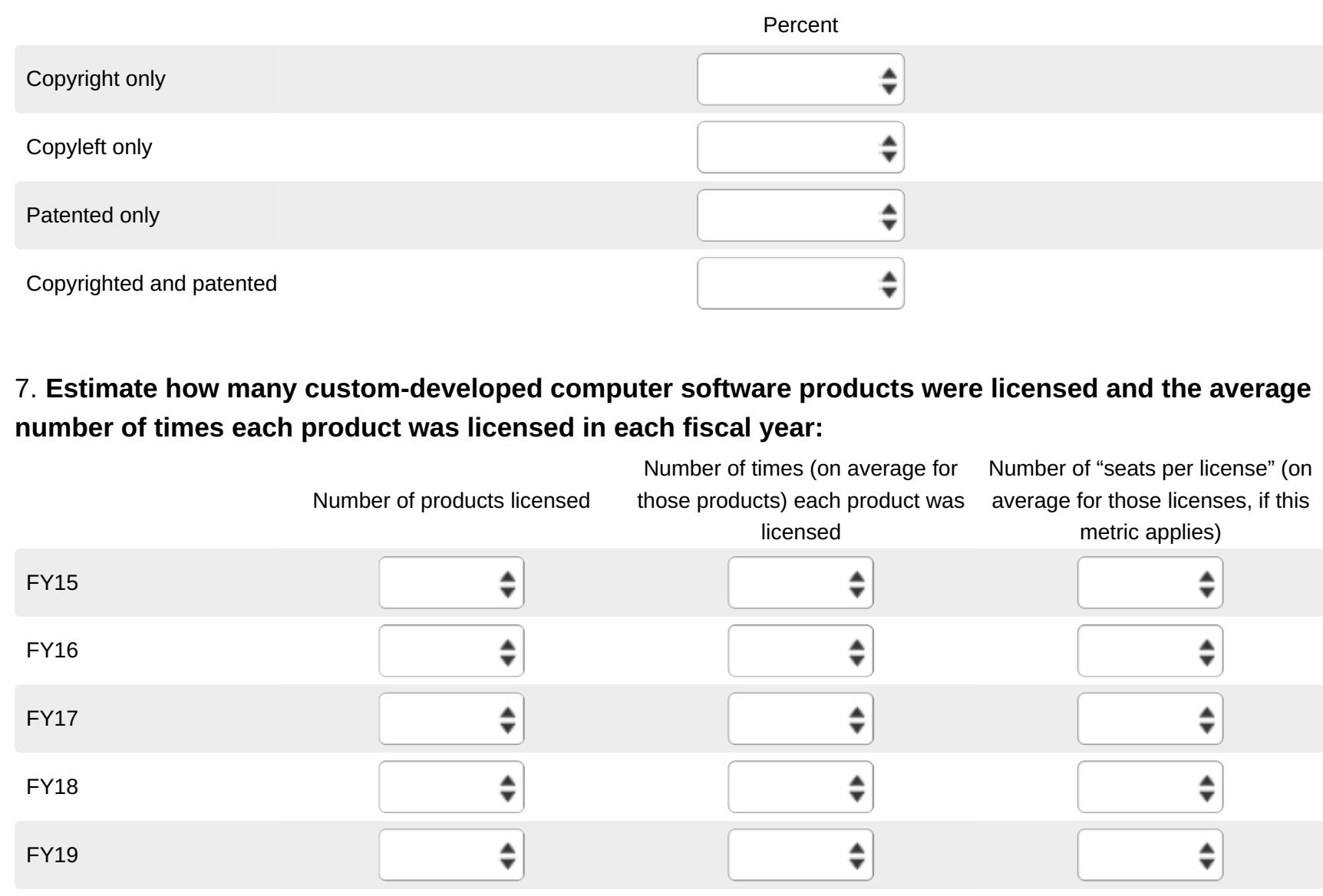

8. Estimate the annual total dollar amount of revenues generated by software licenses:*

* Total revenues should include at least license issue royalties, minimum annual royalties, earned royalties, sub-licensing royalties, and benchmark royalties but not unreimbursed expense royalties. The latter will be included as part of licensing costs.

Annual revenue (nominal dollars):

FY15 (\$)

FY16 (\$)

FY17 (\$)

FY18 (\$)

FY19 (\$) 
9. How many custom-developed computer software products were available for download to the public without a license*?

*Such public release software includes software released to the general public or other federal agencies without copyright or copyleft restrictions, and software released to the general public or other federal agencies for non-commercial use (exclusive of open source).

FY15

FY16

FY17

FY18

FY19

10. To the best of your knowledge, for FY15-FY19 as a whole, estimate the percentage distribution of the software products available from your laboratory/laboratories (or laboratory facility/facilities) across the following categories:

Percent

Percent released as open
source
Percent released to the
general public or other
agencies for non-
commercial use
(exclusive of open
source)
Percent released to
general public without
copyright or copyleft
restrictions
Percent released under
other conditions

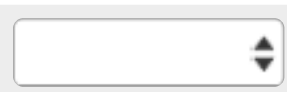



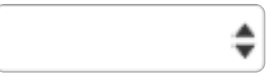

(exclusive of open

source)

Percent released to general public without copyright or copyleft

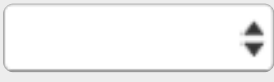

Percent released unde conditions 
OMB Control No. 0693-0033

Expiration Date: 07/31/2022

Software Copyright Impact Survey

\section{Section 3}

Software Development and Management Costs, 2015-2019

(in the laboratory/laboratories or laboratory facility/facilities

for which you are responding)

Costs over the entire period, 2015-2019:

\section{Software Development Costs}

11. Estimate the average, maximum, and minimum number of lines of source code for the typical individual custom-developed software product developed by your laboratory/laboratories (or laboratory facility/facilities):

Average

Maximum

Minimum

12. For the average size software product (in terms of lines of source code), estimate the average number of full-time equivalent (FTE) person-years required for its development (and a representative GS-rating):

Average number of

FTE person-years

Representative General

Schedule (GS)-rating

\section{Software Management Costs}

\section{For software made available for download to the public with or} without a license: 
13. Over and above the cost of developing software that is released to the general public with or without a license, is there a significant annual cost to maintaining this software in terms of writing additional software or managing and administering the inventory once released? If so, please provide estimates of the average annual number of full-time equivalent (FTE) person-years required and a representative GS-rating:

Average annual

FTE person-years writing

supporting software

Representative General

Schedule (GS)-rating

Average annual

FTE person-years

administering software

inventory

Representative General

Schedule (GS)-rating

\section{With reference to licensed software}

14. Internal to the laboratory/laboratories or facility/facilities for which you are responding, what is the average annual number of full-time equivalent (FTE) person-years (and representative GS-rating) dedicated to obtaining and maintaining intellectual property protection, and managing the licensing transactions for your software portfolio?

Average annual number

of FTE person-years

Representative General

Schedule (GS)-rating

15. For the laboratory/laboratories or facility/facilities for which you are responding, estimate the average annual annuity fees (paid to maintain all issued patents) required to maintain your software portfolio:

Average annual cost of annuity fees (\$)

16. External to the laboratory/laboratories or facility/facilities for which you are responding, what is the average annual cost of the legal support required for obtaining and maintaining intellectual property protection, and managing the licensing transactions, for your laboratory's software portfolio (including, if known, unreimbursed expense royalties)?*

* External legal costs include all annual expenses paid to private sector law firms in support of the agency's portfolio of software patents and copyrights.

Average annual cost of

external legal support $(\$)$ 


\section{OMB Control No. 0693-0033}

Expiration Date: 07/31/2022

\section{Software Copyright Impact Survey}

\section{Section 4}

Counterfactual Software Copyright License \& Public Release Activity 2020-2024

(in the laboratory/laboratories or laboratory facility/facilities for which you are responding)

\section{Assuming Elimination of the Copyright Prohibition for Government Works}

We would be grateful for your experience-based forecast of the 2020-2024 period assuming the copyright prohibition for government-produced software is eliminated.

17. Assuming the elimination of the copyright prohibition for government works, estimate the average annual number of custom-developed software products that will be available for licensing:

5-year annual average for number of products available for licensing

18. Assuming the elimination of the copyright prohibition for government works, estimate the average annual number (and frequency) of custom-developed software products that will be licensed:

5-year annual average for the number of software products

5-year annual average for number of times each product is expected to be licensed

5-year annual average of the number of "seats per license" (if this metric applies)

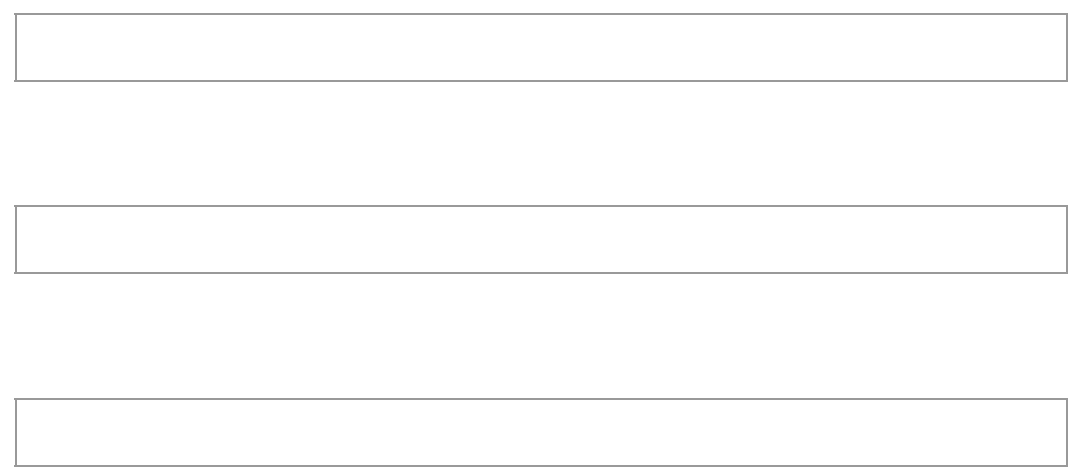


19. If the copyright prohibition for government works was eliminated, estimate the distribution of custom-developed software products across the following software release categories: (Note that with the prohibition eliminated, software inventions could be covered by both copyrights and patents.)

Percent

Percent patented but not

copyrighted

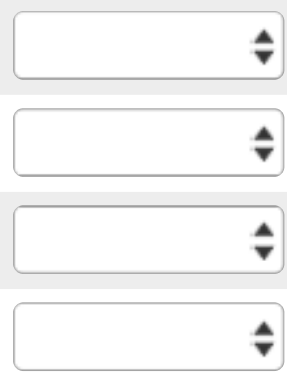

Percent copyrighted but

not patented

Percent patented \&

copyrighted

Percent copyrighted as

open source

Percent released to the general public or other agencies for non-

commercial use

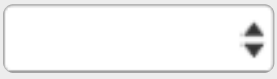

(exclusive of open source)

Percent released to general public without copyright or copyleft restrictions

Percent classified or export controlled

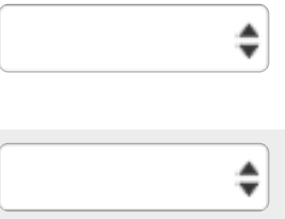

\section{Compared to the 2015-2019 period:}

20. Do you anticipate the average number of source lines of code for individual custom-developed software products available for licensing will grow, decline, or stay roughly the same? (Please choose one response and enter the \%.)

Average annual growth (\%)

Average annual decline (\%)

Remain the same (enter the number 0) 
21. Do you expect the average annual dollar amount of revenues generated per licensed software product (i.e., after removing the effects of inflation and thus using dollars of constant value) to grow, decline, or remain roughly the same? (Please choose one of the first three responses and enter the \%.

Then provide your rationale in the fourth response area.)

Inflation-adjusted average annual growth (\%)

Inflation-adjusted average

annual decline (\%)

Remain the same (enter the number 0)

Please provide a general rationale for your estimate.

\section{Please click "Done" when you are ready to submit your responses.}

\section{You Have Completed the Survey. Thank You!}

